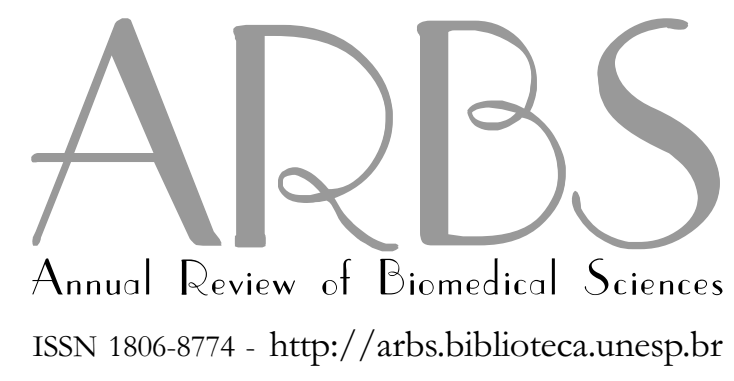

\title{
Aunesp
}

\section{Principle and Applications of X-Ray Microanalysis to Biological Specimens by High Voltage Electron Microscopy}

\author{
Tetsuji Nagata \\ Department of Anatomy and Cell Biology \\ Shinshu University School of Medicine, Matsumoto 390-8621, Japan \\ E-mail: nagatas@po.cnet.ne.jp
}

\section{Abstract}

Nagata T. Principle and Applications of X-Ray Microanalysis to Biological Specimens by High Voltage Electron Microscopy. ARBS Ann Rev Biomed Sci 2004;6:13-78. X-ray microanalysis is a useful technique to qualify and quantify basic elements in biological specimens. This paper reviews the principles, techniques and applications of high voltage electron microscopy (HVEM) at accelerating voltages of $200-400 \mathrm{kV}$ to $\mathrm{X}$-ray microanalysis of various elements in biological specimens developed in our laboratory since the late $20^{\text {th }}$ century. We first quantified the endproducts of histochemical reactions such as $\mathrm{Ag}$ in radioautographs, Ce in acid phosphatase reaction and $\mathrm{Au}$ in colloidal gold immunostaining using semi-thin sections by HVEM. The P/B ratios of $\mathrm{Ag}$, Ce and Au showed peaks at 350, 400 and $300 \mathrm{kV}$, respectively. Then we analyzed various trace elements such as $\mathrm{S}, \mathrm{Cl}, \mathrm{Ca}, \mathrm{Zn}$ which originally existed in cytoplasmic matrix or cell organelles of various cells, and some elements absorbed by experimental administration into cells such as $\mathrm{Al}$, using both conventional chemical fixation and cryo-fixation followed by cryo-sectioning, freeze-drying, or freezesubstitution. As results, some trace elements which originally existed in cytoplasmic matrix or cell organelles of various cells were effectively detected. $\mathrm{Zn}$ was demonstrated in Paneth cell granules of mouse intestines and its $\mathrm{P} / \mathrm{B}$ ratios showed a peak at $300 \mathrm{kV}$. Ca was found in human ligaments and rat mast cells with a maximum of $\mathrm{P} / \mathrm{B}$ ratios at $350 \mathrm{kV}$. S and $\mathrm{Cl}$ were detected in mouse colonic goblet cells with maxima at $300 \mathrm{kV}$. On the other hand, some elements which were absorbed by experimental administration into various organs, such as $\mathrm{Al}$ in hepatocytes and uriniferous tubule cells in mice, was detected with a maximum at $300 \mathrm{kV}$.

Key words: X-ray microanalysis, high voltage electron microscopy, trace elements, metals, reaction products.

Received: 27/03/04 Accepted: 03/10/04

Financial support: Grants-in-Aids for Scientific Research from the Ministry of Education, Science, Sports and Culture of Japan Government (No. 001054, 801066, 801031, 501010, 501533, 56870001, 58015046, 02454564) and Grants for Promotion of Characteristic Research and Education from the Japan Foundation for Promotion of Private Schools (1997, 1998, 1999, 2000).

- The outline of this paper was presented at the Symposium on "Application of high voltage electron microscopy to biological specimens" (Organizer and Chair: Tetsuji Nagata) in the $15^{\text {th }}$ International Congress on Electron Microscopy, held September 1-6, 2002, Durban, South Africa. 


\section{Table of Contents}

Introduction

Principle of X-Ray Microanalysis

Application of X-ray Microanalysis to Various Elements in Biological Specimens

Endproducts of Histochemical Reactions

Silver grains in radioautographs

Cerium deposits in acid phosphatase reaction

Gold particles in colloidal gold immnunostaining

Endogenous Elements in Cells and Tissues

Sulfur in colonic goblet cells

Chlorine in Paneth cells and in Epon sections

Calcium in mast cells and ligaments

Zinc in Paneth cell granules

Absorbed Elements in Various Cells and Tissues

Aluminum in the intestine, kidney and brain

Heavy metals

Other metals and rare earths

Application of X-Ray Microanalysis to the Organ Systems

The Locomotive System

The bones

The ligaments

The muscles

The Digestive System

The oral cavity

The stomach

The intestines

The liver

The pancreas

The Respiratory System

The iron in the lung

Aluminum in the lung

The Urinary System

The electrolytes in the kidney

Cerium in the acid phosphatase activity in the kidney

Aluminum in the kidney after $\mathrm{Al}$ administration

The Reproductive System

Male genital organs

Female genital organs

The Endocrine System

The thyroid

The adrenal gland

The Circulatory System

The heart

The blood vessels

The blood cells

The spleen

The Nervous System

Electrolytes in the cerebral cortex

Calcium in the brain

Aluminum in the brain

The Sensory System

The eye

Concluding Remarks

The skin

Acknowledgments

References 


\section{Introduction}

The principle and application of X-rays in electron microscopy was first carried out by Castaing (1960) in the 1950s who developed analytical electron microscopy and applied it to biological specimens. When we began to use the electron microscopes in 1950s in our laboratory at Shinshu University School of Medicine, we used mainly conventional transmission electron microscopes at accelerating voltages from 50 to 100 kV, such as Hitachi HU-9, HU-11, HS-9 (Hitachi, Tokyo, Japan) to observe histochemical and cytochemical reactions in biological specimens as ultrathin sections. However, we later purchased transmission electron microscopes with higher accelerating voltages than $100 \mathrm{kV}$, such as JEM 1200EX (JEOL, Tokyo, Japan) at accelerating voltages of $120 \mathrm{kV}$ in 1970s, Hitachi H-700 (Hitachi, Tokyo, Japan) at $200 \mathrm{kV}$ in 1980s and JEM-4000EX at $400 \mathrm{kV}$ (JEOL, Tokyo, Japan) in 1990s, in the late 20th century, in order to get better transmission of electron beams and better resolution of the ultrastructures observed. At the same time, we purchased such X-ray analyzers as Horiba EMAX EDX analyzer (Horiba, Kyoto, Japan) equipped to Hitachi H-700 STEM system at 200 kV, or Tracor-Northern TN-5400 EDX analyzers (Tracor-Northern, Middleton, USA) equipped to JEM-4000EX TEM system at $400 \mathrm{kV}$ and JSM-6000F SEM system and used them for analysis of various elements in various cells and tissues (Nagata, 1985 a,b,c , 1993, 2001 a,c ; Nagata \& Usuda, 1985, 1986). This paper deals with the principles and applications of X-ray microanalysis using semi-thin sections and high voltage electron microscopy which has been developed in our laboratory since late $20^{\text {th }}$ century, demonstrating the usefulness of higher voltages for quantifying trace elements in biological specimens (Nagata, 2002 ${ }^{\text {c,d }}$, 2003).

\section{Principle of X-ray Microanalysis}

The principle of X-ray microanalysis (XMA) or electron probe X-ray microanalysis (EPMA) is to observe ultrathin or semi-thin sections by transmission electron microscopy or tissue blocks by scanning electron microscopy and irradiate the tissues with electron beams which emit X-rays specific to the tissues, then analyze the spectra obtained from the tissues by qualifying and quantifying the specific elements (Chandler, 1976). Innumerable papers have been published in the late $20^{\text {th }}$ century, qualifying and quantifying various elements in various cells and tissues by XMA. The authors of these papers used conventional analytical electron microscopes at accelerating voltages of 50 $100 \mathrm{kV}$. Initially they believed that it was essential to use ultrathin sections for X-ray microanalysis of biological specimens (Chandler, 1976). However, it is theoretically obvious that the thinner the sections are, the less they contain the elements to be analyzed. To the contrary, the thicker the sections are, the more they contain the elements. Thus, we used thicker sections and observed them at higher accelerating voltages around $200-400 \mathrm{kV}$ by means of high (or intermediate) voltage electron microscopes (Nagata, 1985c, 1988, 1991, $\left.2002^{c}, 2003\right)$. When we started to analyze several elements in biological specimens, we found the advantages of high voltages around $200-400 \mathrm{kV}$ for quantifying such elements in thick sections, obtaining higher P/B ratios (Nagata, 1985 b,c $, 1988,1991,1993,2001^{\mathrm{a}, \mathrm{c}}$, Nagata \& Usuda, 1985, 1986). At the time when we started to use such high voltage electron microscopes in 1970s, only $200 \mathrm{kV}$ electron microscopes such as Hitachi H700 or JEOL JEM-200CX were available. We first purchased and installed a Hitachi H700 at $200 \mathrm{kV}$ in our laboratory and also we used a JEOL JEM-200CX transmission electron microscope equipped with Kevex 7000-77 (Kevex, UK) in JEOL Laboratory in Akishima, Tokyo, through the courtesy of JEOL Co. Then later, higher voltage electron microscopes such as Hitachi at $300 \mathrm{kV}$ and JEOL at $400 \mathrm{kV}$ became available in 1980s, and finally we purchased and installed a JEOL-JEM-4000EX high voltage electron microscope at 400 $\mathrm{kV}$ in our laboratory. This paper deals with the theory, application and results developed and obtained in our laboratory using the $200 \mathrm{kV}$ and $400 \mathrm{kV}$ electron microscopes since the late $20^{\text {th }}$ century.

The electron microscope equipped with an X-ray analyzer is designated as the analytical electron microscope. There are 3 types of electron microscopes, which are 
commercially available, (1) the scanning electron microscope, (2) the scanning transmission electron microscope and (3) the transmission electron microscope. On the other hand, there are 2 types of X-ray analyzers available, (1) the wave length dispersive X-ray analyzer (WDX) and (2) the energy dispersive X-ray analyzer (EDX). Thus, we have 6 types of combinations for analytical electron microscopes equipped with X-ray analyzers. By scanning electron microscopy, we can observe and analyze only the surface of tissue blocks. Scanning microscopes equipped with EDX spectrometers are often used for scanning surface of structures such as the teeth or bones and analyze the elemental components of the surface structures of hard tissues (Martins et al., 2002). By scanning transmission or transmission electron microscopy we can observe and analyze inside of the tissues examining ultrathin or semi-thin sections. With the wave length dispersive $\mathrm{X}$ ray analyzer, we can analyze only one element at once. To the contrary, we can analyze all the elements at once with the energy dispersive X-ray analyzer. Thus, we prefer to use transmission analytical electron microscopes equipped with EDX for biological specimens in order to analyze all the elements from $\mathrm{Na}$ to $\mathrm{U}$ (all the elements with the atomic numbers over 11 up to 92) in the same specimens at once. Actually, we purchased 3 types of analytical electron microscopes in our laboratory during these 30 years, a Hitachi H-700 scanning transmission electron microscope equipped with a Horiba EMAX EDX analyzer, a JEOL JEM-4000EX high voltage transmission electron microscope at accelerating voltages from 100 to $400 \mathrm{kV}$ equipped with a Tracor-Northern TN-5400 EDX analyzer, and a scanning analytical electron microscope, JEOL JSM-6000F equipped with a TracorNorthern TN-5400 EDX analyzer, and used them for analysis of various elements in various cells and tissues (Nagata, 2000a 2001c).

Since the developments and applications of electron microscopy in the mid $20^{\text {th }}$ century, the accelerating voltages of conventional transmission electron microscopes widely distributed throughout the world were from 50 to $100 \mathrm{kV}$ for many years. Therefore, the applications of transmission electron microscopes to biological specimens have been limited to observe only ultrathin sections at the thicknesses less than $100 \mathrm{~nm}(0.1 \mu \mathrm{m})$, sectioned with ultramicrotomes from resin embedded tissue blocks using glass or diamond knives through the standard procedures, which could easily be transmitted by the electrons emitted from the conventional electron microscopes at the accelerating voltages around $100 \mathrm{kV}$ (Chandler, 1976). However, several high voltage electron microscopes at accelerating voltages around $500-1000 \mathrm{kV}$, designed and constructed in early $1960 \mathrm{~s}$ in Japan and France, were first used for observing lattice structures of materials such as ceramics and metals but not used for biological specimens (Nagata, 1985'). Then, high voltage electron microscopes with much higher (ultrahigh) accelerating voltages at more than 1000 up to $3000 \mathrm{kV}$ were experimentally designed and constructed in France (Toulouse) and Japan (Osaka) at the late 20 $0^{\text {th }}$ century from 1970s to $1980 \mathrm{~s}$, due to the demands for observing thicker inorganic materials but not used for biological specimens at that time (Nagata, $\left.1985^{\circ}\right)$. On the other hand, at the end of $20^{\text {th }}$ century, intermediate high voltage electron microscopes at accelerating voltages around $200-400 \mathrm{kV}$ were designed and commercially sold out by a few makers (JEOL, Hitachi and Phillips) which are less expensive than ultrahigh voltage electron microscopes around $1000 \mathrm{kV}$. Thus, the intermediate voltage electron microscopes (IMEM) have recently become available in many laboratories throughout the world and the applications of intermediate or high voltage electron microscopes to biological specimens have become more common than before in the late $20^{\text {th }}$ century.

The observation of biological specimens by high voltage electron microscopes merits 3 features. The first is the better resolution and the less electron damages by higher accelerating voltages than lower accelerating voltages because the wave lengths of electron beams become shorter in inverse proportion to the accelerating voltages (Nagata, 1985, $2002^{c}$ ). However, if we observe ultrathin sections at higher accelerating voltages, the contrast of structures becomes worse. Thus, the high voltage electron microscopes were not so much used for observing ultrathin sections. The $2^{\text {nd }}$ feature is the better transmittance than the lower voltages, because the electron beams emitted at higher voltages are able to 
penetrate thicker specimens than the electrons at lower voltages. Thus, thicker sections more than $100 \mathrm{~nm}$ or whole mount cells without sectioning as thick as several $\mu \mathrm{m}$ prepared from cultured cells were often used at higher voltages (Nagata, 1985 ${ }^{\mathrm{c}}, 1997,2001^{\mathrm{b}}, 2001^{\mathrm{d}}$ ). Porter et al. (1945) were the first to observe the thin cytoplasmic processes of cultured cells without sectioning at the initial stage of electron microscopy applied to biological specimens by CTEM because the ultramicrotomes which were developed later were not available at that time and there was no other way to obtain thin specimens. However, once ultramicrotomes were developed and ultrathin sections were easily prepared, whole mount cultured cells were not used during the period from the 1950s to 1970s. Cultured cells were embedded and sectioned for electron microscopy. However, in the late 1970s Porter and his associates (Buckley \& Porter, 1975; Wolosewick \& Porter, 1975, 1976, 1977, 1979) again tried to observe the cytoskeletons of whole mount cultured cells by high voltage electron microscopes (HVEM) at $1000 \mathrm{kV}$. This period from the late $1970 \mathrm{~s}$ to early 1980s should be regarded as the $2^{\text {nd }}$ period to apply high voltage electron microscopes to biological specimens (Nagata, 1985 c $2002^{c}$ ). Since the recent developments and spreads of very high voltage electron microscopes at accelerating voltages around $1000 \mathrm{kV}$ as well as high voltage electron microscopes at accelerating voltages of $200-400 \mathrm{kV}$ at the end of the $20^{\text {th }}$ century, many papers dealing with the ultrastructures of various biological specimens have been published. Among them, 3dimensional observations of various cell organelles including not only cytoskeletons as was observed by Porter and his associates (Buckley \& Porter, 1975; Wolosewick \& Porter, 1975, 1976, 1977, 1979) but also other cell organelles such as endoplasmic reticulum, Golgi apparatus, peroxisomes and mitochondria were extensively studied by preparing stereo-pairs taking photographs by tilting the thick specimens stained with cytochemical reactions by high voltage electron microscopy (Nagata, 1995, 1997, 2001 b,c $)$. This period from the 1990 s to early $21^{\text {st }}$ century should be regarded as the $3^{\text {rd }}$ period of HVEM (Nagata, $\left.2001^{\mathrm{d}}, 2002^{\mathrm{b}, \mathrm{c}}\right)$.

The $3^{\text {rd }}$ merit of HVEM should be the decrease of diffractions in the specimens. Theoretically, the size of electron diffractions in the specimens becomes much smaller in inverse proportion to the accelerating voltages. Thus, high voltage electron microscopes by TEM mode are recently used in combination with energy dispersive $\mathrm{X}$-ray microanalysis (EDX) using thicker specimens (Nagata, 2002 $)$.

In order to review and discuss the recent advances in the applications of high voltage electron microscopes to biological specimens, one of the symposia at the $15^{\text {th }}$ International Congress on Electron Microscopy, held in Durban, South Africa, September 1-6, 2002, entitled "Application of high voltage electron microscopy to biological specimens" was organized by the present author. We presented 3-dimensional and 4dimensional ultrastructure of cell organelles in thick specimens both sections and whole mount cultured cells in connection to time-lapse (Nagata, 2002 b), as well as the usefulness of high voltage electron microscopes equipped with EDX showing that high $\mathrm{P} / \mathrm{B}$ ratios of trace elements in biological specimens such as $\mathrm{Ag}, \mathrm{Ce}, \mathrm{Au}, \mathrm{S}, \mathrm{Cl}, \mathrm{Ca}, \mathrm{Zn}, \mathrm{Al}$ were obtained from thicker sections at accelerating voltages of 200-400 kV (Nagata, 2002 ${ }^{\mathrm{c}, \mathrm{d}}$ ). This article summarizes the presentations we made at the symposium. We first started to use X-ray microanalysis in order to quantify the silver grains in electron microscopic radioautographs (Nagata, 1985 , 1991, 2000'; Nagata \& Usuda, 1985), then to quantify the deposits of phosphatase reaction containing Ce (Olea, 1991; Olea \& Nagata, 1991, 1992, 2002; Olea et al., 1991). Then we studied other elements such as Zn (Ichikawa et al., 1988, 1994), S (Maruyama, 1991; Maruyama \& Nagata, 1987; Kametani et al., 1998),

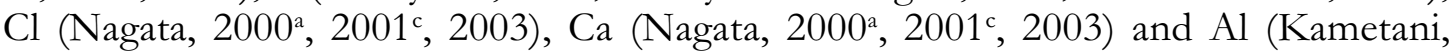
2002; Kametani et al., 2003) observed in various cell types under normal and experimental conditions. We used several systems of transmission analytical electron microscopes equipped with X-ray analyzers, as mentioned above, installed in our EM laboratory in Research Center for Instrumental Analysis at Shinshu University. 


\section{Application of X-ray Microanalysis to Various Elements in Biological Specimens}

The application of X-ray microanalysis to bio-medical researches is to detect various elements localized in the cells and tissues obtained from experimental animals or clinical patients and to qualify several kinds of elements detected in the specimens and further to quantify the contents of the elements in the specific cells, cell organelles and tissues which contain the elements in relation to their localizations (Nagata, 1991, 2000', 2001ㄷ, 2003). The objects of elements in tissues, cells and cell organelles for X-ray microanalysis can theoretically be classified into 3 categories according to the nature of the elements, i.e., (1) endproducts produced through various histochemical reactions, (2) endogenous elements originally existing in cells and tissues, and (3) absorbed elements into cells and tissues of the human or animal bodies by administrations of drugs or chemical agents under environmental or experimental conditions (Nagata, 2002c , 2003). As for the materials used in our studies cited here, all the procedures relating to the human materials and animal experiments were in accordance with the protocol reviewed and approved by either the ethical standards laid down in the 1964 Declaration of Helsinki revised 2000 and the guidelines of the principles of laboratory animal care (NIH publication No. 8523, revised 1985) as well as either the Ethics Committee of Shinshu University School of Medicine and the Animal Research Committee of Shinshu University School of Medicine.

\section{Endproducts of Histochemical Reactions}

There are many histochemical and cytochemical stainings available to demonstrate chemical components of cells and tissue using various principles which can be classified into 3 categories according to the procedures employed, i.e. chemical, physical and biological methods (Nagata, 1994, 2001 a,c). As the results of applications of these methods to various cells and tissues, varieties of endproducts are produced in situ through various chemical, physical and biological procedures and these endproducts can be observed by light and electron microscopy to localize the chemical components in cells and tissues (Nagata, 2001 ${ }^{\mathrm{c}}$ ). Among these techniques, we first applied X-ray microanalysis for quantifying the silver contents of silver grains in radioautographs (Nagata, 1985 a,b, 1988, 1991, 1992, 1993, 1996; Nagata et al. 1991). Then, we used the same procedure for quantifying cerium contents in enzyme histochemical staining in the specimens of the spleens and kidneys of mice demonstrating acid phosphatase activity (Olea, 1991; Olea \& Nagata, 1991, 1992, 2002; Olea et al., 1991). Finally we used the similar method to quantify the gold contents of gold particles in the specimens stained with immuno-gold staining (Usuda \& Nagata, 1991, 1995; Usuda et al., 1990, 1991ª, , 1992, 1994, 1995, 1996; Nagata \& Kametani, 2004). Respective procedures shall be described in detail as follows.

\section{Silver grains in radioautographs}

In order to quantify the concentrations of radiolabeled compounds which were incorporated into cells and tissues synthesizing macromolecular compounds (Nagata, 1999, 2001 , 2002 ${ }^{\mathrm{a}, \mathrm{e}}$ ) such as DNA (Ma \& Nagata, 1988; Olea \& Nagata, 1992; Gao et al., 1995; Ito \& Nagata, 1996; Sun et al., 1997a), RNA (Ma \& Nagata, 1990; Nagata et al., 1991, 1988; Gunarso et al. 1996; Lian et al., 1999), proteins (Gao et al., 1994; Sun et al. 1997b; Cui et al., 2000; Olea \& Nagata, 2002), glucides (Murata et al., 1979; Joukura et al., 1996; Nagata \& Kawahara, 1999; Nagata et al., 1999; Nagata, 2000b), and lipids (Nagata et al., 1990) or soluble compounds (Momose et al., 1995; Nagata, 1992, 1994) by radioautography, the numbers of silver (Ag) grains in either LMRAG (light microscopic radioautograph) or EMRAG (electron microscopic radioautograph) are counted with naked eyes, which was designated as visual grain counting (Nagata, 1985a,b,c, 1992, 1996, 1998, 2000, 2002). However, it is very a troublesome work to count the numbers of silver grains on many photographs one by one. In order to reduce the hard works in grain counting, we first tried to quantify the numbers of silver grains on LMRAG as well as on EMRAG 
by means of various image analyzers available at that time (1970-80s), such as PPA 250 (Rhesca, Tokyo, Japan), Digigramer G (Mutoh Kogyo, Tokyo, Japan), MOP (Kontron, München, Germany), IBAS II (Carl-Zeiss, Jena, Germany), Quadra 900 (Macintosh, Cupertine, CA, USA), Luzex III (Nireco, Tokyo, Japan) (Nagata, 1985 a,b, 2000) and then later we quantified the silver contents on EMRAG by using X-ray microanalyzers with analytical electron microscopes (Nagata, 1985, , 1993, 1996). As for the X-ray microanalysis on EMRAG, we initially used either a Hitachi H-700 electron microscope equipped with Horiba EMAX-1800E, the energy dispersive X-ray microanalyzer by STEM (scanning transmission electron microscopy) mode, or a JEOL JEM 200CX equipped with Kevex 7000-77, where the specimens were observed by STEM mode at accelerating voltages of $100-200 \mathrm{kV}$. When we analyzed the EMRAG obtained from newborn day 1 and day 14 pancreatic acinar cells labeled with ${ }^{3} \mathrm{H}$-uridine demonstrating RNA synthesis in the nucleoli, nuclei and cytoplasm, fixed, embedded and sectioned at $0.1 \mu \mathrm{m}$ thickness, observed at accelerating voltages of either $100 \mathrm{kV}$ or $200 \mathrm{kV}$, the peak counts of $\mathrm{Ag}-\mathrm{K} \alpha$ lines were counted with a probe currents of 500 pico ampere and a small probe diameter $(2 \mu \mathrm{m})$ almost the same as the nucleolus for 100 seconds with a dead time of $30 \%$ (Nagata, 1985a , 1993; Nagata et al., 1988 , 1990, 1991). In the spectra, there were two peaks of silver, $A g-K \alpha$ and $A g-L \alpha$, respectively (Fig. 1). These spectra showed that peak of AgK $\alpha$ line at accelerating voltage of $200 \mathrm{kV}$ (Fig. 1B) was higher than the peak of AgK $\alpha$ line at $100 \mathrm{kV}$ (Fig. 1A). Likewise, the backgrounds obtained at $200 \mathrm{kV}$ were higher than thebackgrounds obtained at $100 \mathrm{kV}$. Thus, the $\mathrm{P} / \mathrm{B}$ ratio of $\mathrm{Ag}-\mathrm{K} \alpha$ at $200 \mathrm{kV}$ was higher than the $\mathrm{P} / \mathrm{B}$ ratio obtained at $100 \mathrm{kV}$. It was demonstrated that the $\mathrm{P} / \mathrm{B}$ ratios obtained at $200 \mathrm{kV}$ were higher than those at $100 \mathrm{kV}$. However, we changed lately (1990s) to use a JEOL JEM-4000EX high voltage electron microscope at accelerating voltages of $400 \mathrm{kV}$, equipped with a Tracor-Northern TN-5400 EDX by TEM (transmission electron microscopy) mode which was better than the former method by STEM mode, because we could observe the ultrastructure directly when measuring as well as observing thicker sections with higher accelerating voltages at $400 \mathrm{kV}$ and obtaining higher $\mathrm{P} / \mathrm{B}$ ratios (Nagata, 1991; Nagata et al., 2000). In order to establish routine procedure for quantifying the silver content in silver grains in radioautographs, we used the electron radioautographs prepared from mouse hepatocytes labeled with ${ }^{3} \mathrm{H}$-thymidine as the models. Figure $2 \mathrm{~A}$ shows an example of EMRAG of mouse hepatocyte labeled with ${ }^{3} \mathrm{H}$-thymidine, fixed, embedded and sectioned at $0.2 \mu \mathrm{m}$ thickness, and processed for radioautography demonstrating DNA synthesis. The diameters of microprobe were from 0.2 to $1 \mu \mathrm{m}$, integrating detecting time was $100 \mathrm{~s}$ and the detecting dead time was $30 \%$. The beam currents were from 2 to 8 nano ampere and the accelerating voltages were 100, 200, 300, 350 , and $400 \mathrm{kV}$. Figure 3 shows 4 spectra obtained from a single silver grain on $0.2 \mu \mathrm{m}$ thick section observed at accelerating voltages of 100, 200, 300 and $400 \mathrm{kV}$, respectively. There were two peaks of silver, $\mathrm{Ag}-\mathrm{L} \alpha$ and $\mathrm{Ag}-\mathrm{K} \alpha$. From the results, the mean peak counts and background counts of silver grains measured at different accelerating voltages, $100,200,300,350$ and $400 \mathrm{kV}$ were recorded and the peak to background ratios $(\mathrm{P} / \mathrm{B})$ at respective accelerating voltages were counted. The transitional curve of the $\mathrm{P} / \mathrm{B}$ ratios of silver grains calculated from these data, at different accelerating voltages from 100 to $400 \mathrm{kV}$, is shown in Figure 4. From the results, the maximum was found at $350 \mathrm{kV}$ (Nagata, 2000). We further tested to quantify several elements in biological specimens by $400 \mathrm{kV}$ high voltage analytical electron microscopy and found the usefulness of HVEM to increase the P/B ratios (Nagata, 1985 ${ }^{\mathrm{b}}$, 1988, 1991, 1993, 1996, 1999, 2001, 2002 c,d 2003, Nagata \& Usuda, 1985). It was also shown by Bando (1995) and Bando et al. (1985) that the P/B ratios of $\mathrm{Ag}, \mathrm{Al}$ and $\mathrm{Ge}$ in inorganic materials such as ceramics increased with the increase of the accelerating voltages from 100 to $400 \mathrm{kV}$ by using a JEOL JEM-4000EX TEM, similarly to the results obtained from biological specimens in our laboratory.

When EMRAG obtained from the pancreases of fetal day 19 embryos, newborn day 1 and newborn day 14 mice labeled with ${ }^{3} \mathrm{H}$-uridine, demonstrating RNA synthesis, the number of silver grains in the nucleoli, nuclear chromatin and cytoplasm increased by visual grain counting. The $\mathrm{P} / \mathrm{B}$ ratios expressing relative silver contents were counted by 

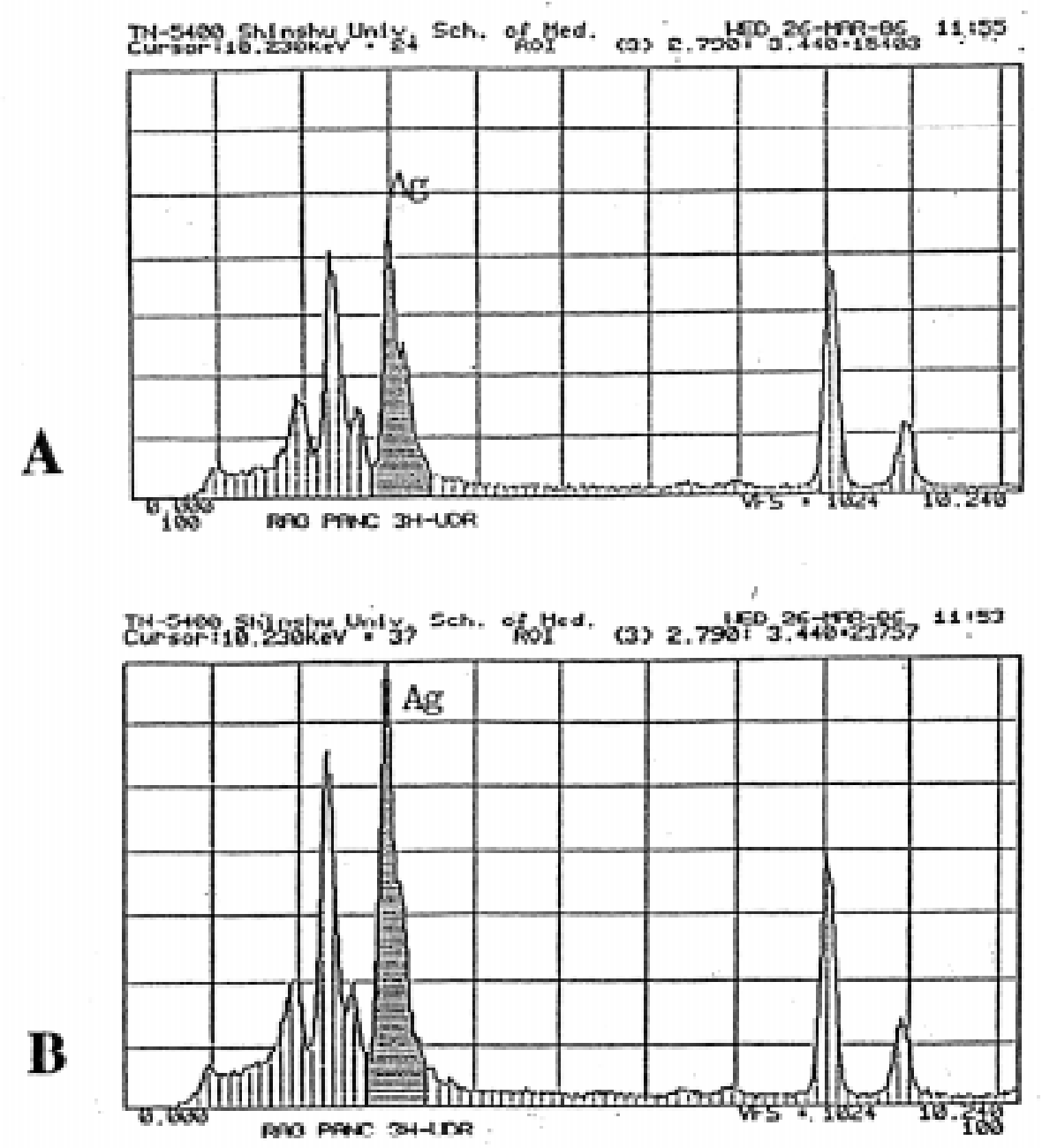

Figure 1. X-ray microanalysis of silver grains in radioautographs, showing X-ray spectra of Ag-Ka obtained from the silver grains in EMRAG of pancreatic acinar cells labeled with ${ }^{3} \mathrm{H}$-uridine, observed in a Hitachi H-700 STEM at 200kV. 1A. Spectrum from the pancreas of a newborn mouse at postnatal day 1.1B. Spectrum from the pancreas of a young mouse at postnatal day 14. From Nagata (1993a).

using JEM-4000EX equipped with TN-5400 EDX system at $350 \mathrm{kV}$ and the data were compared between the two age groups. These two results, the results obtaining from visual grain counting and the silver contents analyzed by X-ray microanalysis were in good accordance with each other (Nagata, $\left.1985^{\mathrm{b}}, 1991,1993\right)$. Thus, it was demonstrated that $\mathrm{X}$-ray microanalysis by TEM mode was useful in quantifying silver grains in EMRAG instead of visual grain counting. In the literature, Hodges and Muir (1975) were the first to quantify silver contents on EMRAG obtained from cultured cells labeled with ${ }^{3} \mathrm{H}$ thymidine by scanning electron microscopy (SEM) equipped with EDX but observing the cell surface without confirming the nuclei and cell organelles surrounded with the cytoplasm. Our reports (Nagata, 1985 , 1991, 1993) were the first to quantify the silver grains by TEM mode observing both the silver grains and the nuclei and cell organelles. This procedure should be useful in calculating and recording the data of grain counting by $\mathrm{X}$-ray microanalysis with an on-line computer when analyzing many radioautographs quantitatively in a short time.

\section{Cerium Deposits in Acid Phosphatase Reaction}

We had studied ${ }^{3} \mathrm{H}$-thymidine incorporation into the splenic cells of aging mice from newborn to adult and senescence in connection to the lysosomal acid phosphatase activity (Olea, 1991; Olea \& Nagata, 1991, 1992, 2002; Olea et al., 1991) as 
Figure 2. Electron micrographs showing original pictures from which the X-ray spectra were observed. Scale $\mathrm{bar}=0.1 \mu \mathrm{m}$. 2A. Electron microscopic radioautograph of a hepatocyte of mouse liver labeled with ${ }^{3} \mathrm{H}$-thymidine, fixed in buffered glutaraldehyde and osmium tetroxide, embedded in Epoxy resin and sectioned at $0.2 \mu \mathrm{m}$ thickness, demonstrating DNA synthesis From Nagata (2000d). 2B. Electron micrograph of a reticular cell in the spleen of a newborn mouse at postnatal day 1, showing AcPase activity by cerium substrate method. Electron dense deposits are localized in lysosomes. From Nagata $\left(2000^{\mathrm{d}}\right)$. 2C. Electron micrograph of a hepatocyte of a normal adult male Wistar rat liver, fixed in paraformaldehyde and glutaraldehyde mixture, embedded in Lowicryl K4M, sectioned, stained with anticatalase antibody by the protein A-gold technique. Gold particles for catalase can be seen over the peroxisomal matrix. From Nagata (2001'). 2D. Electron micrograph of a goblet cell of mouse proximal colon, fixed with $2.5 \%$ glutaraldehyde in phosphate buffer, embedded in Epoxy resin, sectioned according to conventional technique, stained with uranyl acetate and lead
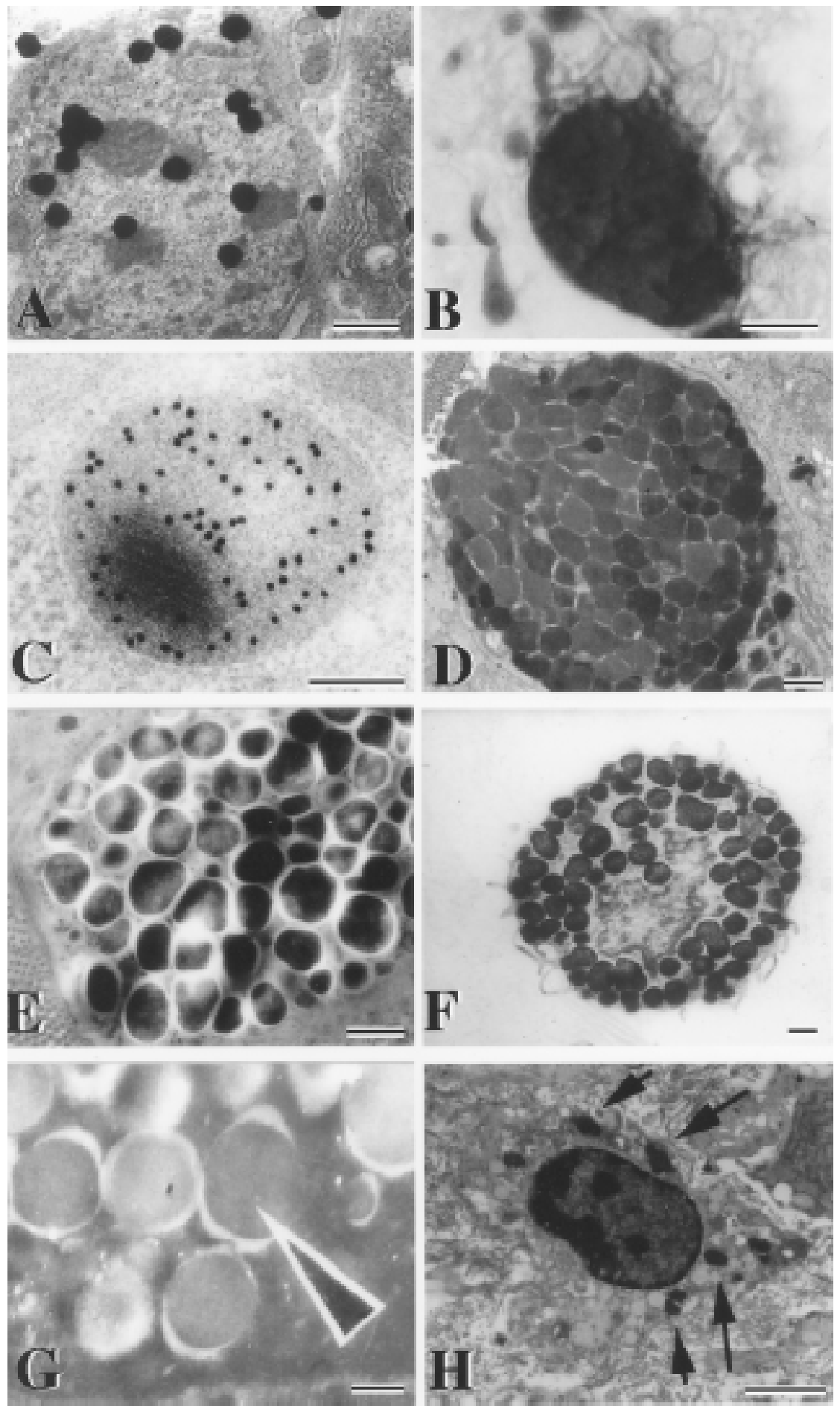

citrate. From Nagata et al. $\left(2000^{c}\right)$. 2E. Electron micrograph of a goblet cell of mouse proximal colon, cryofixed by metal contact method using a JFD-RFA freezing apparatus cooled with liquid nitrogen, freezesubstituted in absolute acetone containing osmium tetroxide, embedded in Epon, and dry-sectioned using ethylene glycol. From Nagata et al. $\left(2000^{c}\right)$. 2F. Electron micrograph of a mast cell collected from the peritoneal exudate of a Wistar strain, centrifuged, cryo-fixed in isopentane cooled with liquid nitrogen, freeze-substituted in aceton containing osmium tetroxide, embedded in Epoxy resin and dry-sectioned using ethylene glycol at $0.4 \mu \mathrm{m}$ thickness and observed at $300 \mathrm{kV}$. From Nagata $\left(2000^{\mathrm{d}}\right)$. 2G. Electron micrograph of a Paneth cell of mouse duodenum, fixed with 2.5\% glutaraldehyde in phosphate buffer, embedded in Epoxy resin, sectioned according to conventional technique, stained with uranyl acetate and lead citrate. The granule indicated with an arrow was studied by X-ray microanalysis. From Nagata et al. $\left(2000^{c}\right) .2 \mathrm{H}$. Electron micrograph of a wandering cell in the submucosa of the duodenum of an adult mouse injected intraperitoneally with Aluminum chloride, fixed in buffered glutaraldehyde and osmium tetroxide, embedded in Epoxy resin, sectioned at $1.0 \mu \mathrm{m}$ thick, stained with uranyl acetate and lead citrate. From Kametani (2001). 
Figure 3. X-ray spectra obtained from a specimen prepared from mouse hepatocytes labeled with ${ }^{3} \mathrm{H}$-thymidine and observed in a JEOL JEM-4000EX high voltage electron microscope equipped with TracorNorthern TN-5400 EDX in the TEM system. The accelerating voltages were changed from 100, 200, 300 and $400 \mathrm{kV}$, demonstrating $\mathrm{Ag}-\mathrm{K} \alpha$, respectively. From Nagata (2001').
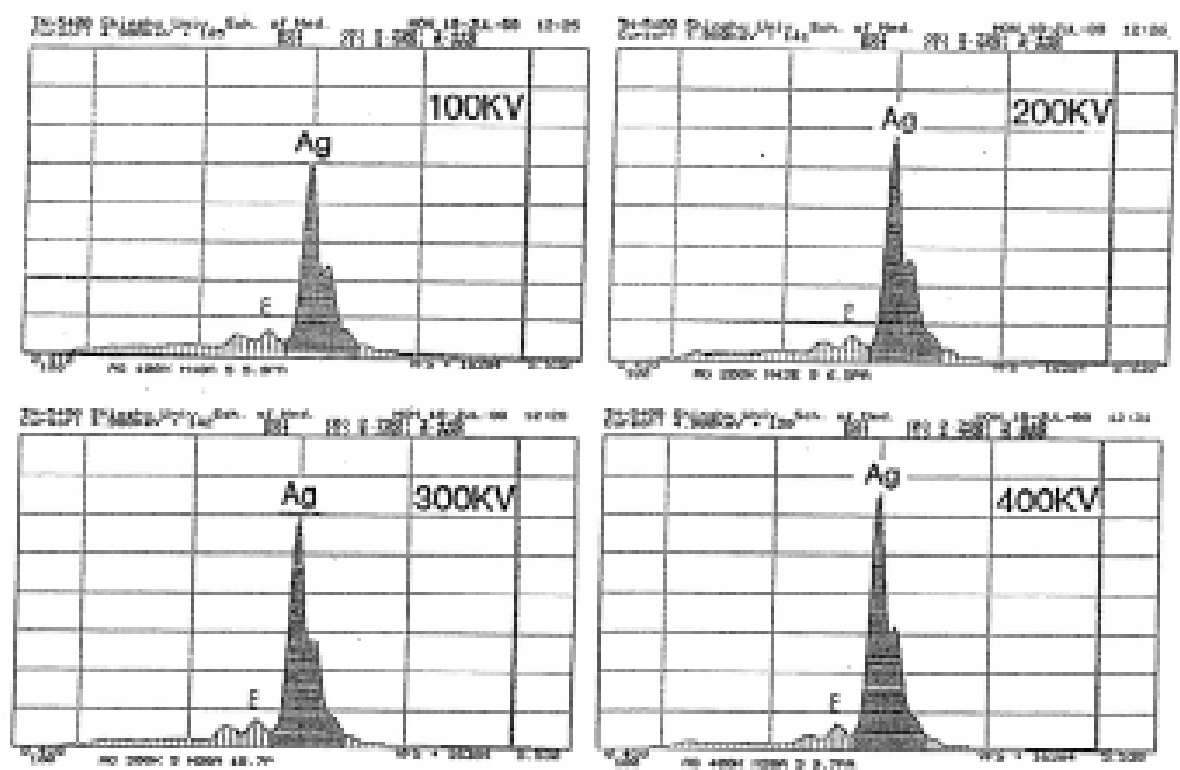

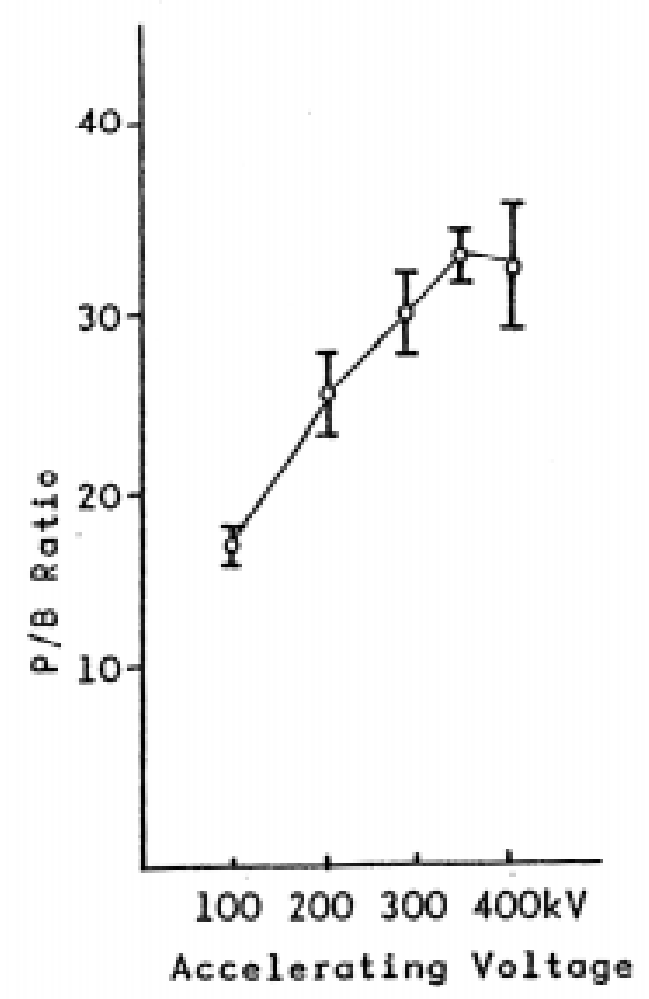

Figure 4. Relation between $\mathrm{P} / \mathrm{B}$ ratios of $\mathrm{Ag}$ and accelerating voltages. The peak to background ratios $(\mathrm{P} /$ $\mathrm{B})$ at the different accelerating voltages from the spectra in Figure 3 were measured and calculated. The curve of the $\mathrm{P} / \mathrm{B}$ ratios of silver grains determined and plotted as a function of the accelerating voltage from 100 to $400 \mathrm{kV}$. The maximum was found at $350 \mathrm{kV}$. From Nagata $\left(2001^{\mathrm{c}}\right)$. 
a part of systematic studies on macromolecular synthesis of various organs in aging mice (Nagata, 2002a). The acid phosphatase activity of splenic macrophages was demonstrated by means of cerium substrate method, one of the chemical reactions (Olea, 1991; Olea \& Nagata, 1991, 1992; Olea et al., 1991). Electron dense cerium (Ce) deposits were observed in lysosomes of macrophages and reticular cells in the splenic tissues (Fig. 2B). By X-ray microanalysis in TEM mode, at the accelerating voltages from 100, 200, 300, 350 and $400 \mathrm{kV}$, the localization of cerium deposits was confirmed with two peaks at 4.84 and $5.26 \mathrm{keV}$, respectively (Fig. 5). These spectra did not interfere with the osmium line at $1.914 \mathrm{keV}$. When the cerium spectra were observed by changing the accelerating voltages at $100-400 \mathrm{kV}$, the intensities of the peaks increased with increasing accelerating voltages from 100 to 400. On the other hand, the background also decreased with the changes of accelerating voltages. However, the average peak to background ratios $(\mathrm{P} / \mathrm{B})$ counted at 100, 200, 300 and $400 \mathrm{kV}$ increased from 100 to $400 \mathrm{kV}$ (Fig. 6 ) similarly to Ag. Therefore, $\mathrm{X}$-ray microanalysis in quantifying cerium contents showing acid phosphatase activity in lysosomes of both the macrophages in the spleens (Olea \& Nagata, 1991) and the uriniferous tubules in the kidneys (Olea et al., 1991) in several groups of aging mice from newborn day 1 to 10 months were carried out using the accelerating voltage at $400 \mathrm{kV}$. This method is useful in quantifying acid phosphatase activity when analyzing numerous specimens quickly.

\section{Gold Particles in Colloidal Gold Immunostaining}

Concerning biological reactions such as immunostaining, we formerly studied immunostaining for peroxisomal enzymes in the liver. We first studied immunostaining of peroxisomal enzymes in mouse liver, such as urate oxidase (Yokota \& Nagata, 1973, 1977) and catalase (Yokota \& Nagata, 1974), using cryo-sections and ferritin-antibody oxidase conjugates, together with the conventional enzyme cytochemical methods. The two enzymes were localized on the peroxisomes of mouse hepatocytes and it was found that the number of peroxisomes in mouse hepatocytes decreased after birth but sometimes increased after administrations of several peroxisome proliferators such as clofibrate, bezafibrate and DEHP. The peroxisomal enzyme activity as demonstrated by immuno-ferritin method could be studied by $\mathrm{X}$ ray microanalysis of $\mathrm{Fe}$ in the ferritin-conjugates. However, the trial was not carried out at that time. We later developed immunostaining of peroxisomal enzymes by protein A-colloidal gold complex technique using cryo-fixation and freeze-substitution embedding for electron microscopy in correlation to the intracellular localization of peroxisome proliferators (Usuda \& Nagata, 1991, 1995; Usuda et al., 1990, 1991a, $\left.1991^{\mathrm{b}}, 1992,1994,1995,1996\right)$. The hepatic tissues of Wistar rats were fixed in 4\% paraformaldehyde/ $0.1 \%$ glutaraldehyde/ $0.1 \mathrm{M}$ phosphate buffer at $\mathrm{pH} 7.4$, embedded in Lowicryl $\mathrm{K} 4 \mathrm{M}$ at $-20^{\circ} \mathrm{C}$, and immunostained with antibodies for catalase, acylCoA oxidase, bifunctional proteins, 3-ketoacyl-CoA thiolase, urate oxidase, HMG CoA reductase, serine: pyruvate aminotransferase, sterol carrier protein 2, 2,4-dienoylCoA reductase, apolipoprotein E, L $\alpha$ hydroxiacid oxidase, glycolate oxidase, acyCoA oxidase, D-amino acid oxidase for peroxisomal matrix and 70, 40, 26, $22 \mathrm{kDa}$ PMPs for peroxisomal membrane by protein A-gold technique (Usuda \& Nagata, 1991, 1995; Usuda et al., 1990, 1991 a,b, 1992, 1994, 1995, 1996). The results demonstrated that a peroxisome of rat hepatocyte is a spherical organelle with a single limiting membrane, containing a homogeneous matrix and a high electron dense core. The peroxisomal matrix of rat hepatocytes can be divided into two subcompartments, the electron-lucent subcompartment and the electron-dense subcompartment (Usuda et al., $\left.1991^{\mathrm{a}}\right)$. The peroxisomal membrane contains $70 \mathrm{kDa}, 41 \mathrm{kDa}, 26 \mathrm{kDa}$, and $22 \mathrm{kDa}$ PMPs (Usuda et al., 1990, 1991 $\left.{ }^{\mathrm{b}}, 1994,1996\right)$. The matrix of hepatic peroxisomes contains catalase (Fig. 2C), D-amino acid oxidase, acyl-CoA oxidase, Lohydroxiacid oxidase, glycolate oxidase, acy-CoA oxidase, bifunctional protein, and 3-ketoacyl-CoA thiolase in the peroxisomal matrix and urate oxidase in the core. The electron-lucent subcompartment of the matrix contains only D-amino acid oxidase while the electron- 

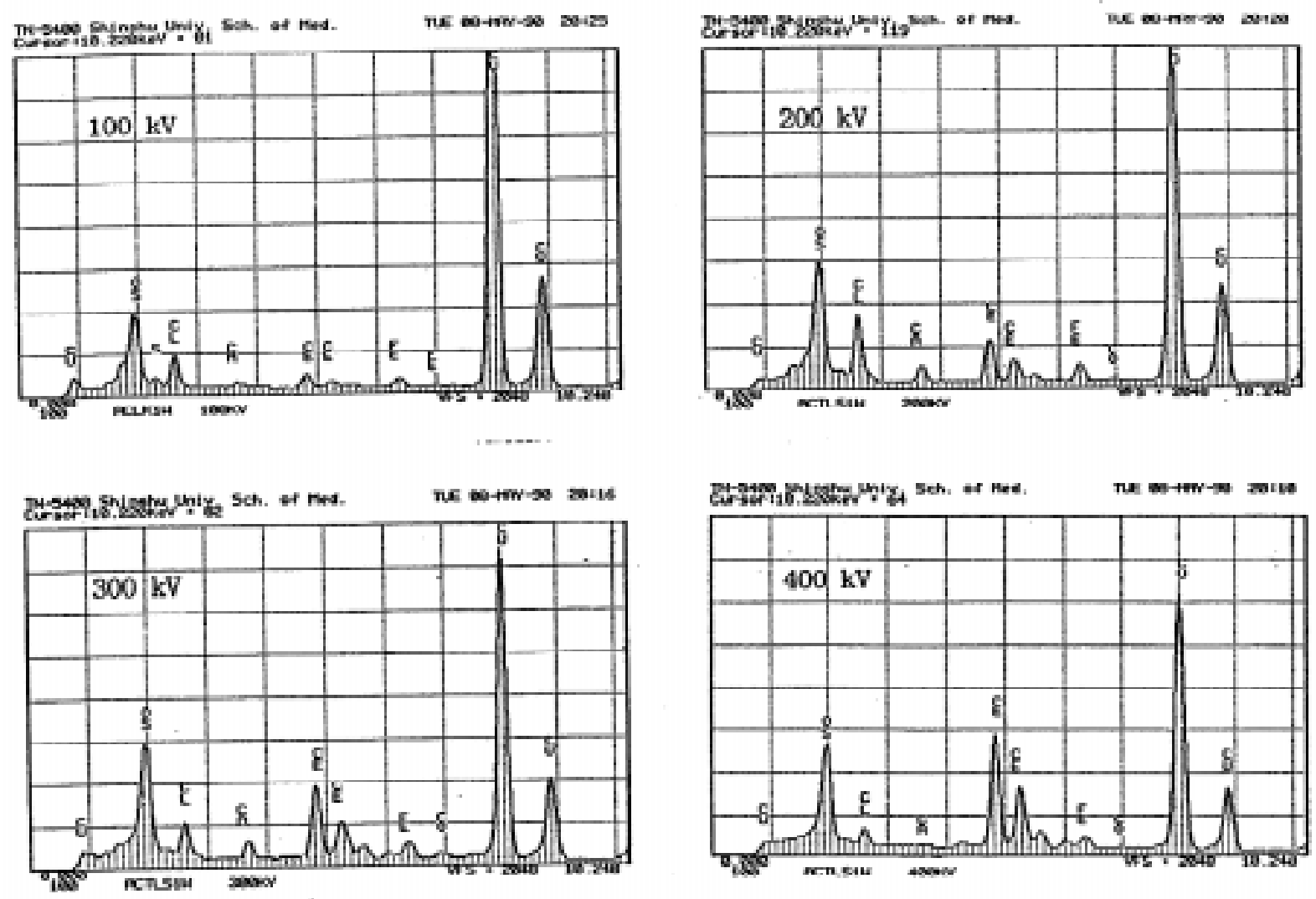

Figure 5. X-ray spectra of Ce-K $\alpha$ obtained from sections stained with acid phosphatase reaction by cerium substrate method shown in Figure $2 \mathrm{~B}$, as observed by X-ray microanalysis at different accelerating voltages of 100, 200, 300 and 400 kV, respectively. From Olea \& Nagata (1991).

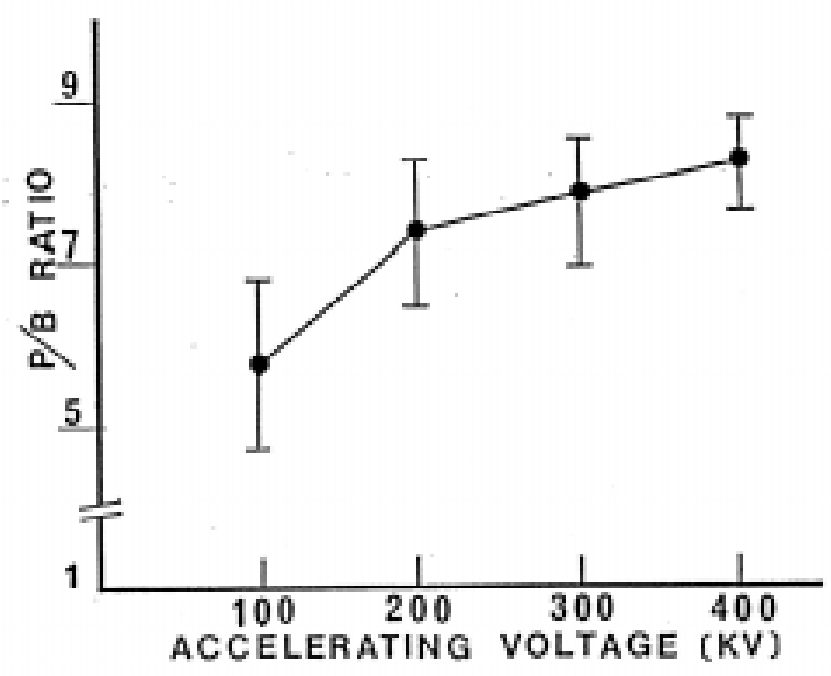

Figure 6. Relationship between accelerating voltages and $\mathrm{P} / \mathrm{B}$ ratios of $\mathrm{Ce}$ from acid phosphatase activity in mouse splenic reticular cell, measured and calculated from the spectra in Figure 5. The maximum was found at $400 \mathrm{kV}$. From Olea \& Nagata (1991). 
dense subcompartment contains all other enzymes. The immunogold techniques were also applied to the livers of different species (Usuda et al., 1995, 1996). Thus, it was demonstrated that species specific differences were observed in the size and shape of the peroxisomes and the ultrastructure of the core in man, monkey, cow, cat, dog, rat, mouse, frog and so on (Usuda \& Nagata, 1991, 1995; Usuda et al., 1990, 1991a,b, 1992, 1994, 1995, 1996).

In order to quantify the gold $(\mathrm{Au})$ content in immuno-gold staining for catalase by X-ray microanalysis, we first used hepatocytes of a normal adult male Wistar rat, fixed in paraformaldehyde and glutaraldehyde mixture, embedded in Lowicryl K4M, sectioned and stained with anti-catalase antibody by the protein Agold technique as the models. Figure $2 \mathrm{C}$ shows examples of electron microscopic photographs of rat hepatocytes stained by anti-catalase antibody. Figure 7 shows four spectra obtained from a single gold particle observed at accelerating voltages of 100 , 200, 300 and $400 \mathrm{kV}$, respectively. There are two peaks of gold, Au-L $\alpha$ and Au-M $\alpha$, respectively. From the results, the peak of $\mathrm{Au}-\mathrm{L} \alpha$ to background ratios $(\mathrm{P} / \mathrm{B})$ in respective accelerating voltages were calculated. The transitional curve of the $\mathrm{P} / \mathrm{B}$ ratios of gold particles at different accelerating voltages from 100 to $400 \mathrm{kV}$ is shown in Figure 8. From the results, the maximum was found at $300 \mathrm{kV}$. Thus, X-ray microanalysis at $300 \mathrm{kV}$ for quantifying the Au contents of the gold particles in several experimental groups stained with protein A-gold technique could be carried out (Nagata \& Kametani, 2004). This procedure should be useful in calculating and recording the data with an on-line computer when analyzing many immunostained specimens by X-ray microanalysis.

\section{Endogenous Elements in Various Cells and Tissues}

After applying X-ray microanalysis to endproducts of histochemical reactions, we studied other endogenous elements originally existing in cells and tissues such as $\mathrm{S}, \mathrm{Cl}$, $\mathrm{Ca}$ and $\mathrm{Zn}$ which were occasionally observed in various cell types under normal conditions. The applications and results of X-ray microanalysis to these elements should be described according to the order of the periodic law of the elements as is listed in the periodic table in physics. The endogenous elements naturally detected in animal and human tissues are light elements such as ${ }^{11} \mathrm{Na},{ }^{14} \mathrm{Si},{ }^{15} \mathrm{P},{ }^{16} \mathrm{~S},{ }^{17} \mathrm{Cl},{ }^{19} \mathrm{~K},{ }^{20} \mathrm{Ca}$ and ${ }^{30} \mathrm{Zn}$, which are found in the upper parts of the periodic table. Heavy metals such as ${ }^{47} \mathrm{Ag},{ }^{48} \mathrm{Cd},{ }^{58} \mathrm{Ce},{ }^{79} \mathrm{Au},{ }^{80} \mathrm{Hg},{ }^{82} \mathrm{~Pb}$ are not usually detected except as the endproduct precipitations produced by various histochemical reactions.

\section{Sulfur in colonic goblet cells}

Formerly, we studied mucosubstance synthesis incorporating radiosulfate labeled with ${ }^{35} \mathrm{SO}_{4}$ in goblet cells of mouse colon, demonstrated by light and electron microscopic radioautography (Nagata, 2000; Nagata \& Kawahara, 1999; Nagata et al., 1989a , 1999). Many silver grains due to radiosulfate were observed to localize over the Golgi zones and the mucigen granules of the goblet cells. Among many goblet cells in the crypts of Lieberkuehn, more silver grains can be seen over the cells in the upper region of the crypt than the lower region. It was shown that the turnover rate of radiosulfate in the goblet cells in the deeper region was more rapid than those in the upper region by quantitative analysis (Nagata et al., 1988a). In order to clarify whether the total contents of sulfur (S) in the Golgi zones and the mucigen granules of the goblet cells in different regions of the colons at different ages of ddY mice might differ or not as well as if the total contents of sulfur in the goblet cells change according to the fixation procedures, X-ray microanalysis was carried out in several experiments (Maruyama, 1991; Maruyama \& Nagata, 1987; Kametani et al., 1998; Nagata \& Usuda, 1985). Figure 2D is an electron micrograph showing mucigen granules of colonic goblet cells in the lower crypts of the proximal colon of an aging mouse at postnatal 15 month, fixed chemically with buffered $2.5 \%$ glutaraldehyde, embedded 
in Epoxy resin and sectioned using water. Figure 2E shows an electron micrograph of a goblet cell of a mouse proximal colon, cryo-fixed, freeze-substituted, embedded in Epoxy resin and dry-sectioned. The X-ray spectra obtained from the granules of mouse colonic goblet cells are shown (Fig. 9). Figure 9A shows the spectrum from the tissue fixed in phosphate buffered $2.5 \%$ glutaraldehyde followed by dehydration, embedding in Epoxy resin and cut by conventional sectioning using water, while Figure 9B shows the spectrum from the tissue fixed by cryo-fixation with metal contact method and followed by freeze-substitution in absolute acetone, embedding in Epoxy resin and dry-sectioned without water, picked up onto nickel grid meshes (VECO, Eerbeek, Netherlands) and observed at $300 \mathrm{kV}$. For X-ray microanalysis a high voltage JEM 4000EX TEM with a Tracor-Northern energy dispersive X-ray microanalyzer TN5400 was used. Thus, higher peaks of S, Cl, K as well as other elements such as $\mathrm{Na}$,

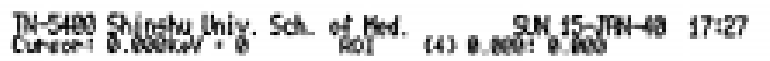

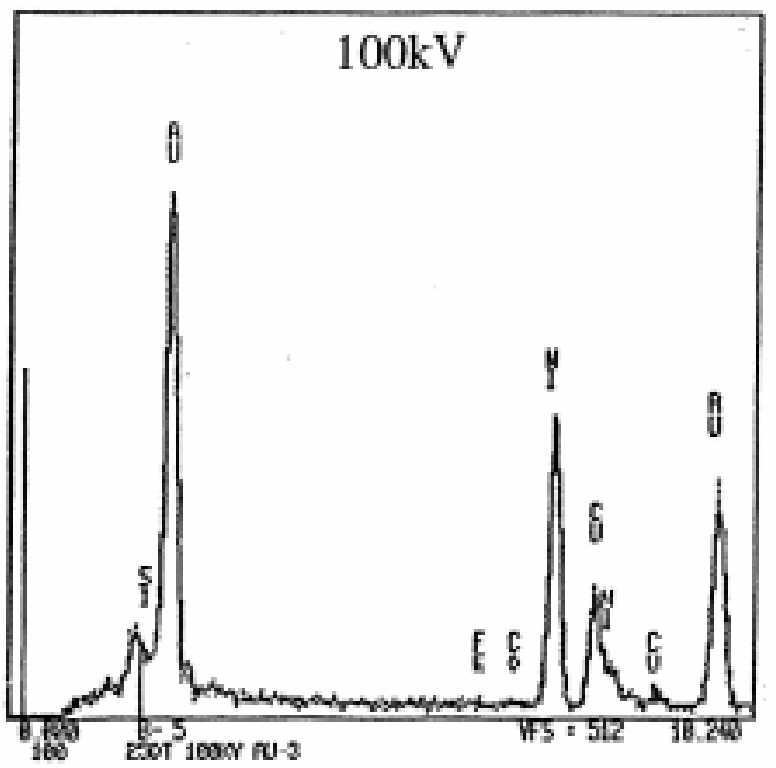

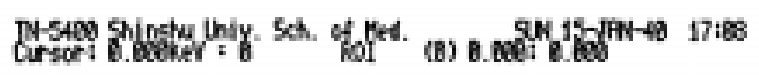

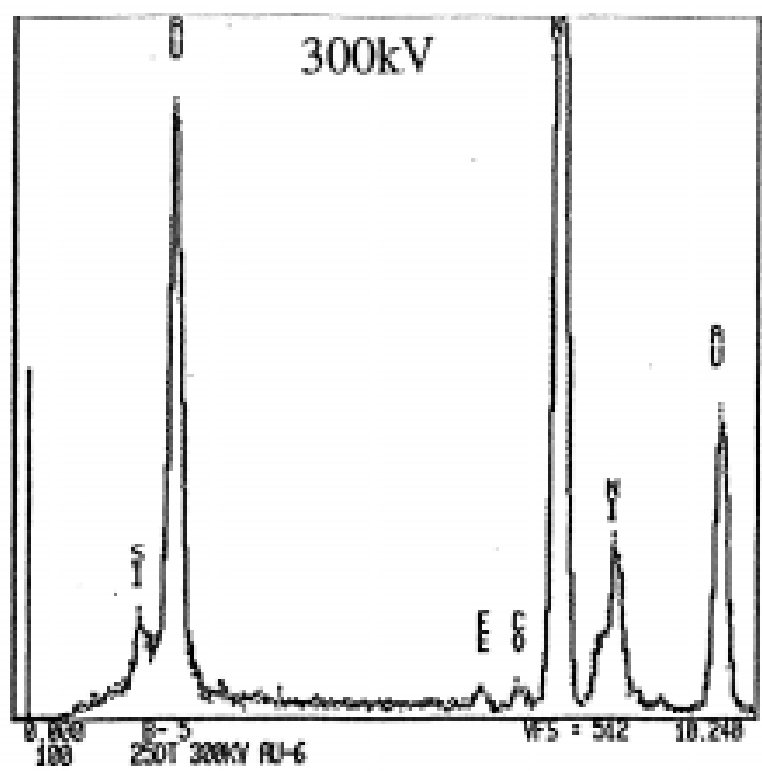

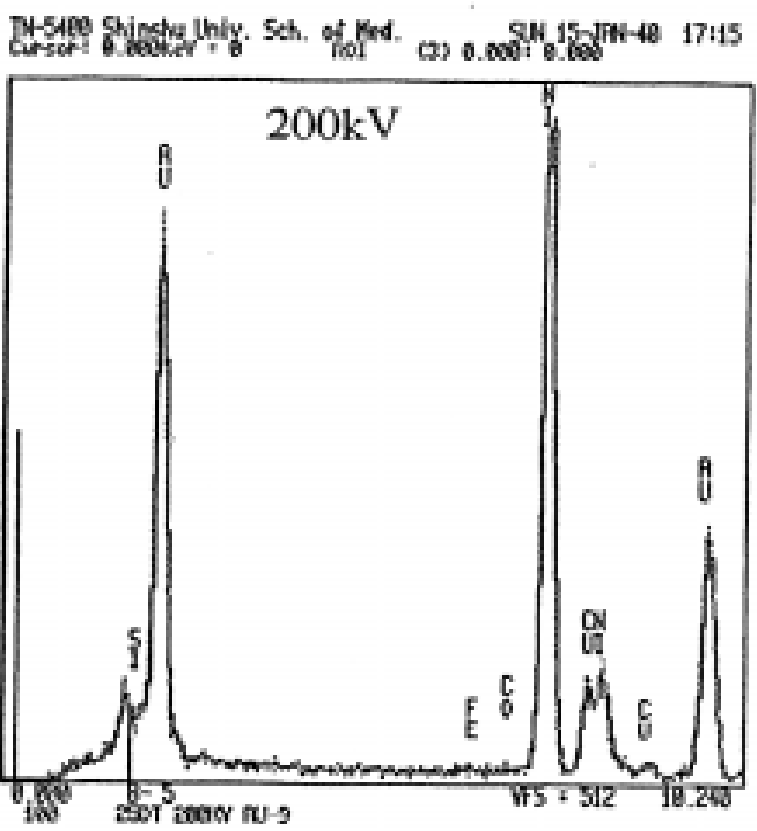

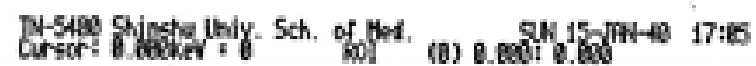

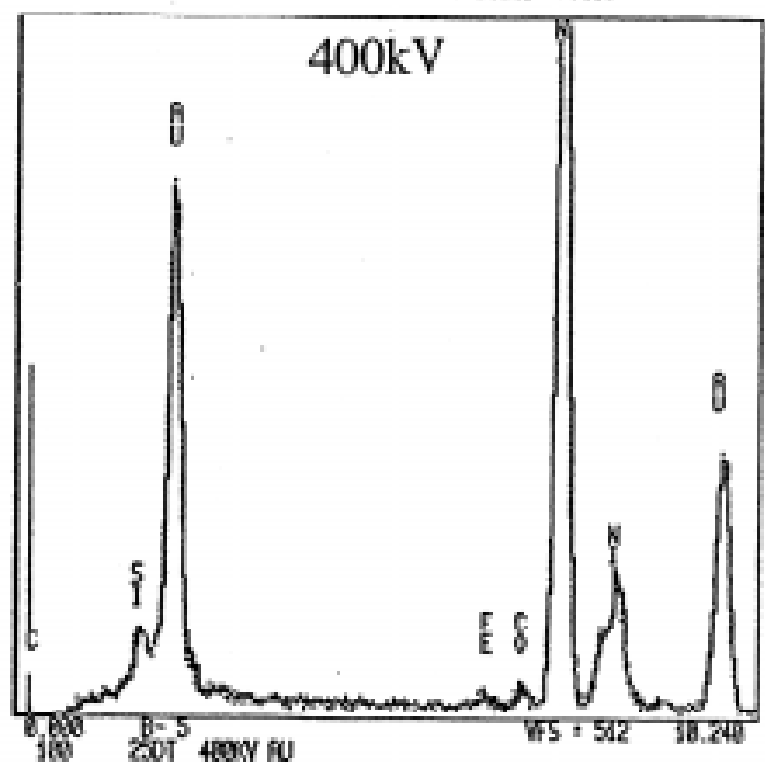

Figure 7. X-ray spectra of Au-L $\alpha$ obtained from rat liver sections stained with anti-catalase antibody by the protein A-gold technique as shown in Figure $2 \mathrm{C}$ and observed by $\mathrm{X}$-ray microanalysis at different accelerating voltages of 100, 200, 300 and $400 \mathrm{kV}$, respectively. The maximum was found at $300 \mathrm{kV}$. From Nagata (2003). 
Fig. 8. Relationship between accelerating voltages and $\mathrm{P} / \mathrm{B}$ ratios of $\mathrm{Au}$ from Wistar rat hepatocyte stained with anti-catalase antibody by the protein A-gold technique, measured and calculated from the peaks of $\mathrm{Au}-\mathrm{L} \alpha$ and backgrounds in the spectra in Fig. 7. The maximum was found at $300 \mathrm{kV}$. From Nagata (2003).
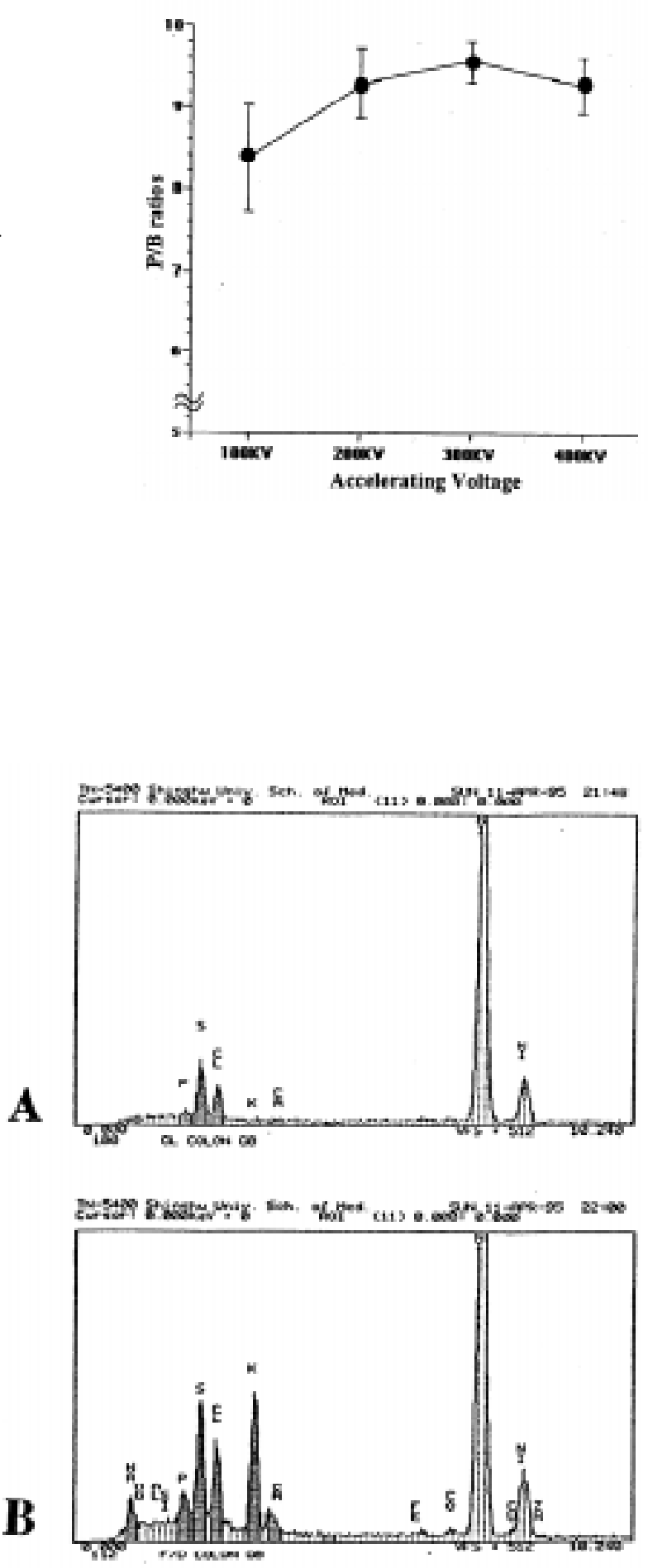

Fig. 9. X-ray spectra of $\mathrm{S}-\mathrm{K} \alpha$ and $\mathrm{Cl}-\mathrm{K} \alpha$ obtained from the granules of mouse colonic goblet cells fixed in either phosphate buffered $2.5 \%$ glutaraldehyde followed by dehydration, embedding and conventional sectioning (A) or cryo-fixation followed by freeze-substitution with osmium tetroxide, embedding in Epon and dry-sectioning (B) and observed at $300 \mathrm{kV}$. From Nagata (2003). 


\section{Chlorine in Paneth cells and in Epon sections}

Previously, we had found the existence of low peaks of zinc $(\mathrm{Zn})$ with high peaks of sulfur $(\mathrm{S})$ and chlorine $(\mathrm{Cl})$ in the spectra obtained from the specific granules of Paneth cells of mouse duodenum by X-ray microanalysis (Ichikawa et al., 1988, 1994; Nagata et al. 1988a). In order to quantify the zinc content in these granules, we first studied the relation between the $\mathrm{Zn}$ peaks in the spectra and the zinc concentrations in a model system. As a model experiment, we prepared Epoxy sections containing zinc sulfate at concentration of $0.1 \%$ dissolved in the Epoxy mixtures and polymerized. The Epoxy blocks were cut on an Porter-Blum MT-2B ultramicrotome (Dupont-Sorvall, Newtown, USA) at 0.1 or $0.4 \mu \mathrm{m}$ thicknesses, picked up onto nylon meshes (Veco, Eerbeek, Netherlands) and observed by JEM4000EX TEM with Tracor-Northern NT-5400 EDX system, changing the accelerating voltages from 100 to $400 \mathrm{kV}$. The spectra showing $\mathrm{Zn}$ peaks as well as $\mathrm{S}$ and $\mathrm{Cl}$ peaks were obtained respectively (Fig. 9). The peak counts as well as the backgrounds changed from 100 to $400 \mathrm{kV}$. The results from $\mathrm{Cl}$ peaks were plotted as the changes of $\mathrm{P} / \mathrm{B}$ ratios in connection to accelerating voltages (Fig. 12). The peak of the transitional curve obtained from $\mathrm{P} / \mathrm{B}$ ratios of $\mathrm{Cl}$ was found at $300 \mathrm{kV}$, similarly to S (Nagata, 2003).

\section{Calcium in mast cells and ligaments}

Formerly we had demonstrated intracellular localization of a synthetic antiallergic drug, tranilast (Kissei Pharmaceutical Co., Matsumoto, Japan), in the peritoneal mast cells of Wistar rats by means of radioautography (Nagata et al., 1986a). In relation to silver grain accumulation over mast cell granules to the inhibition of degranulation of mast cells for anti-allergic reaction, it was presumed that this agent might interfere with the calcium (Ca) influx resulting in the histamine release in allergic reaction (Nagata et al., 1986; Nishigaki et al., 1987, 1990). Thus, we tried to detect the intracellular localization and quantification of $\mathrm{Ca}$ in peritoneal mast cells which were cryo-fixed and freeze-dried by XMA. We also found Ca localizing in the human lumbar yellow ligaments (ligamentum flavum) in the patients suffering from the ossification of the ligaments and lumbar canal stenosis (Ono, 1991; Ono \& Nagata, 1989, 1992; Ono et al., 1988, 1994). In order to find the effect of chemical fixation on Ca contents in mast cells, we collected mast cells from the peritoneal exudate of Wistar strain rats, centrifuged, cryo-fixed in isopentane cooled with liquid nitrogen $\left(-165^{\circ} \mathrm{C}\right)$, freeze-substituted in acetone $\left(-80^{\circ} \mathrm{C}\right)$ containing osmium tetroxide, embedded in Epoxy resin and dry-sectioned using ethylene glycol at 0.2 or 0.4 $\mu \mathrm{m}$ thicknesses keeping soluble compounds by cryo-techniques (Nagata, 1991, 1994). As control specimens, some of the centrifuged mast cells were fixed in buffered $2.5 \%$ glutaraldehyde, embedded in Epoxy resin, sectioned at either 0.2 or $0.4 \mu \mathrm{m}$ thicknesses. Those specimens were observed at 100-400 kV. Figure $2 \mathrm{~F}$ shows an electron micrograph of a rat mast cell, cryo-fixed, freeze-substituted, embedded in Epon and dry-sectioned. For X-ray microanalysis a JEM 4000EX TEM system with a Tracor-Northern TN-5400 analyzer was used. As the results, the spectra obtained from the cryo-sections showed more $\mathrm{Ca}$ than the chemically fixed specimen, similarly to $\mathrm{S}$ as shown in Figure 9. Then, in order to find the relationship between the $\mathrm{P} / \mathrm{B}$ ratios of $\mathrm{Ca}$ and the accelerating voltages, we observed the chemically fixed mast cells, changing the accelerating voltages from 100 to $400 \mathrm{kV}$. Figure 13 shows the 4 spectra obtained from a mast cell granule, sectioned at $0.2 \mu \mathrm{m}$ and observed at 100,200, 300 and $400 \mathrm{kV}$, while Figure 14 shows the 4 spectra from another section at $0.4 \mu \mathrm{m}$ thickness. The peak counts of $\mathrm{Ca}-\mathrm{K} \alpha$ and background counts of mast cell cytoplasm obtained from either 0.2 or $0.4 \mu \mathrm{m}$ thick sections observed at $100,200,300,350$ and $400 \mathrm{kV}$ were recorded and the $\mathrm{P} / \mathrm{B}$ ratios were calculated, respectively. Figure 15 shows two transitional curves of the $\mathrm{P} / \mathrm{B}$ ratios of $\mathrm{Ca}$ in mast cell cytoplasm from 100 to $400 \mathrm{kV}$. The maxima of the two curves, both thicknesses at 0.2 and $0.4 \mu \mathrm{m}$, were found at $300 \mathrm{kV}$ (Nagata, 1999, 2003). Therefore, we used $300 \mathrm{kV}$ for further quantification of Ca (Ono, 1991; Ono \& Nagata, 1989, 1992; Ono et al., 1988, 1994). 


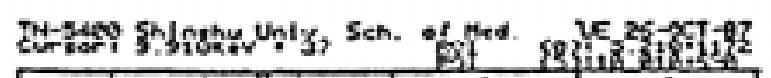

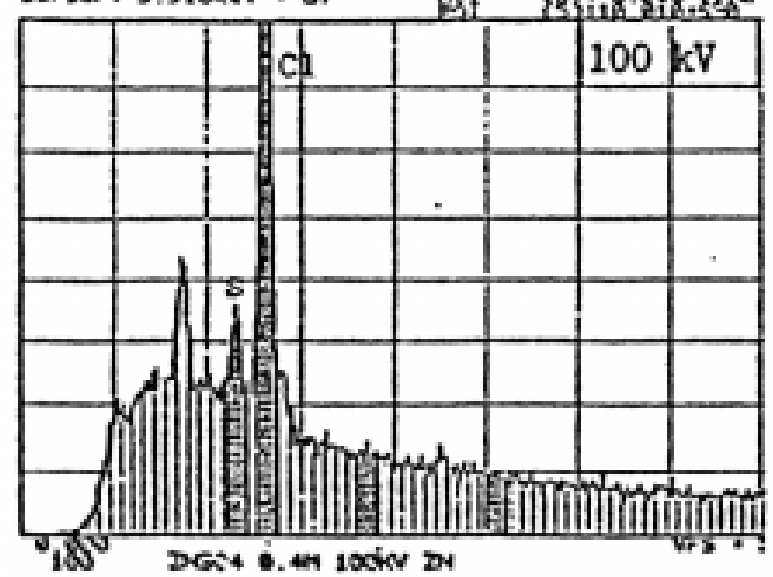

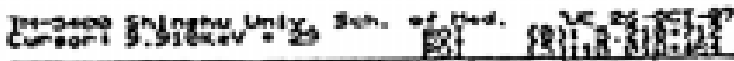

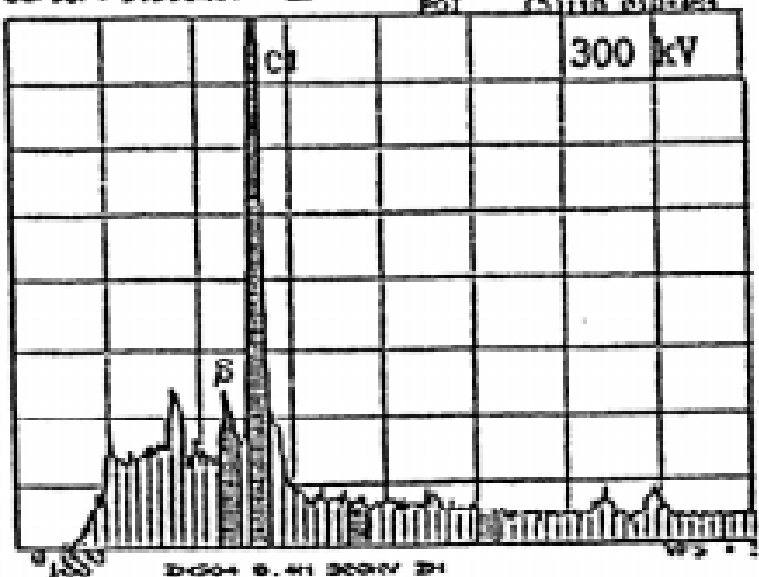

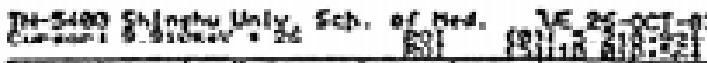

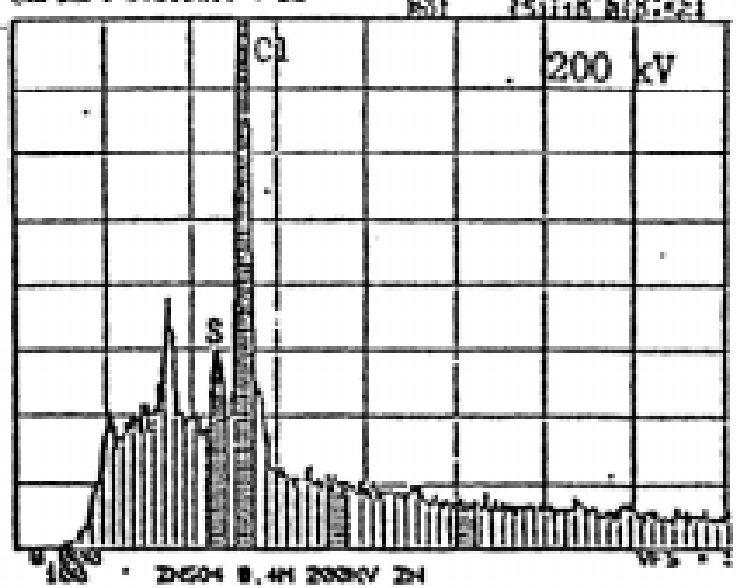

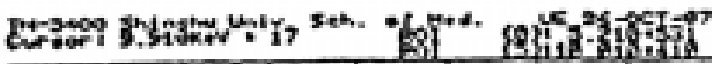

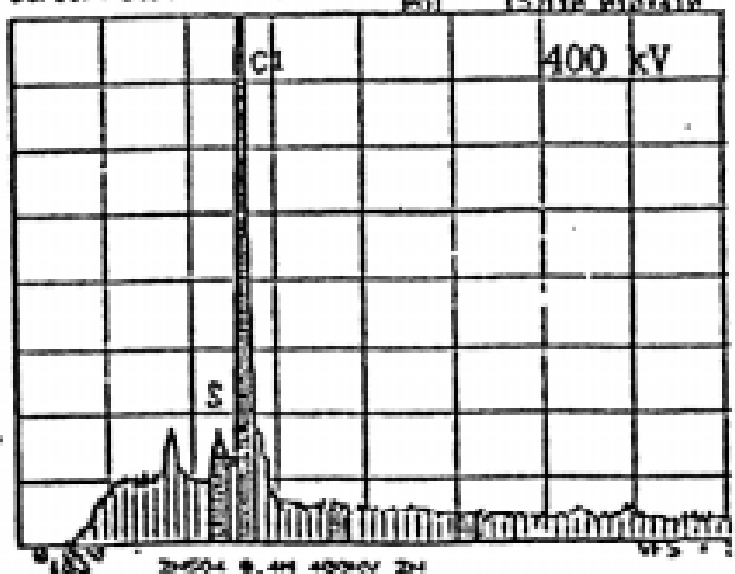

Figure 10. X-ray spectra from Epoxy resin sections cut at $0.2 \mu \mathrm{m}$ thick and observed by $\mathrm{X}$-ray microanalysis at different accelerating voltages of $100,200,300$ and $400 \mathrm{kV}$, respectively. The $\mathrm{S}$ and $\mathrm{Cl}$ peaks were due to Epoxy resin. From Nagata $\left(2001^{\mathrm{c}}\right)$.

Figure 11. Relationship between the accelerating voltages and the $\mathrm{P} / \mathrm{B}$ ratios of $\mathrm{S}$ in Epoxy resin sections, measured and calculated from the spectra in Figure 10. The maximum was found at 300 kV. From Nagata $\left(2000^{c}\right)$.

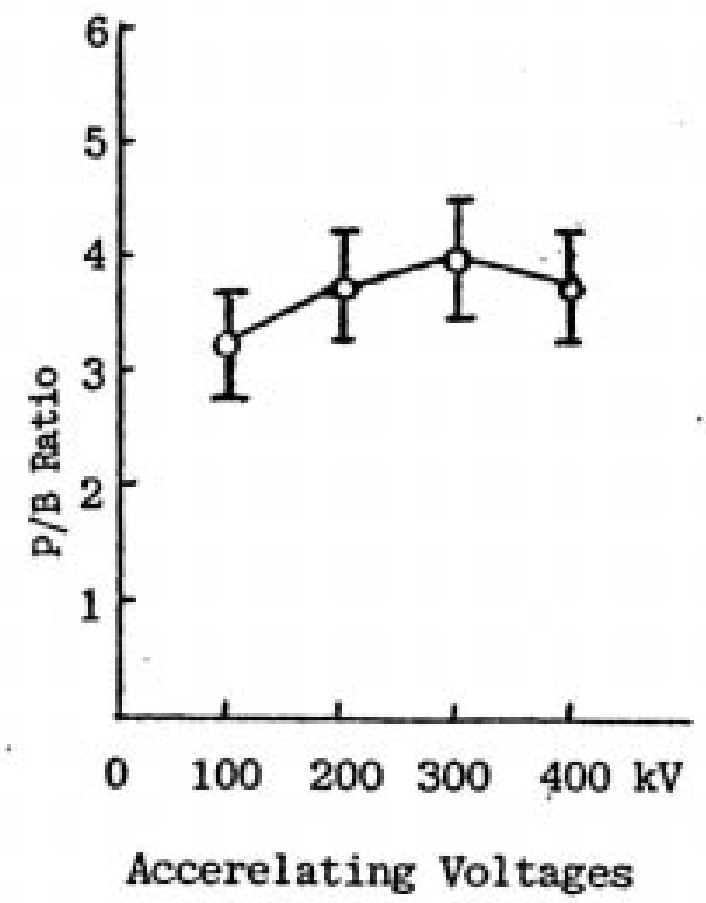

Nagata T - Principle and Applications of X-Ray Microanalysis 
Figure 12. Relationship between the accelerating voltages and the $\mathrm{P} / \mathrm{B}$ ratios of $\mathrm{Cl}$ in Epoxy resin sections, measured and calculated from the spectra in Figure 10. The maximum was found at 300 kV. From Nagata $\left(2000^{c}\right)$.

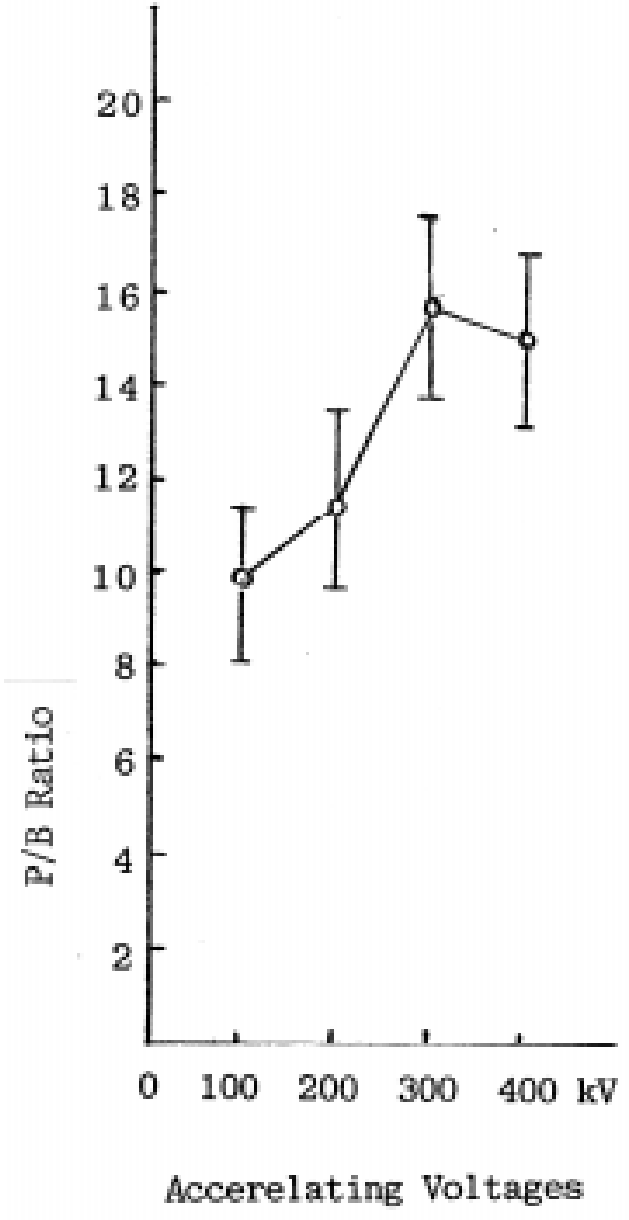

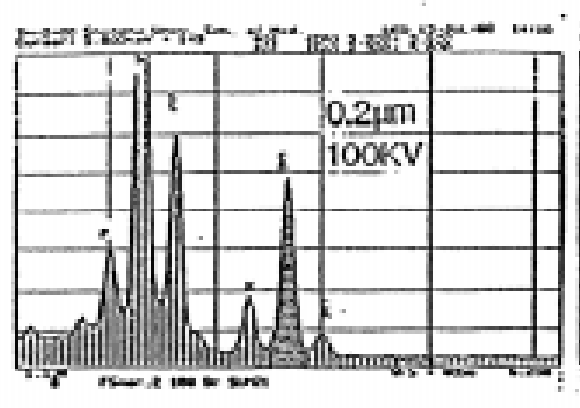
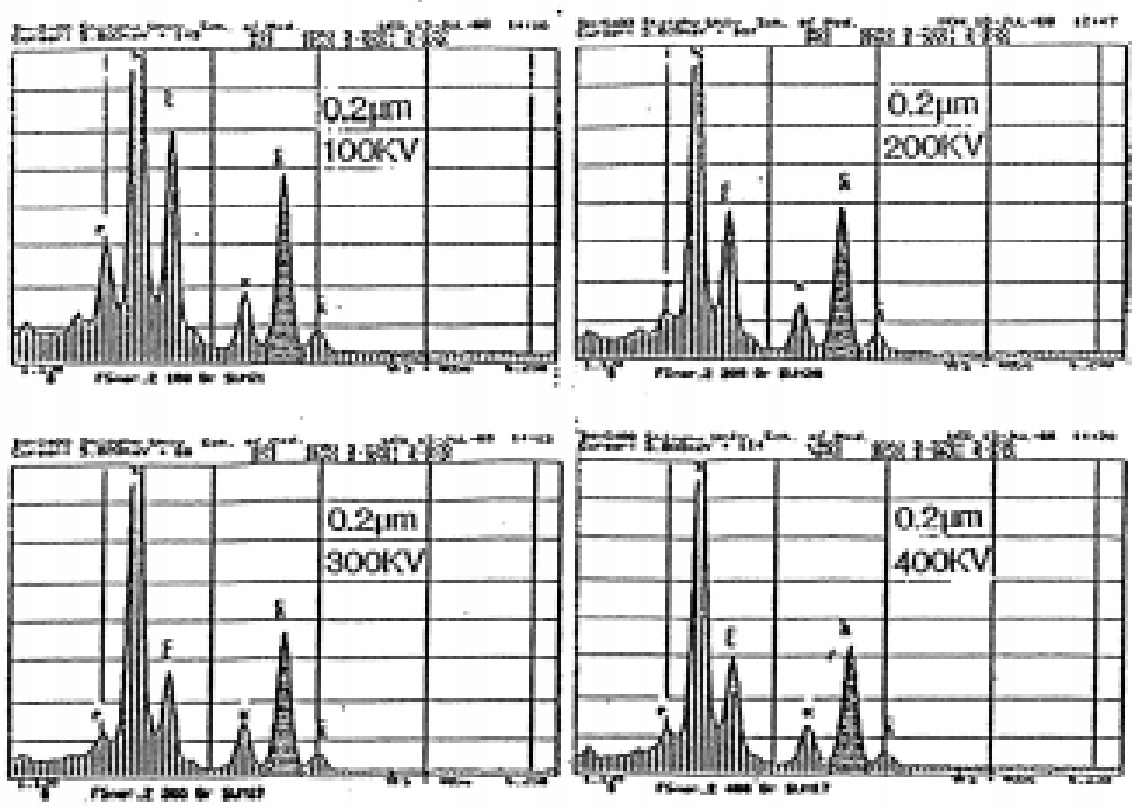

Figure 13. X-ray spectra obtained from a mast cell granule, cryo-fixed in isopentane cooled with liquid nitrogen, freeze-substituted, embedded in Epoxy resin, dry-sectioned at $0.2 \mu \mathrm{m}$ and observed at 100, 200, 300 and $400 \mathrm{kV}$. From Nagata $\left(2000^{c}\right)$. 


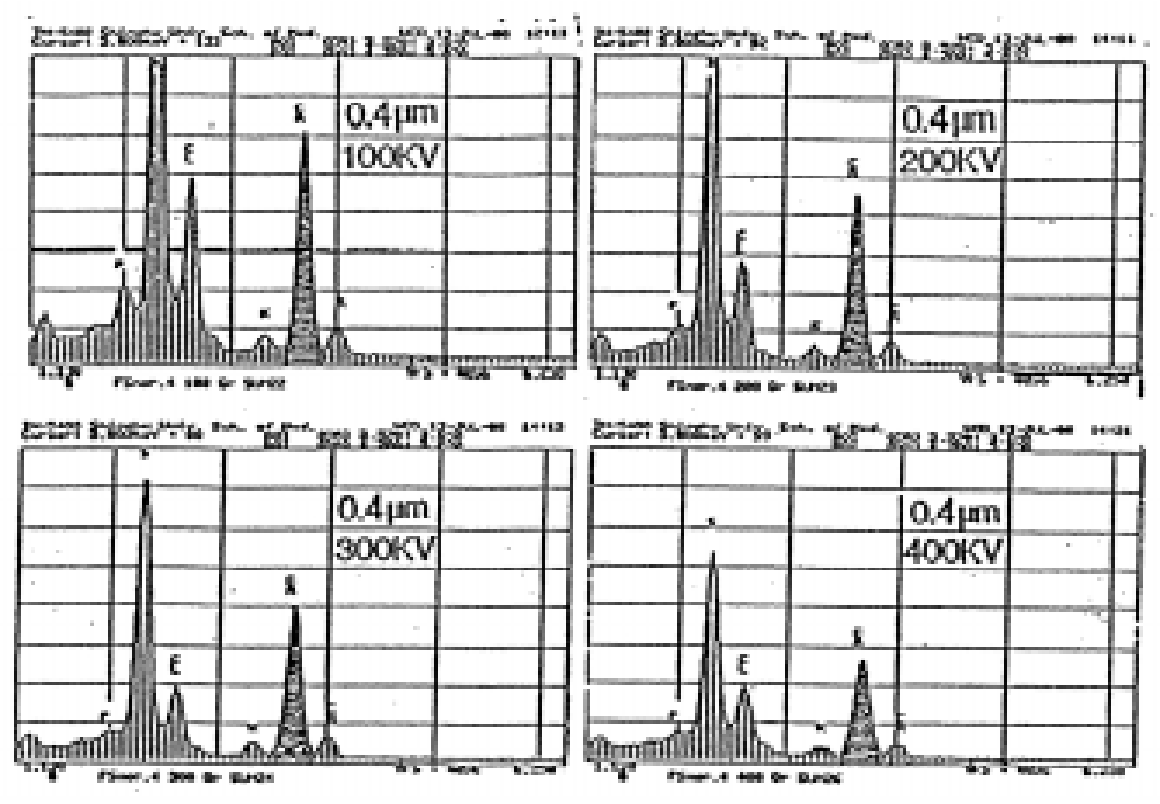

Figure14. X-ray spectra obtained from a mast cell granule, cryo-fixed in isopentane cooled with liquid nitrogen, freeze-substituted, embedded in Epoxy resin, dry-sectioned at $0.4 \mu \mathrm{m}$ and observed at 100, 200, 300 and $400 \mathrm{kV}$. From Nagata $\left(2000^{\mathrm{c}}\right)$.

\section{Zinc in Paneth cell granules}

Previously, we had found the existence of low peak zinc $(\mathrm{Zn})$ with high peak sulfur (S) in the spectra (Fig. 16) obtained from the specific granules of Paneth cells of mouse duodenum (Fig. 2G) by X-ray microanalysis (Ichikawa et al., 1988, 1994; Nagata et al., 1988a). In order to compare the effects of fixation upon the morphology of Paneth cell granules and their zinc contents, we first studied the effects of several different chemical fixations on the granules. Figure $2 \mathrm{G}$ shows an electron micrograph of a Paneth cell of a 1 month old mouse duodenum, fixed doubly with $0.1 \mathrm{M}$ phosphate buffered $2.5 \%$ glutaraldehyde and $1 \%$ osmium tetroxide, embedded in Epoxy resin, sectioned at $0.2 \mu \mathrm{m}$, picked up onto nylon meshes (Veco, Eerbeek, Netherlands), stained with uranyl acetate and lead citrate and observed at $300 \mathrm{kV}$. The X-ray spectrum obtained from the granules (arrow in Fig. 2G) shows Zn peak as well as osmium (Os) peak when fixed with both glutaraldehyde and osmium tetroxide (Fig. 16A). On the other hand, when the same materials, Paneth cells of the same 1 month old mouse duodenum, were fixed with only buffered $2.5 \%$ glutaraldehyde, embedded in Epoxy resin, sectioned at $0.2 \mu \mathrm{m}$, picked up onto nylon meshes, stained with uranyl acetate and lead citrate, the electron density of the granules appeared less dense (Fig. 2G). The X-ray spectrum obtained from the transparent granules fixed only with glutaraldehyde shows $\mathrm{Zn}$ peak without Os peak (Fig. 16B). Thus, we decided to fix the tissues only with buffered $2.5 \%$ glutaraldehyde, and embed in Epoxy resin, section at $0.2 \mu \mathrm{m}$ and stain with uranyl acetate and lead citrate, in order to obtain $\mathrm{Zn}$ peak avoiding the osmium peak.

In order to quantify the zinc content in these granules, on the other hand, we then studied the relation between the $\mathrm{Zn}$ peaks in the spectra and the zinc concentrations in a model system (Ichikawa et al., 1988, 1994; Nagata et al., 1988a). As a model experiment, we prepared Epoxy sections containing zinc sulfate at concentrations of either 0.05 and $0.10 \%$ dissolved in the Epoxy mixtures and polymerized. The Epon blocks were cut on an Porter-Blum MT-2B ultramicrotome (Dupont-Sorvall, Newtown, USA) at $0.2 \mu$ m thickness, picked up onto nylon meshes (Veco, Eerbeek, Netherlands) and observed by JEM-4000EX TEM with Tracor-Northern NT5400 EDX system at accelerating voltage of $300 \mathrm{kV}$. Figure 17A shows two spectra obtained from two Epon sections containing $0.05 \%$ (top) and $0.1 \%$ (bottom) zinc sulfate cut at $0.2 \mu \mathrm{m}$ thickness. Comparing the two peaks of $\mathrm{Zn}$ obtained from $0.05 \%$ and $0.10 \%$ concentrations, the latter was higher than the former. The average peak counts and backgrounds in two kinds of sections containing 0.05 and $0.10 \%$ concentrations were measured and calculated. From the results, P/B ratios at 
Figure 15. Relationship between the accelerating voltages and the $\mathrm{P} / \mathrm{B}$ ratios of $\mathrm{Ca}$ in mast cell cytoplasm in Epoxy resin sections at 0.2 and $0.4 \mu \mathrm{m}$ thicknesses, measured and calculated from the spectra in Figs. 13 and 14. The both maxima were found at $300 \mathrm{kV}$. From Nagata $\left(2000^{c}\right)$.

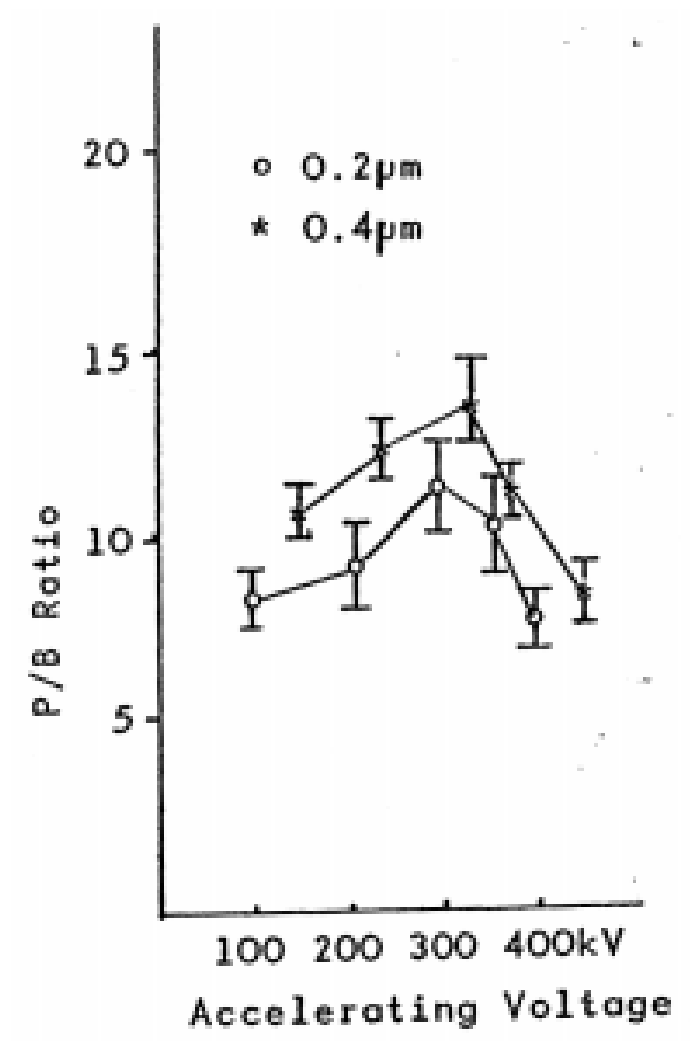

Figure 16. X-ray spectra obtained from the granule of the Paneth cell of a mouse duodenum at postnatal month 1 , fixed doubly with $0.1 \mathrm{M}$ phosphate buffered 2.5\% glutaraldehyde and 1\% osmium tetroxide, embedded in Epoxy resin, sectioned at $0.2 \mu \mathrm{m}$, stained with uranyl acetate and lead citrate and observed at $300 \mathrm{kV}$. 16A. The $\mathrm{X}$-ray spectrum obtained from the granule (arrow in Fig. 2G) shows $\mathrm{Zn}$ peak as well as osmium peak. 16B. The X-ray spectrum obtained from the granule fixed in glutaraldehyde and processed as above shows Zn peak without osmium peak. From Nagata $\left(2000^{c}\right)$.
A
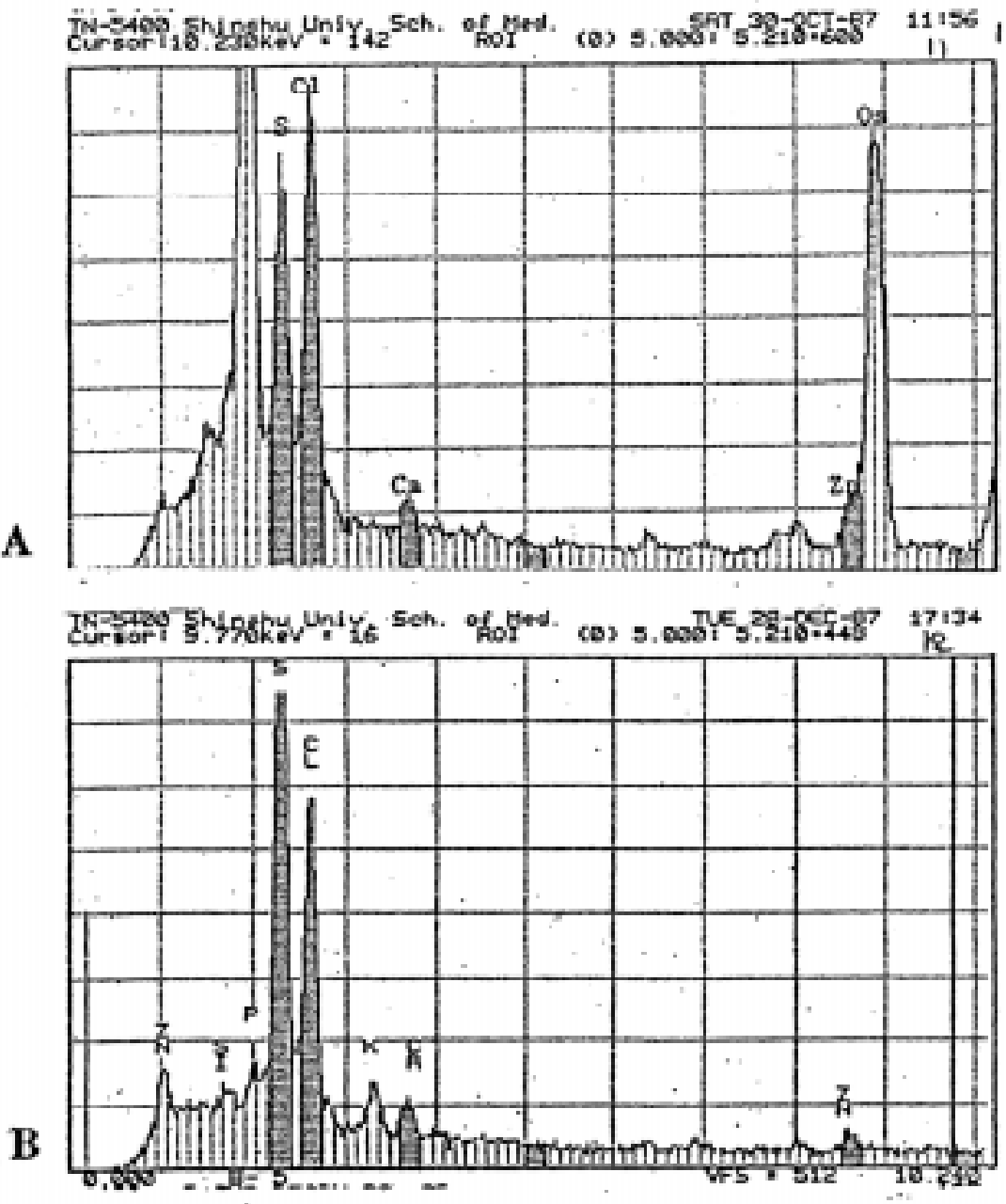
different concentrations were plotted in Figure 17B. In this figure the parallel relationship between the $\mathrm{P} / \mathrm{B}$ ratios and the concentrations was confirmed approximately like Beer's law in case of microspectrophotometry as was formerly observed (Nagata, 1972).

When the sections containing $0.10 \%$ and $0.05 \%$ zinc sulfate cut at $0.2 \mu \mathrm{m}$ thickness were analyzed with the JEM-4000EX NT-5400 TEM system, changing the accelerating voltages from 100 to $400 \mathrm{kV}$, the spectra showing Zn peaks were obtained respectively (Fig. 18). The peak counts as well as the backgrounds changed from 100 to $400 \mathrm{kV}$. The results were plotted as the changes of $\mathrm{P} / \mathrm{B}$ ratios in connection to accelerating voltages. The peak of the transitional curve of $0.10 \%$ sections was found at $200 \mathrm{kV}$, but the peak of $0.05 \%$ sections was not found. Thus, we tried again to find out the peak at thicker sections at the thickness of $0.4 \mu \mathrm{m}$ which contained much more zinc sulfate than those thinner sections. Figure 19 shows the transitional curve of $\mathrm{P} / \mathrm{B}$ ratios obtained from sections containing $0.1 \%$ zinc sulfate sectioned at $0.4 \mu \mathrm{m}$. The maximum of this curve was observed at $200 \mathrm{kV}$ (Fig. 19). Thus, we decided to use $0.4 \mu \mathrm{m}$ sections observed at $300 \mathrm{kV}$ for further quantification of $\mathrm{Zn}$ (Ichikawa et al., 1988, 1994; Nagata et al., 1988a, 2000; Nagata, 2001c, 2003).

\section{Absorbed Elements in Various Cells and Tissues}

It is well known that such metals as aluminum, copper, cadmium, mercury in aqueous solutions are absorbed from the gastrointestinal tracts or $\mathrm{Al}$ dusts and vapor can also be absorbed from the respiratory tracts in men and animals which are incorporated into cells and tissues of various organs (Yokel, 2000; Yokel \& McNamara, 2001). These elements in cells and tissues can be detected in situ by means of $\mathrm{X}$-ray microanalysis.

\section{Aluminum in the intestine, kidney and brain}

The element aluminum (Al) is abundantly found in the earth and dissolved into acidic rains, thus it spreads into the earth soil and water which can be absorbed into the plants, animals and men, and can accumulate in various kinds of cells and tissues (Martin, 1986). The toxicity of $\mathrm{Al}$ accumulation in living body was experimentally shown in the livers, kidneys and brains in experimental animals (Wilhelm et al., 1990; Yokel, 2000). In human patients, many cases of aluminum intoxication which caused several diseases such as anemia, bone, kidney and brain diseases were reported (Alfrey et al., 1976; Nakamura et al., 2000; Recker et al., 1977; Shirabe et al., 2002). Since the quantity of Al which should be absorbed into living body is very small, X-ray microanalysis using both thick sections and high voltage electron microscopy is advantageous to detect the intracellular localization of absorbed $\mathrm{Al}$ in various organs. We tried to detect $\mathrm{Al}$ in several organs of adult male ddY strain mice, at postnatal 4 weeks, which were administered with deionized water containing $2.0 \%$ aluminum chloride $\left(\mathrm{AlCl}_{3}\right)$ ad libitum for 2 weeks or other mice which were injected with $2.0 \%$ aluminum chloride aqueous solution intraperitoneally (Kametani, 2002). We also detected $\mathrm{Al}$ intracellularly in the kidneys during the postnatal development in aging mice from postnatal day 1 to 17 weeks administered orally with $\mathrm{Al}$ (Kametani et al., 2003). In order to decide the appropriate accelerating voltage for analyzing $\mathrm{Al}$ by $\mathrm{X}$-ray microanalysis, the mucosal tissues of the duodenum were taken out, fixed in $2.5 \%$ glutaraldehyde in phosphate buffer, dehydrated, embedded in Epoxy resin, sectioned with an OUm3 ultramicrotome (Reichert-Jung, Vienna, Austria) at 0.1, 0.5, 1.0 and $2.0 \mu \mathrm{m}$ thicknesses, respectively, and mounted onto nickel grids (Veco, Eerbeek, Netherlands), stained with uranyl acetate. The sections were observed and analyzed in a JEOL JEM-4000EX TEM with TN-5400 EDX microanalyzer at 100-400 kV. Electron beams were focused onto the highly electron dense lysosomes of each macrophage found in the submucosa of the duodenum of mouse injected intraperitoneally with aluminum chloride (Fig. 2H). Electron beams (beam current $93 \mu \mathrm{A}$ ) were irradiated to a small spot (diameter $200 \mathrm{~nm}$ ) and the emitted X-rays were analyzed. Representative spectra at respective accelerating voltages are shown in Figure 20. The quantification of $\mathrm{Al}$ was done by calculating the ratio of $\mathrm{Al}$ peak counts $(\mathrm{P})$ to background $(\mathrm{B})$, as $\mathrm{P} / \mathrm{B}$ ratios. Thus, the relative concentrations of $\mathrm{Al}$ in each measurement condition and 3 portions of the cells were represented by the mean $\mathrm{P} / \mathrm{B}$ ratio from 12 14 randomly selected lysosomes in each cell. The results obtained from the 
Figure 17. Graphs showing the relation between the $\mathrm{X}$-ray spectra and the concentrations of zinc sulfate. 17A. Two X-ray spectra obtained from two Epon sections containing $0.05 \%$ and $0.1 \%$ zinc sulfate cut at $0.2 \mu \mathrm{m}$ thickness. Comparing the two peaks of $\mathrm{Zn}$ obtained from $0.05 \%$ (top) and $0.10 \%$ concentrations (bottom), the latter was higher than the former. The average peak counts and back grounds in two kinds of sections containing 0.05 and $0.10 \%$ concentrations were measured and calculated. 17B. P/B ratios at different concentrations, $0.05 \%$ and $0.10 \%$, were calculated and plotted. In the graph the parallel relationship between the $\mathrm{P} / \mathrm{B}$ ratios and the concentrations was confirmed. From Nagata $\left(2001^{c}\right)$.
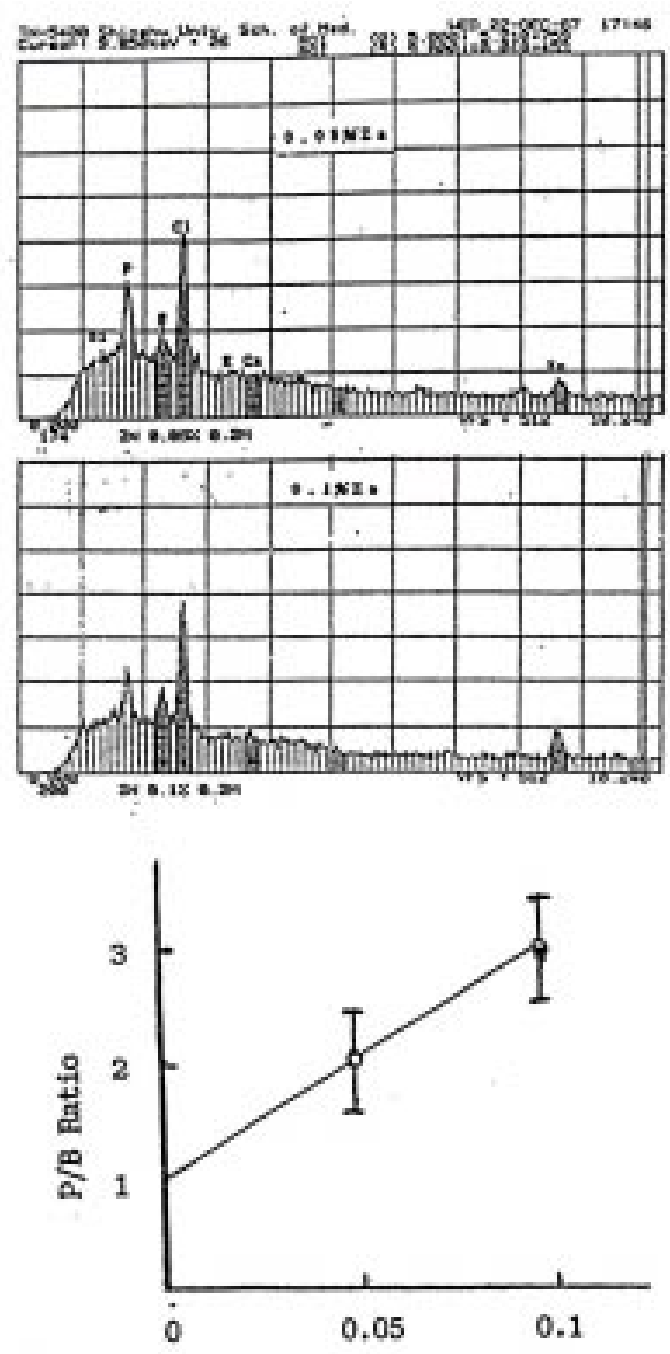

Concentration of $\mathrm{Zn}$
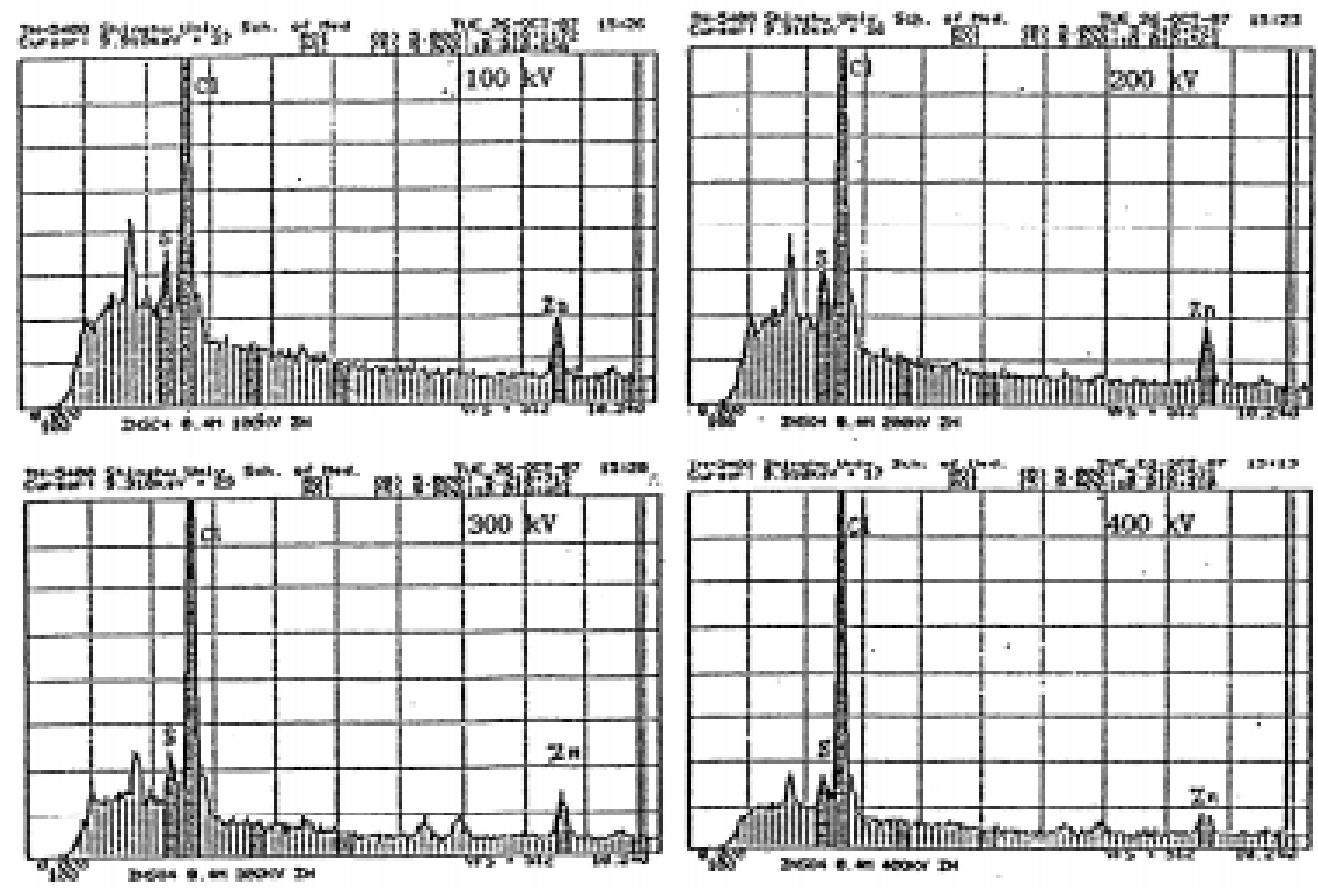

Figure 18. X-ray spectra obtained from an Epoxy resin section containing $0.1 \%$ zinc sulfate, cut at $0.4 \mu \mathrm{m}$ thickness and observed at 100, 200, 300 and $400 \mathrm{kV}$, respectively. From Nagata $\left(2000^{\mathrm{c}}\right)$. 
Figure 19. Relationship between the accelerating voltages and the $\mathrm{P} / \mathrm{B}$ ratios of $\mathrm{Zn}$ in Epoxy resin sections at $0.4 \mu \mathrm{m}$ thicknesses, measured and calculated from the spectra in Figure 18. The both maxima were found at 200 kV. From Nagata $\left(2000^{c}\right)$.

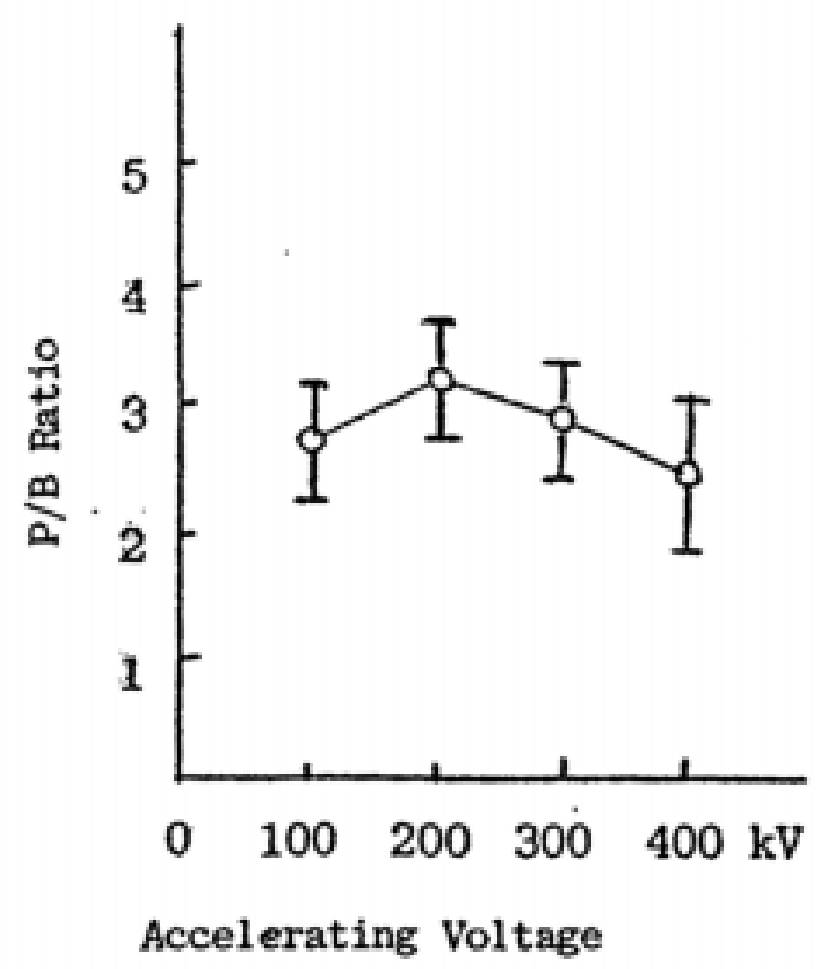

analysis demonstrating the relationship between the respective section thicknesses and respective accelerating voltages are shown in Figure 21. The results suggested that the highest peak of the $\mathrm{Al} \mathrm{P} / \mathrm{B}$ ratio was obtained at $300 \mathrm{kV}$ with $1.0 \mu \mathrm{m}$ thick sections, resulting in a $\mathrm{P} /$ $\mathrm{B}$ ratio about 3.55. The conventional ultrathin sections at $0.1 \mu \mathrm{m}$ thickness showed a peak $\mathrm{Al}$ $\mathrm{P} / \mathrm{B}$ ratio between the accelerating voltages at $200-300 \mathrm{kV}$, resulted in a $\mathrm{P} / \mathrm{B}$ ratio of about 2.0. It was shown that the values of the $\mathrm{P} / \mathrm{B}$ ratios became dispersed at $300-400 \mathrm{kV}$ with 0.1 and $0.5 \mu \mathrm{m}$ thick sections. In the thicker sections at $2.0 \mu \mathrm{m}$, the $\mathrm{P} / \mathrm{B}$ ratios were shown to increase with the increasing accelerating voltages reaching 3.2 at $400 \mathrm{kV}$. However, the significant difference was not observed between $100-400 \mathrm{kV}$. The significant difference was observed between the $\mathrm{P} / \mathrm{B}$ ratio obtained with $1.0 \mu \mathrm{m}$ thick sections measured at $300 \mathrm{kV}$ and other sections measured at $100-400 \mathrm{kV}$ (Kametani, 2002). Thus, it was decided to use $1.0 \mu \mathrm{m}$ thick sections observing at the accelerating voltage of $300 \mathrm{kV}$.

\section{Heavy metals}

Heavy metals such as copper $(\mathrm{Cu})$, cadmium $(\mathrm{Cd})$, mercury $(\mathrm{Hg})$ and lead $(\mathrm{Pb})$ are also reported to be taken into animals and men. Intracellular localization of methallothionein containing $\mathrm{Cu}$ was demonstrated by histochemical staining or $\mathrm{Cd}$ was detected either with histochemical staining or X-ray microanalysis (Schmid et al., 1993; Yoshizaki et al., 1990). The localization in respective organs will be described elsewhere. We have not yet tried to detect the relationships between the $\mathrm{P} / \mathrm{B}$ ratios and accelerating voltages of these metals. Further studies on these metals are required for clarifying this point.

\section{Other metals and rare earths}

Berry (1996) reviewed the intracellular localizations of various elements by X-ray microanalysis and described that 21 elements out of 92 elements of the periodic table, once injected in soluble forms, were selectively concentrated within lysosomes of several types of mammalian cells. These elements could be detected by X-ray microanalysis which allowed in situ analysis on any elements with atomic numbers greater than 11 present in ultrathin sections. Among the 21 elements, 15 elements were concentrated and precipitated in insoluble forms in association with phosphorus. They are aluminum (Al), 


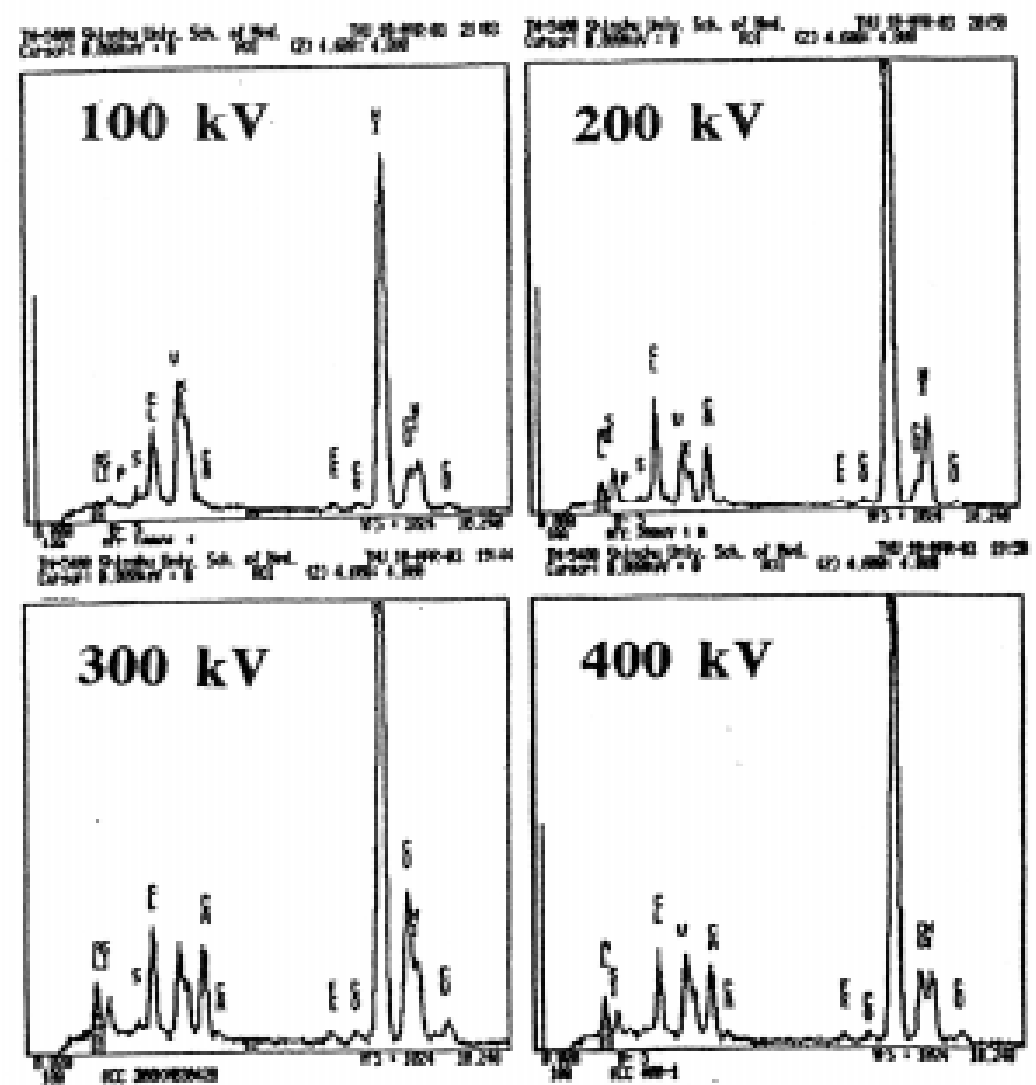

Figure 20. X-ray spectra obtained from one of the electron dense bodies of wandering cells found in the submucosa of the duodenum of a mouse injected with $\mathrm{Al}$ as shown in Figure $2 \mathrm{H}$ (arrow), and observed at 100, 200, 300 and 400 kV, respectively. From Kametani (2001).
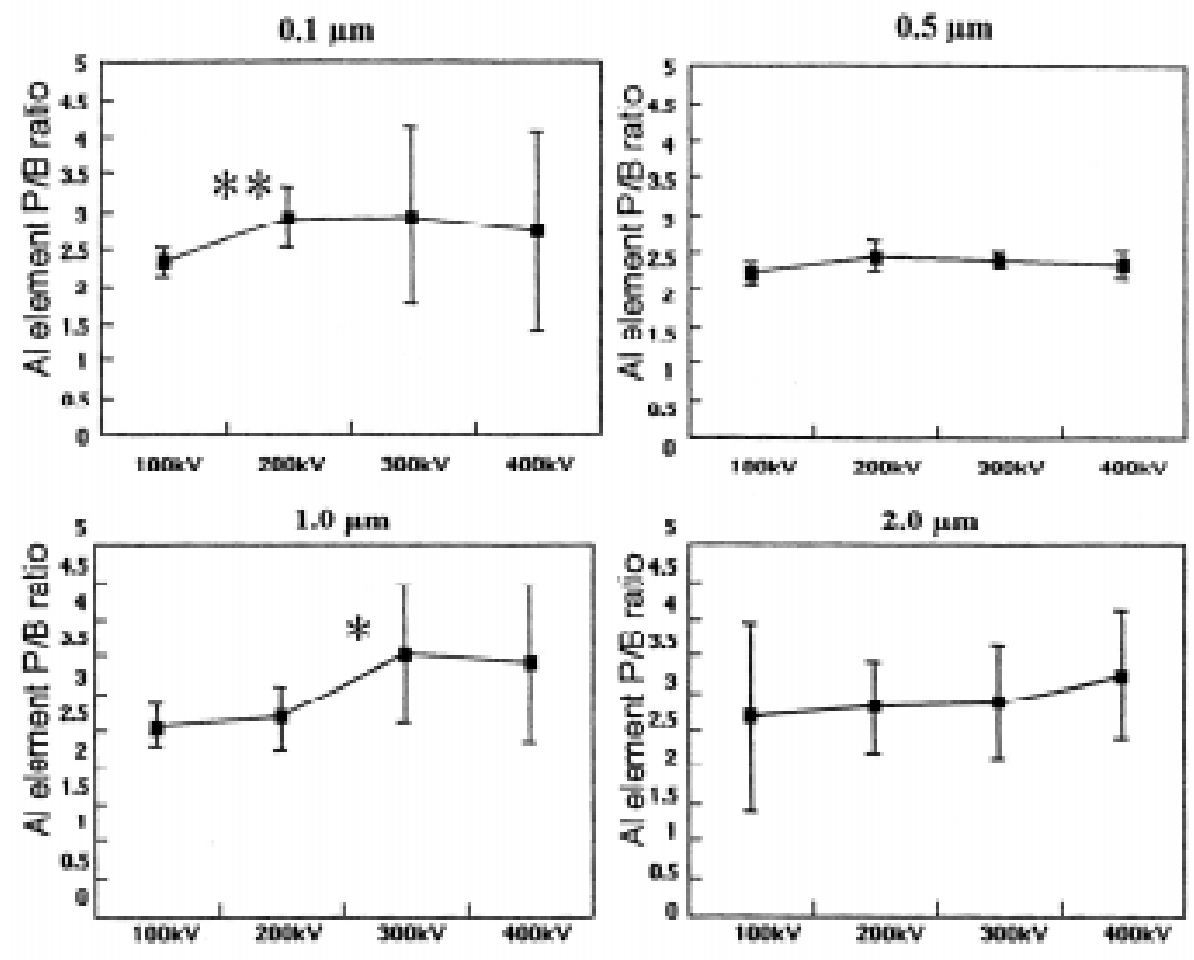

* *: Siznificant at $\mathbf{P}$ <0.01

* : Significant at P elés

Accelerating Voltage

Figure 21. Relationship between accelerating voltages and $\mathrm{P} / \mathrm{B}$ ratios of $\mathrm{Al}$ in Epoxy resin sections at various thickness from 0.1 to $2.0 \mu \mathrm{m}$, measured and calculated from the spectra as in Figure 20. The maximum was found at $300 \mathrm{kV}$ in $1.0 \mu \mathrm{m}$ thick section. From Kametani (2001). 
gallium $(\mathrm{Ga})$ and indium (In) which belong to group IIIB elements of periodic table, and lanthanum $(\mathrm{La})$, cerium $(\mathrm{Ce})$, samarium $(\mathrm{Sm})$, gadolinium $(\mathrm{Gd})$ and thulium $(\mathrm{Tm})$ which belong to rare earths, hafnium (Hf) and zirconium ( $\mathrm{Zr}$ ) which belong to group IVA elements, uranium $(\mathrm{U})$ and thorium which are actinides, and niobium $(\mathrm{Nb})$ and chromium $(\mathrm{Cr})$ which are group V and VI elements. On the other hand, the other 6 elements were precipitated in association with sulfur. They are nickel $(\mathrm{Ni})$, palladium $(\mathrm{Pd})$ and platinum $(\mathrm{Pt})$ which belong to group VIII elements, and copper $(\mathrm{Cu})$, silver $(\mathrm{Ag})$ and gold $(\mathrm{Au})$ which belong to IB elements. Among these metals, we have studied only Al. The localizations of respective elements in various organs and the relationships between the $\mathrm{P} / \mathrm{B}$ ratios and the accelerating voltages require further investigations.

\section{Application of X-ray Microanalysis to the Organ Systems}

The applications of X-ray microanalysis to various elements, including the endproducts of histochemical reactions, endogenous elements originally existing in cells and tissues and the elements absorbed from outside into the living bodies, and the results obtained mainly in our laboratory referring briefly to some other results obtained in other laboratories will be here described according to the order of the cells and tissues in various organ systems as in normal histology, starting from the locomotive system to digestive, respiratory, uro-genital, endocrine, circulatory and finally to nervous and sensory systems. However, it should be noted that the results obtained in our laboratory were analyzed by means of high voltage electron microscopy (HVEM) at accelerating voltages of 200, 300, 350 and $400 \mathrm{kV}$ depending upon the elements with the highest P/ $\mathrm{B}$ ratios different from the results obtained in other laboratories that used accelerating voltages around $100 \mathrm{kV}$ with lower $\mathrm{P} / \mathrm{B}$ ratios by conventional transmission electron microscopy (CTEM).

\section{The Locomotive System}

The locomotive system consists of the bones, the joints, ligaments and the skeletal muscles. Among the special cells and tissues in the locomotive system, we studied mainly the human ligaments. Therefore, studies on other organs such as bones and skeletal muscles should be briefly mentioned from the literature.

\section{The bones}

The bones are composed of various organic and inorganic compounds. Recently, many situations in clinical practice in orthopedic or oral and maxilofacial surgery require metallic implants to be combined with bone grafts and/or bone substitutes such as bioactive glass. Thus, characterization of osseous tissues around metal implants has been extensively studied by means of EDX microanalysis with either transmission or scanning electron microscopy. (Gorustovich et al., 2002; Langford \& Frame, 2002). Upon implantation, silica-based bioactive glass particles were transformed into a shell containing calcium and phosphate that loses its inner silicon-rich core. The releases of silicon by bioactive glass particles and its incorporation by newly formed bone tissue in the peri-implant area were experimentally studied in rats. Under anesthesia, a commercially pure titanium (Ti) laminar implant was placed inside the medullary compartment of the tibia, while in the contralateral tibia a titanium laminar implant and melt-derived bioactive glass particles were implanted. The animals were sacrificed 14, 30, and 60 days postimplantation. The tibiae were resected, radiographed, and embedded in methyl methacrylate resin. Sections were analyzed by light microscopy and CTEM with EDX. The presence of silicon, calcium, and phosphorus was detected in the bioactive glass particles and in the peri-implant bone tissue for each of the experimental times. EDX of newly formed bone tissue showed a transient appearance of silicon at 14 and 30 days postimplantation and a rise in the calcium:phosphorus ratio in peri-implant bone tissues (Gorustovich et al., 2002). On the other hand, Surface analysis 
of titanium maxillofacial plates and screws retrieved from patients were studied by SEM with EDX (Langford \& Frame, 2002). The surface appearances and elemental composition of 50 titanium maxillofacial plates and associated screws retrieved from 39 patients were compared with a control sample of unused plates and screws. There were two surface finishes, either anodized or non-anodized. Surface contamination was detected on both retrieved and control plates consisting of aluminium and silica and was more commonly present on non-anodized specimens. Manufacturing defects comprising rough metal edges and protuberances were identified on the unused controls and surgical damage was evident on the retrieved specimens. There were no signs of corrosion or surface deterioration on the retrieved plates and screws which had been in the tissues for between 1 month and 13 years.

\section{The ligaments}

Among numerous ligaments constituting many joints of the human body, the yellow ligament (ligamentum flavum) of the spine is well known to show ossification with aging of patients in clinical orthopedic surgery who complain lumbago or lumbar pains (Cooper \& Misol, 1970). The ossification of the human yellow ligament was clinically found to start at the superior margin of the vertebral arch. This portion was designated as enthesis and structurally composed of 4 zones. We studied calcium and phosphorus contents by XMA in the biopsied materials of the lumbar yellow ligaments obtained from human patients suffering from the ossification of the ligaments and the lumber canal stenosis (Ono 1991; Ono \& Nagata 1989, 1992; Ono et al. 1988, 1994). The lumber yellow ligaments with the lamellar bones of the superior margins of the vertebral arches were surgically taken out from 12 patients at various ages. Among them, 6 patients aged from 27 to 34 years were suffering from the lumbar disc herniation, while other 6 patients, aged from 62 to 81 years, suffered from the lumbar canal stenosis. All the tissues obtained from respective patients were cut into 3 portions, i.e., 1) the interlaminar portion, 2) the ligament inserted portion in the upper part of the lamina and 3) the upper part of the laminar portion (the ossified tissues). Each tissue piece was further divided into 2 parts and one part was chemically fixed doubly in $0.1 \mathrm{M}$ phosphate buffered $(\mathrm{pH} \mathrm{7.4)} 2.5 \%$ glutaraldehyde and 1\% osmium tetroxide, dehydrated and embedded in Epoxy resin. Semithin sections $(0.2 \mu \mathrm{m}$ thick) were cut on LKB-NOVA ultramicrotome and were mounted on carbon-coated nylon grids. The tissue pieces from the remaining half of each portion were cut into triangular prism without any chemical fixation and were affixed with Tissue-Tek O.C.T. compound (Miles Inc., Boston, MA, USA) to the tops of silver pins and were quickly frozen by metal contact method at $-192^{\circ} \mathrm{C}$ followed by cryo-sectioning (0.5 $\mu \mathrm{m}$ thick) with an LKB cryo-NOVA ultramicrotome (LKB, Bromma, Sweden) equipped with cryokit at a knife temperature of $-90^{\circ} \mathrm{C}$. The cryo-sections were collected on collodion coated copper grids and pressed with a pre-cooled copper club. The grids were transported to a specimen holder of cryo-transfer equipment EM-CTH 40 (JEOL, Tokyo, Japan) and freeze-dried at $-80^{\circ} \mathrm{C}$ in a vacuum $\left(5 \times 10_{-5} \mathrm{~Pa}\right)$ for several hours. Both the semithin Epon sections and cryo-sections were analyzed with a JEM 4000EX HVEM system equipped with a Tracor-Northern energy dispersive X-ray microanalyzer TN-5400 at an accelerating voltage of $300 \mathrm{kV}$ with a fixed beam current of $4.3 \times 10^{-8} \mathrm{~A}$ and a beam spot of $0.2 \mu \mathrm{m}$ in diameter. The accelerating voltage at $300 \mathrm{kV}$ was decided according to the data obtained from $\mathrm{Ca}$ analysis in rat peritoneal mast cells in the previous section. For the elemental analysis of $\mathrm{Ca}$, X-ray spectra were obtained by measuring 10 random spot areas of the microprobe targeted at collagen fiber areas between elastic fibers in each section and all the essential X-ray pulse counts were counted for $100 \mathrm{sec}$. The detecting dead time was about $25 \%$ for data acquisition. The respective 10 spectra were summed up for each zone and the essential X-ray peak counts (P) for the Ca-K $\alpha$ and $\mathrm{P}-\mathrm{K} \alpha$ emission and respective background (B) were calculated. The results of X-ray microanalysis is shown in Figure 22. From the results: 1) Ca content in the collagen fiber area of the ligament zone was significantly higher in the cryo-sections than in the Epon sections $(\mathrm{P}=0.05)$; 2) Ca content in the collagen fiber area of the unmineralized fibrocartilage zone 
was significantly higher in cryo-sections than in Epon sections $(\mathrm{P}=0.01)$. These results suggest the presence of an additional amount of $\mathrm{Ca}$ in the yellow ligaments that was not preserved in specimens processed through the conventional chemical fixation, dehydration and embedding. However, Ca content in the collagen fiber area of the lamellar bone zone in the Epon sections was about 10 times higher than that found in the other 2 zones in Epon sections, but showed no significant difference from that of the lamellar bone zone in the cryo-sections $(\mathrm{P}<0.05)$. From these $\mathrm{X}$-ray spectra, $\mathrm{P} / \mathrm{B}$ ratios of $\mathrm{Ca}, \mathrm{P}$ and $\mathrm{S}$ contents in the 3 portions of the human yellow ligaments are shown as histograms in Figure 23, respectively. The results suggest that almost the entire $\mathrm{Ca}$ content in this zone could have accumulated in an insoluble crystalline form (Ono \& Nagata 1989, 1992; Ono et al. 1994). At the same time, $\mathrm{S}$ peak was observed in correlation to $\mathrm{Ca}$ in Epon sections. The $\mathrm{P} / \mathrm{B}$ ratios of $\mathrm{S}$ in microfibrils at the peripheral portions and the collage fibers between elastic fibers were higher than the central amorphous materials in elastic fibers (Ono et al., 1988). The results suggested the correlation between the calcification and glycoprotein contents.

On the other hand, higher peak of $\mathrm{P}$ was observed in cryo-sections than in Epon sections (Ono et al., 1994). The data strongly suggest the presence of an additional soluble P in cryo-sections over the stable P fraction preserved in Epon sections. Apparently, the soluble amount of $\mathrm{P}$ was lower than that of $\mathrm{Ca}$ and did not accompany the rates of soluble $\mathrm{Ca}$ found in the unmineralized fibrocartilage zone. As soluble $\mathrm{Ca}$ and $\mathrm{P}$ were abundant in the unmineralized fibrocartilage zone, we examined this zone to compare their soluble contents between two age groups. Soluble $\mathrm{Ca}$ and $\mathrm{P}$ were higher in the specimens from the 61-81 age group than those from 27-34 age group. In conclusion, it was shown that soluble $\mathrm{Ca}$ and $\mathrm{P}$ were much more demonstrated in freeze-dried cryosections than chemically fixed specimens of the same patients and a seizable fraction of soluble $\mathrm{Ca}$ was demonstrated in the unmineralized fibrocartilage zone which is considered to be characteristic of the mineralizing process in the human yellow ligaments related to aging.

\section{The muscles}

The muscular system of the human body consists of around 200 skeletal muscles. Each skeletal muscle consists of numerous muscle fibers including actin and myosin filaments and sarcoplasm which contain various organic compounds and electrolytes. Thus, the advantages of cryo-fixation followed by freeze-substitution or freeze-
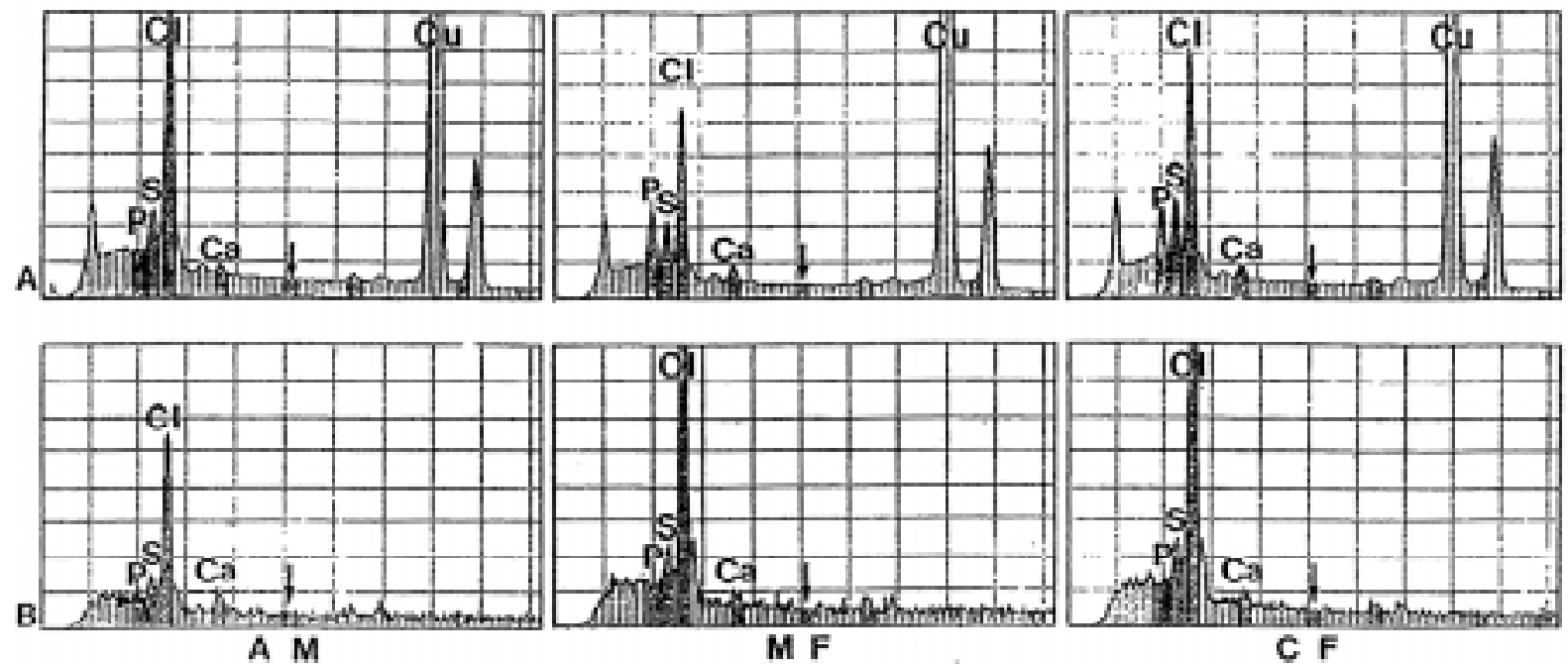

Figure 22. X-ray spectra obtained from the circular or oval-shaped elastic fibers composing of both amorphous materials (AM) with moderately electron dense areas and less dense microfilaments (MF) surrounded with less electron dense collagen fibers $(\mathrm{CF})$ of the yellow ligaments which were either cryo-fixed freeze-dried cryosections (A) or chemically fixed Epon sections (B) of the interlaminar portion of a patient suffering from lumbar canal stenosis. From Ono (1991). 
Figure 23. Histograms showing $\mathrm{P} / \mathrm{B}$ ratios of $\mathrm{Ca}$, $\mathrm{P}$ and $\mathrm{S}$ contents in the yellow ligaments of human patients suffering from lumber canal stenosis. The $\mathrm{P} / \mathrm{B}$ ratios were obtained from calculating the peak counts and background counts by measuring 10 spots area of each sub-area such as amorphous material (AM), microfibrils (MF), collagen fibers $(\mathrm{CF})$ in the interlaminar portion and the ligament inserted portion, as well as the ossified tissues (OT) in the laminar portion (OT). From Ono et al. (1994).
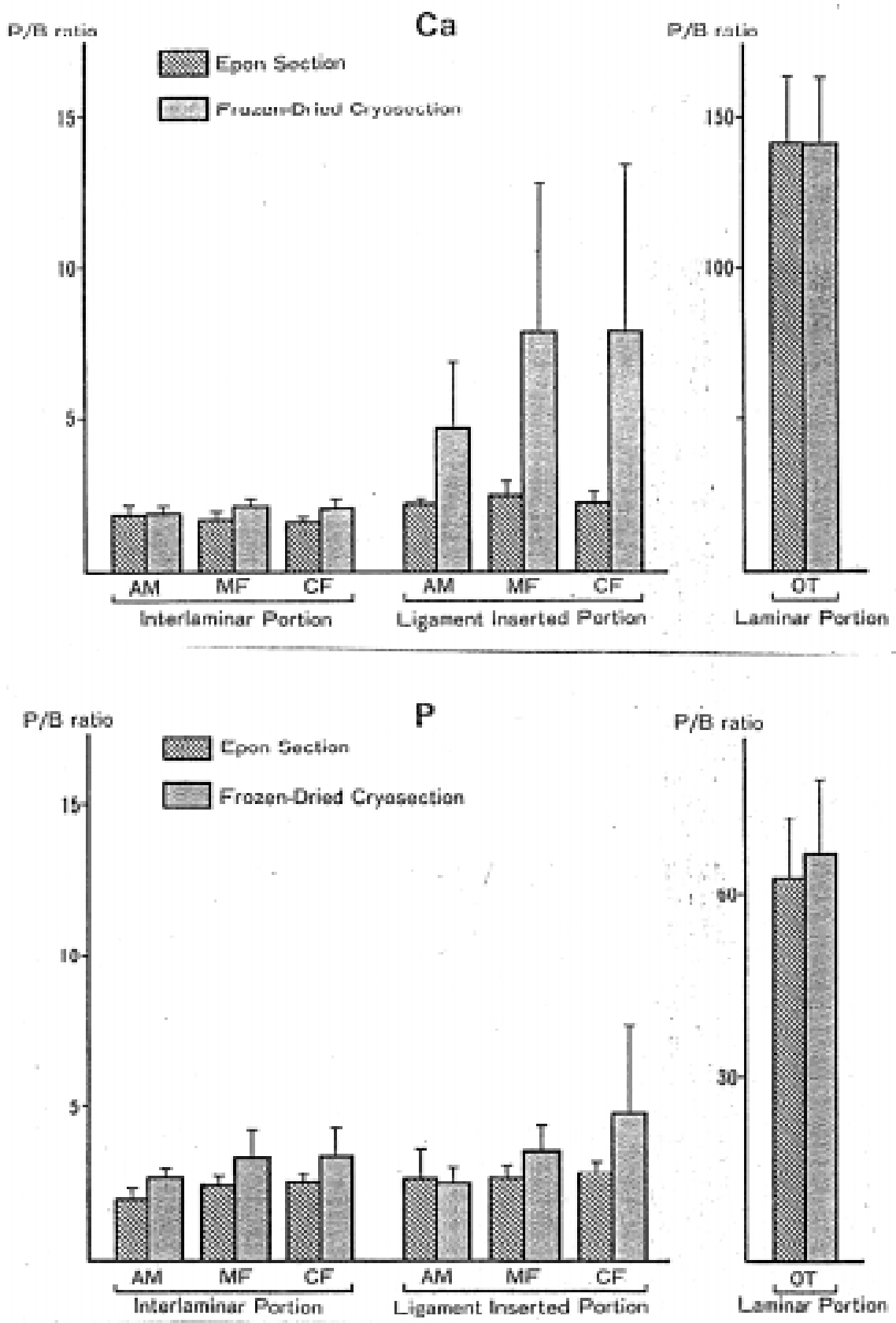

$\mathrm{S}$

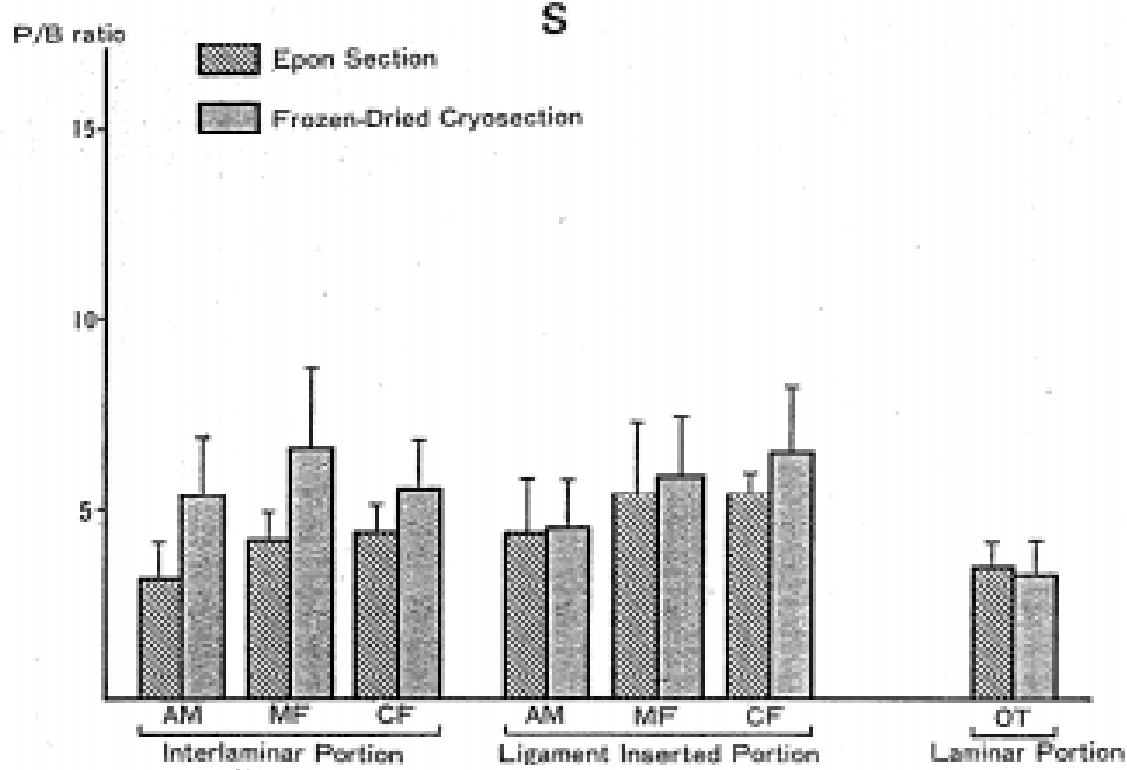


drying for examining electrolytes by X-ray microanalysis were formerly used and discussed by many authors in the skeletal muscle tissues, demonstrating several electrolytes such as K (Edelmann, 1984). However, we have not studied this tissue so much.

\section{The Digestive System}

The digestive system anatomically consists of the digestive tract (or gastrointestinal tract) and the digestive glands. The former is divided into several portions, from cranial to caudal, the oral cavity, the esophagus, the stomach, the small and large intestines and the anus. The small intestine can be subdivided into the duodenum, the jejunum and the ileum, while the large intestine into the caecum, the colon and the rectum. The digestive glands consist of the salivary glands, the liver and the pancreas. We have extensively studied on several elements of these digestive organs by XMA. The results shall be described according to the anatomical order as mentioned above.

\section{The oral cavity}

\section{The salivary glands}

The advantages of cryo-fixation followed by freeze-substitution or freezedrying for examining electrolytes by X-ray microanalysis were formerly used and discussed by many authors in various kinds of organs and tissues such as several electrolytes such as $\mathrm{K}$ and $\mathrm{P}$ in the parotid, submandibular and labial glands (Izutsu et al., 1994), chloride in the submandibular glands (Mörk et al., 1996) were demonstrated.

\section{The teeth}

The human teeth are divided into the 32 permanent teeth and the 20 deciduous teeth. They are derivatives of the oral mucous membrane whose surface is covered by a calcified layer originating from epithelium and connective tissue. The surface structure of the teeth can be observed by scanning electron microscopy. Recently, the afibrillar cementum and cementicle-like structures in human teeth were studied by scanning electron microscopy and energy-dispersive $\mathrm{X}$-ray microanalysis (Kodaka \& Debari, 2002). The afibrillar cementum showed a spur- or island, plate- and mass-like structure with appositional laminations, while large masses in the enamel fissures enclosed cementicle-like structures showing concentric appositional rings. Such afibrillar cementum was observed in enamel fissures, an abnormal enamel pit, dens invaginatus and root furcations with enamel droplets, as well as on the cervical enamel surfaces, where ameloblasts are differentiated at the later or last stage of enamel formation. Cementicle-like structures were occasionally found independent from afibrillar cementum and some cementicle-like structures contained epithelial cell-like or ameloblast-like remnants in the core, surrounded by a few or many concentric rings. In addition, cementicles in the root furcations also contained the remnants of Malassez's epithelial-rest cells surrounded by a few concentric rings. In some areas, afibrillar cementum was mixed with enamel structures. These results showed that the organic material in some parts of afibrillar cementum and cementicle-like structures may be derived from epithelial cells similar to that of cementicles. Calcification values of afibrillar cementum and cementiclelike structures were significantly higher than that of fibrillar cementum, and the minute crystals are probably apatite (Kodaka \& Debari 2002). Thus, scanning microscopes equipped with EDX analyzers are useful in qualifying and quantifying calcification of tooth cementum such as afibrillar cementum and cementicle-like structures of human teeth .

\section{The stomach}

The stomachs of men and experimental animals have been one of the interesting objects to observe the absorption of some elements orally administered. Several papers have been available reporting the uptakes of ions or metals across the gastrointestinal tract using CTEM equipped with EDX. 


\section{Electrolytes in insect and vertebrate gastrointestinal tracts}

It is known from the physical chemistry that mucoid substances (glycosaminoglycans, proteoglycans, glycoproteins) constitute polyanionic gels with anomalous colligative behavior and differential preference for binding some cations such as $\mathrm{H}^{+}, \mathrm{K}^{+}, \mathrm{Ca}^{2+}$. The mucus secreting membranes in animals also constitute ion and water transporting epithelia with morphologically characterized pericellular compartments. These pericellular compartments are not free-fluid spaces as is assumed in conventional physiological thought, but contain polyanionic mucoid matrices with a prevalence of sulfated varieties such as heparan sulfates. Measurements with electron probe X-ray microanalysis of cryo-sections show that at the various pericellular sites the local dry mass of these matrices can vary from less than $5 \%$ to greater than $30 \%$ of the wet mass (Gupta, 1989). XMA measurements in several epithelia from insects and from vertebrates (gastro-intestinal tract) also show that the total concentrations of the major chemical elements $(\mathrm{P}, \mathrm{S}, \mathrm{Na}, \mathrm{K}, \mathrm{Mg}, \mathrm{Cl})$ at these pericellular sites are distinct both from their concentrations in the cytoplasm and in the bulk mucosal and serosal compartments. In all the examples a particular role of pericellular polyanions in sequestering $\mathrm{K}^{+}$and $\mathrm{Ca}^{2+}$, and excluding $\mathrm{Cl}^{-}$is indicated. It is proposed that the general $\mathrm{K}$-sequestering ability of these pericellular mucoids conserves the $\mathrm{K}^{+}$ions leaking out of the cells and thus reduces the energy load for active transport in the cells through a K-recycling mechanism. On the other hand, XMA also revealed that cytoplasmic $\mathrm{Ca}^{2+}$ concentration increased in the restricted apical cytoplasm during stimulation of isolated guinea pig parietal cells with gastrin (Tsunoda et al., 1988). Furthermore, this study, using ${ }^{45} \mathrm{Ca}^{2+}$, aequorin and fura-2, revealed the mechanism involved in intracellular $\mathrm{Ca}^{2+}$ shifts caused by gastrin and the involvements of inositol 1,4,5trisphosphate (IP3) and diacylglycerol in producing those shifts.

\section{Zinc in rat stomach}

The relationship between the absorption of an organic zinc $(\mathrm{Zn})$ salt, zinc acetamate, and its antiulcerogenic activity in a model of cold-restraint stress was studied by XMA (Navarro, 1990). Serum and gastric levels of zinc, as well as its antiulcerogenic effect, were determined after oral or intravenous administration of zinc acetamate. In the rats subjected to cold-restraint stress, gastric levels of zinc correlated with the antiulcerogenic effect observed after administration of zinc acetamate. However, it was not possible to establish a relationship between serum levels and the pharmacologic effect of zinc. These results in animals subjected to regular diet indicated that the antiulcerogenic effect exhibited by zinc compounds could be associated with the presence of zinc at different levels of gastric tissue.

On the other hand, $\mathrm{Zn}$ ions have been reported to stabilize cellular membranes, protecting the gastric mucosa against a wide variety of ulcerative agents (Rodrigues et al., 1990). The treatment with zinc sulfate intragastrically administered as one dose $(20 \mathrm{mg} /$ $\mathrm{kg}$ body weight) daily for 30 consecutive days did not modify the normal aspect of rat gastric mucosa as observed by scanning electron microscopy. Furthermore, the X-ray microanalysis of the lysosome content performed on different gastric mucosa cells did not show the zinc element. These results suggest that zinc ion is a relatively nontoxic element for the rat gastric mucosa.

\section{The intestines}

The intestines of men and mammals can be anatomically divided into 2 portions, small and large intestines, which are further subdivided into several portions, the duodenum, the ileum, the jejunum, the caecum, the colon and the rectum. The intestinal walls in any portions consist of 4 layers, the mucosa covered with columnar epithelial cells including absorptive and secretory cells, the submucosa, the smooth muscular layer and the serosa. We studied $\mathrm{Zn}, \mathrm{S}, \mathrm{Cl}, \mathrm{P}$, and $\mathrm{Al}$ in various intestinal cells. 


\section{Zinc in the duodenal Paneth cells}

The small intestines of experimental animals, such as mice and rats, consist of 3 segments, the duodenum, the jejunum and the ileum, and their walls are composed of 4 layers, the mucosa, the submucosa, the muscularis and the serosa. The free surface of the mucosa is covered with the epithelial cells which form the intestinal villi to the lumen. Between the villi there are small openings of simple tubular glands into the mucosa designated as the intestinal glands or the crypts of Lieberkühn. In the bottom of the crypts, several large pyramidal cells with basophilic basal cytoplasm and large apical acidophilic secretory granules are found which are named Paneth cells. These Paneth cell granules in the mouse contain a sulfated mucosubstance and a basic protein which is supposed to be lysozyme and lyses bacteria (Spicer et al., 1967).

We had previously found the existence of low peak $\mathrm{Zn}$ with high peak $\mathrm{S}$ in the spectra obtained from the specific granules of Paneth cells of mouse duodenum by X-ray microanalysis (Ichikawa et al., 1988; Nagata et al., 1988a). After examining the model system using Epon sections containing different concentrations of zinc sulfate at $0.2 \mu \mathrm{m}$ thickness, observed by JEM-4000EX TEM equipped with Tracor-Northern NT-5400 EDX system at accelerating voltage of $100,200,300$, and $400 \mathrm{kV}$, we obtained the peaks of transitional curves of P/B ratios were found at $200 \mathrm{kV}$. Therefore, we used $200 \mathrm{kV}$ for further quantification in case of $\mathrm{Zn}$. In order to compare the effects of fixation upon the morphology of Paneth cell granules and their zinc contents, on the other hand, several different chemical fixations were studied. Figure $2 \mathrm{G}$ shows an electron micrograph of a Paneth cell of a 1 month old mouse duodenum, fixed doubly with $0.1 \mathrm{M}$ phosphate buffered $2.5 \%$ glutaraldehyde, embedded in Epon, sectioned and stained with uranyl acetate and lead citrate. The X-ray spectrum obtained from the granules (arrow in Fig. 2G) shows Zn peak without osmium peak (Fig. 16B). On the other hand, when the same materials, Paneth cells of the same 1 month old mouse duodenum, were fixed with both buffered $2.5 \%$ glutaraldehyde and $1.0 \%$ osmium tetroxide, embedded in Epon, sectioned and stained with uranyl acetate and lead citrate, the granules appeared electron dense. The X-ray spectrum obtained from the dense granules shows Zn peak with Os peak (Fig. 16A). After analyzing many individual mice at various ages from newborn day 2, 7, 10, 22, to adult 1, 2, 3, 4, and 6, 9 months, and further to senescent 1 and 2 years, all the data expressing P/B ratios are plotted (Fig. 24). From the data it is clear that the aging changes of zinc contents in the granules of mouse duodenum Paneth cells as expressed by $\mathrm{P} / \mathrm{B}$ ratios increased from postnatal days $2,7,10$ to 1 and 2 months, reaching a peak at 1 month, and then decreased to 1 and 2 years (Nagata, 2000 ${ }^{\mathrm{b}}$ ). The results demonstrated that the $\mathrm{Zn}$ bound to proteins in the Paneth cell granules, which were supposed to act antibacterial function, changed with the aging of animals.

\section{Aluminum in the duodenal epithelial cells}

It is generally accepted that aluminum (Al) which is orally administered to experimental animals such as rats and mice is absorbed from the gastrointestinal tracts and accumulated in various organs (Recker et al., 1977). We studied the absorption of $\mathrm{Al}$ from the gastrointestinal tracts and accumulations in some organs of adult ddY mice and analyzed the intracellular localization of Al by X-ray microanalysis (Kametani, 2002; Kametani et al., 2003). We first studied several adult ddY mice 4 weeks after birth which were intraperitoneally injected with aluminum chloride and the duodenal tissues were examined by both aluminon staining and X-ray microanalysis at accelerating voltages of 100-400kV (Kametani, 2002). By LM aluminon staining, no positive reaction was observed in the duodenal tissues. By EM observation, however, electron dense lysosomes were observed in the absorptive epithelial cells and the wandering cells in the duodenal mucosa (Fig. 2H), which showed $\mathrm{Al}$ peaks by XMA (Fig. 20). When the accelerating voltages were changed from 100 to 200,300 , and $400 \mathrm{kV}$, the highest $\mathrm{P} / \mathrm{B}$ ratios were obtained at $300 \mathrm{kV}$ using thick sections at $1.0 \mu \mathrm{m}$ (Fig. 21). Thus, we used $300 \mathrm{kV}$ to detect $\mathrm{Al}$ peak and quantify the $\mathrm{Al} \mathrm{P} / \mathrm{B}$ ratios. Then, we studied 9 groups of $\mathrm{ddY}$ mice at various aging stages, each consisting of 3 littermates, from postnatal week 1, 3, 5, 7, 9, 11, 13, 15 and 
17. They were administered orally with deionized water containing $2 \%$ aluminum chloride (AlCl3) at $\mathrm{pH} 2.5$, ad libitum immediately after birth until 17 weeks. As normal control animals, some animals were administered with only deionized water without aluminum chloride. The animals were sacrificed at each administration period and the duodenal tissues were fixed only in $2.5 \%$ glutaraldehyde in phosphate buffer, dehydrated in ethanol, substituted in propylene oxide and embedded in Technovit VL7200 resin (Meiwa Co., Tokyo, Japan). Thick sections at $1.0 \mu \mathrm{m}$ were cut, mounted on nylon grids, stained with only uranyl acetate, observed and analyzed in a JEOL JEM-4000EX TEM equipped with a TN-5400 EDX microanalyzer (Tracor-Northern, Wisconsin, USA) at an accelerating voltage of $300 \mathrm{kV}$. The results showed that many high electron dense lysosomes were observed in the absorptive epithelial cells and the wandering cells in the mucosa (Fig. 2B) of the duodenum, which showed $\mathrm{Al}$ peaks by XMA (Fig. 25A). The results suggested that $\mathrm{Al}$ orally administered was absorbed from the intestinal epithelial cells.

\section{Electrolytes in the jejunal and colonic goblet cells}

Goblet cells are well known in histology and physiology to secrete mucins and are generally supposed to belong a single cell population distributed throughout the intestinal tract (Lacy, 1991). They are irregularly scattered among the absorptive epithelial cells interspersed between the absorptive columnar epithelial cells in the covering epithelium of the small and large intestines. The goblet cell takes the form like a goblet, with its expanded cup-shaped rim of cytoplasm called the theca filled with secretory granules and the thin stem of the cell extending to the base of the epithelium. The epithelial cells contain flattened nuclei which are deformed by the accumulated secretory granules and located vertically to the base of the epithelium. The secretory granules are the droplets of mucin glycoproteins which are synthesized from amino acids, carbohydrates and sulfation as was demonstrated by radioautography (Bennet et al. 1974; Nagata et al., 1988a). We have studied the qualitative and quantitative changes of several macromolecular precursors by light and electron microscopic radioautography (Nagata, 1992, 2000a , 2002a) as well as the quantitative changes of several elements in the secretory granules of goblet cells in the jejunums and colons of ddY strain mice during postnatal development and aging by

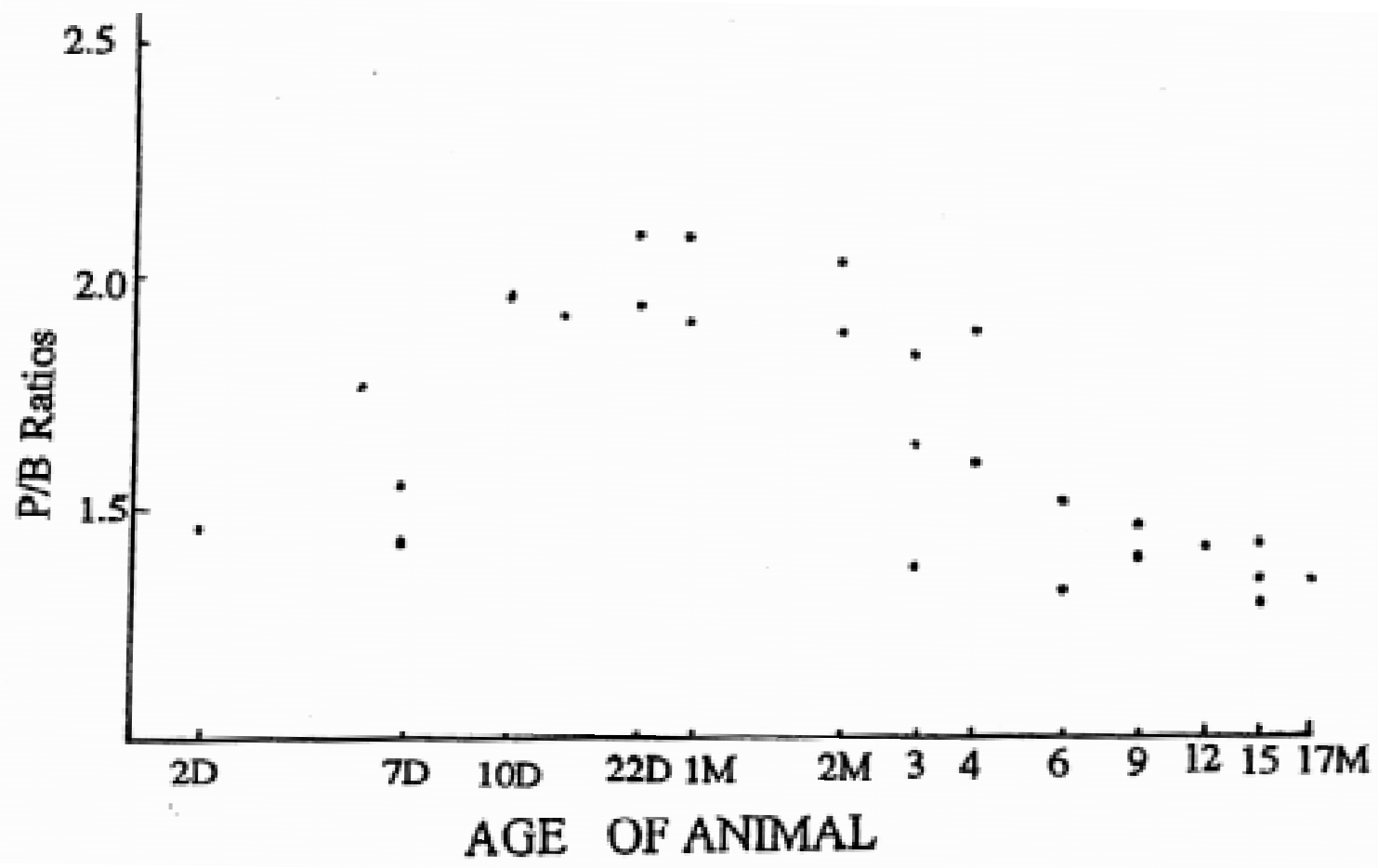

Figure 24. Relationship between the aging of mice and $\mathrm{P} / \mathrm{B}$ ratios of $\mathrm{Zn}$ in the granules in Paneth cells of the duodenum at respective ages. From Nagata $\left(2000^{c}\right)$. 
X-ray microanalysis (Ichikawa et al., 1994). For X-ray microanalysis, we formerly studied the quantitative difference of the electrolytes in mucigen granules of colonic goblet cells in adult mice by changing the fixation procedure, including 1) chemical fixation with glutaraldehyde and osmium tetroxide, cryo-fixations by 2) immersion into isopentanepropane mixture cooled in liquid nitrogen followed by freeze-substitution or 3) acrolein gas prefixation followed by immersion and freeze-substitution and 4) by metal contact method with a JEOL JFD-RFA freezing apparatus (JEOL, Tokyo, Japan) cooled with liquid nitrogen or 5) acrolein gas prefixation followed by metal contact method with a JEOL JFD-RFA freezing apparatus and 6) metal contact method followed by cryosectioning with LKB-NOVA ultramicrotome equipped with cryokit (LKB, Bromma, Sweden) and freeze-drying with JFD-RFA freezing apparatus (JEOL, Tokyo, Japan). The results are shown in Figure 26 as histograms. From the results, it was clear that most electrolytes were better demonstrated in cryo-sections than chemically fixed ones. Among the cryo-techniques tested, cryo-sections followed by freeze-drying was the best to preserve various elements such as $\mathrm{Na}, \mathrm{P}, \mathrm{S}, \mathrm{Cl}, \mathrm{K}$ and $\mathrm{Ca}$ (Nagata 2000ª).

Then, we have studied the total contents of electrolytes in the colonic goblet cells of mice using cryo-techniques to demonstrate both soluble and insoluble compounds and to compare the data with the previous data obtained from the conventional chemical fixation. Several adult ddY mice aged from 30 to 60 days after birth were used as materials. They were bred in our laboratory and fed on normal mouse diet (Clea CE-2, Clea Co., Tokyo, Japan) and access to water ad libitum. All the animals were sacrificed by decapitation, and the colonic tissues were taken out from the proximal colons, which were trimmed and fixed by 6 different fixations including either rapid freezing or chemical fixation, by changing the fixation procedures. For chemical fixation all the tissues were fixed in conventional chemical fixatives, $2.5 \%$ glutaraldehyde in phosphate buffer at $\mathrm{pH} 7.4$, or doubly fixed with both $2.5 \%$ glutaraldehyde and $1 \%$ osmium tetroxide in the same buffer ( $\mathrm{pH} 7.2$ ), dehydrated in graded ethanol and embedded in epoxy resin Epok 812 (Oken, Tokyo, Japan). They were sectioned on an LKB NOVA ultramicrotome (LKB, Bromma, Sweden) at $0.1 \mu \mathrm{m}$ thick according to the conventional method using glass knives with water in the knife troughs. For cryo-fixation, tissues were quickly frozen either by immersion into isopentane-propane mixture cooled in liquid nitrogen at $-196^{\circ} \mathrm{C}$ or by metal contact method with a JEOL JFD-RFA freezing apparatus (JEOL, Tokyo, Japan) cooled with liquid nitrogen at $-196^{\circ} \mathrm{C}$. Some tissues were prefixed with acrolein gas for $1 \mathrm{hr}$ before cryo-fixation. After the cryo-fixation, some tissues were freeze-substituted in absolute acetone containing osmium tetroxide with a freeze-substitution apparatus at $-80^{\circ} \mathrm{C}$ for $48 \mathrm{hr}$, and embedded in epoxy resin or some tissues were cryo-sectioned and freeze-dried. The procedures are classified according to the combination of cryo-fixation and the following procedures. For immersion cryo-fixation and freeze-substitution, tissues were quickly frozen by immersion into isopentane-propane mixture cooled in liquid nitrogen at $-196^{\circ} \mathrm{C}$ and they were transferred into a CS-Auto freeze-substitution apparatus (Reichert-Jung, Germany) containing absolute acetone with saturated osmium tetroxide at $-80^{\circ} \mathrm{C}$ for $48 \mathrm{hr}$ for freezesubstitution, and embedded in epoxy resin Epok 812 (Oken, Tokyo, Japan). All the cryofixed and embedded specimens were dry-sectioned at $0.2 \mu \mathrm{m}$ thick on an LKB ultramicrotome using glass knives without using any water but ethylene glycol in the knife troughs (Nagata, 1991). This sectioning procedure should be called as dry-sectioning on ethylene glycol. For acrolein pre-fixation immersion cryo-fixation and freeze-substitution, some tissues were prefixed with acrolein gas for $1 \mathrm{hr}$ at room temperature before cryofixation and then freeze-substituted, embedded and dry-sectioned on ethylene glycol as described above. For metal contact cryo-fixation and freeze-substitution, some tissues were cryo-fixed by metal contact method using a JFD-RFA freezing apparatus cooled with liquid nitrogen at $-196^{\circ} \mathrm{C}$, then freeze-substituted using acetone either containing $2 \%$ osmium tetroxide or simple acetone without osmium and then embedded and dry-sectioned on ethylene glycol as above. Some tissues were sectioned without using any ethylene glycol nor any trough liquid, thus obtaining complete dry sections. This procedure should be called as absolute dry-sectioning. For acrolein pre-fixation metal contact cryo-fixation 


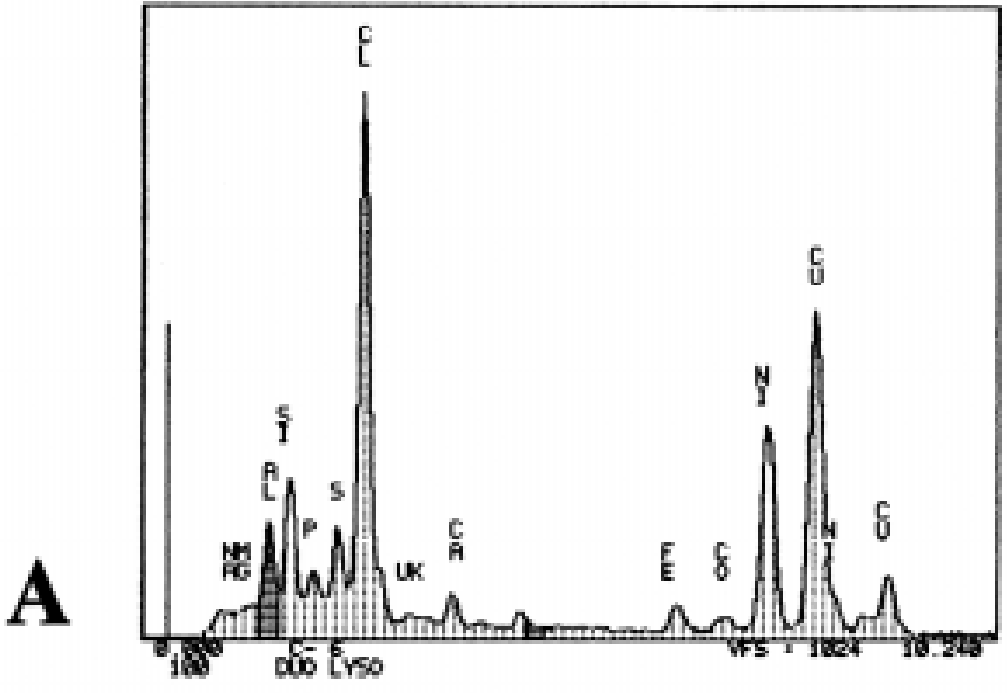

Figure 25. Spectra obtained from the absorptive epithelial cells of the duodenum (A), the hepatocytes (B) and the proximal convoluted tubule cells of the kidney (C) of adult mice injected with aluminium chloride intraperitoneally. From Kametani (2002).
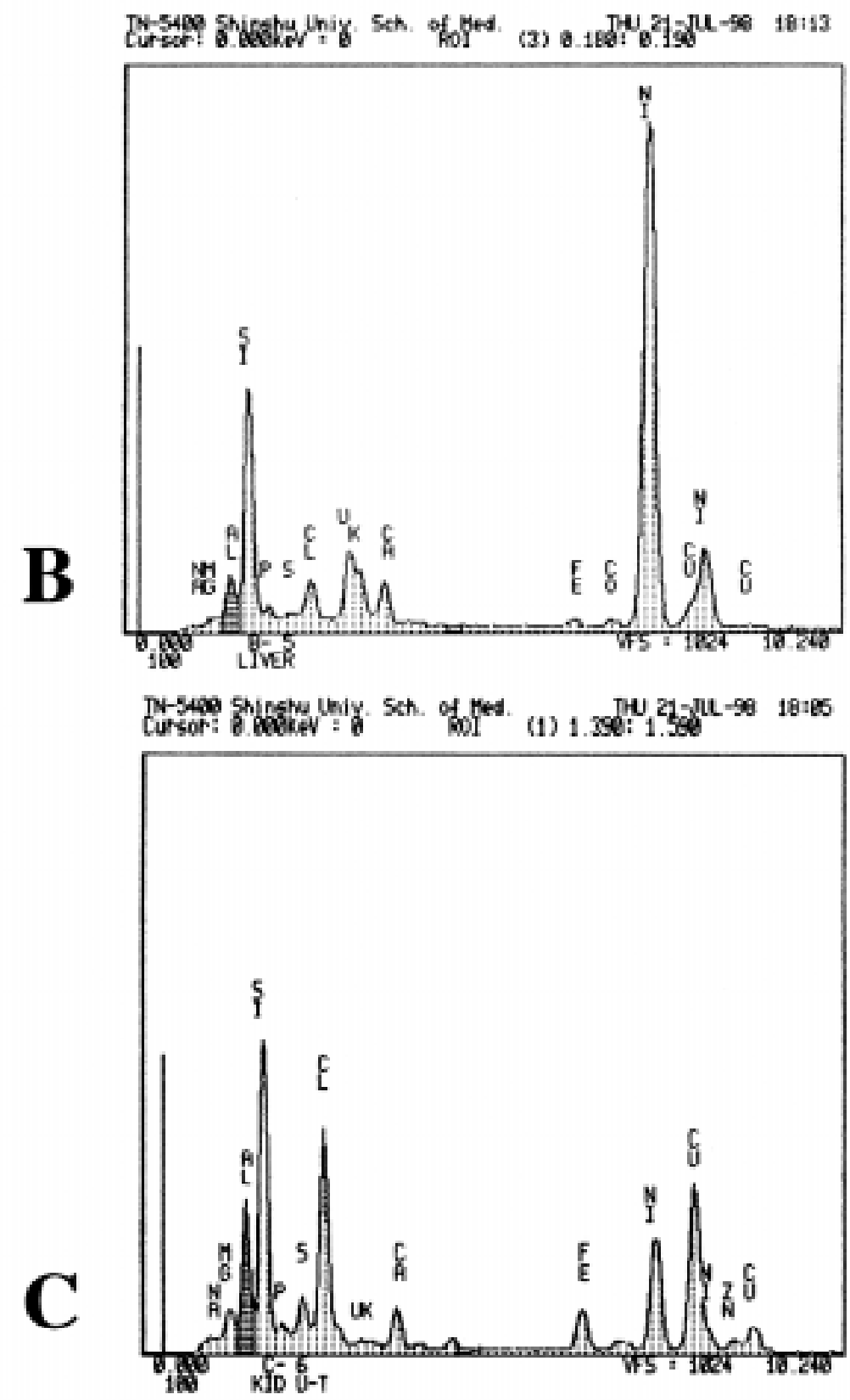


\section{P/B ratios by various methods}

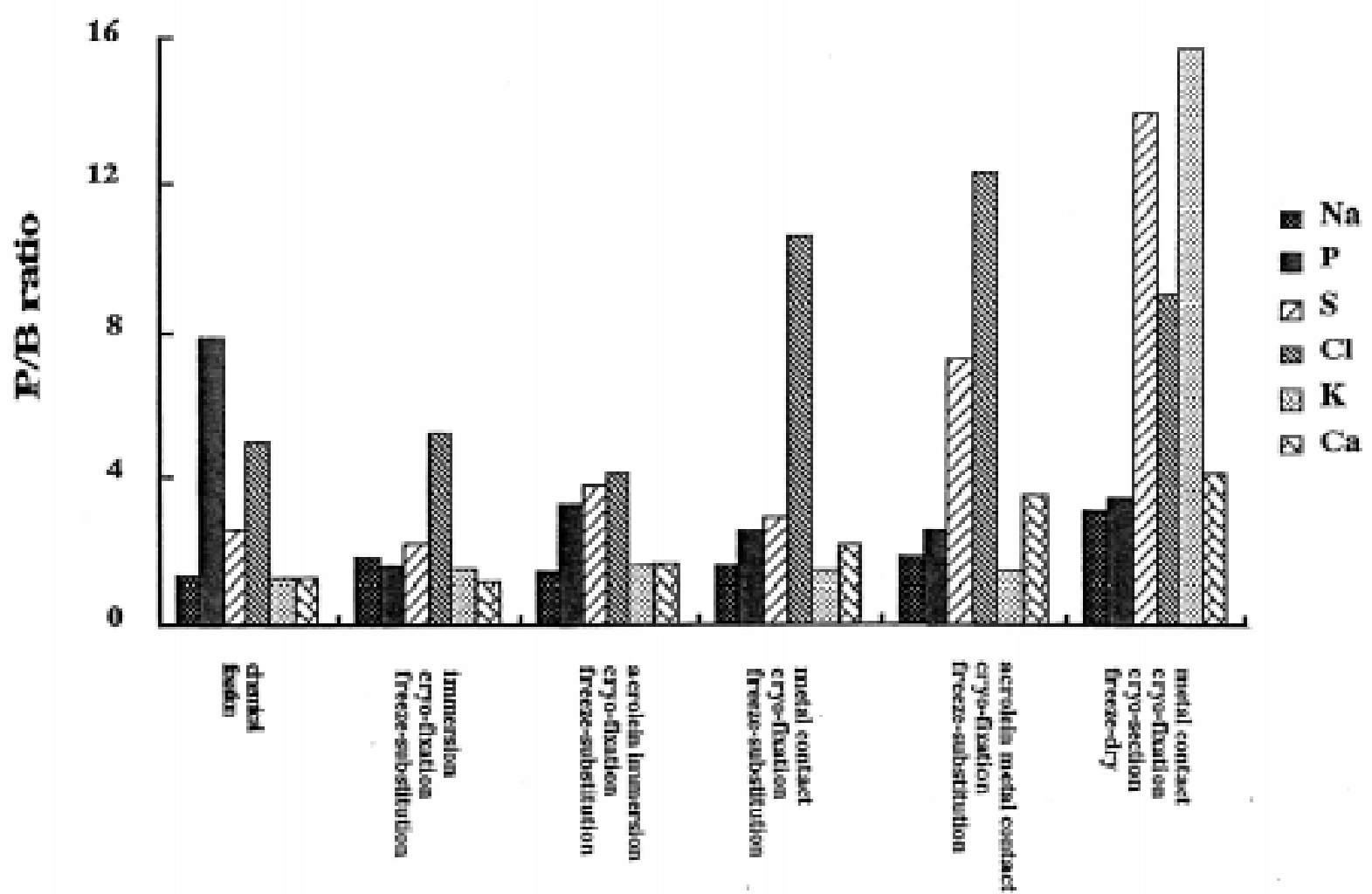

Figure 26. Histogram showing the $\mathrm{P} / \mathrm{B}$ ratios of several elements detected in the goblet cells of the proximal colons of adult mice and calculated from the spectra obtained by various fixing procedures as shown in the Figure From Nagata $\left(2000^{c}\right)$.

and freeze-substitution, some tissues were prefixed with acrolein gas for $1 \mathrm{hr}$ and cryofixed by metal contact method using a JEOL JFD-RFA freezing apparatus at $-196^{\circ} \mathrm{C}$ and freeze-substituted, embedded and dry-sectioned on ethylene glycol as above. For metal contact cryo-fixation cryo-section and freeze-drying, some tissues were cryo-fixed by metal contact method using a JEOL JFD-RFA freezing apparatus at $-196^{\circ} \mathrm{C}$, and cryo-sectioned on an LKB Cryo-NOVA ultramicrotome at $0.2 \mu \mathrm{m}$ thick, using a diamond knife (Diatom, Bienne, Switzerland) with the knife temperature at $-96^{\circ} \mathrm{C}$ and the specimen temperature at $-90^{\circ} \mathrm{C}$ with sectioning speed of $0.5 \mathrm{~mm} / \mathrm{s}$. The sections were picked up onto collodion coated copper grid meshes or formvar coated 100-200 double holding nickel grid meshes (VECO, Eerbeek, Netherlands), using eyelash probes and pressed with a pre-cooled metal stick and freeze-dried in an FD3 freeze-drying apparatus (Eiko, Tokyo, Japan) at $-95^{\circ} \mathrm{C}$ and $5 \times 10_{-7}$ Pascal for $3 \mathrm{hr}$. They were coated with carbon layers at 100-200 nm thick before observation. All the specimens thus prepared were observed and analyzed with an analytical electron microscope, JEOL JEM 4000EX (JEOL, Tokyo, Japan) equipped with an EDX TN5400 (Tracor-Northern, Middleton, WI, USA) analyzer by TEM mode while the specimen chamber was cooled with liquid nitrogen. We used the accelerating voltages at $300 \mathrm{kV}$ because of the highest P/B ratio (Maruyama \& Nagata, 1987; Nagata, 1988a, $1991,1998)$ and the fixed spot size at $0.2 \mu \mathrm{m}$ in diameter which was focused on a granule of a goblet cell, and the specific X-ray spectra counts were analyzed with a dead time of $25 \%$ for 100 s. On the spectra the peak counts of respective elements and background counts were measured and $\mathrm{P} / \mathrm{B}$ ratios were calculated in several granules of each goblet cell. As the results, when the goblet cells in the proximal colons of adult mice were fixed chemically in buffered glutaraldehyde, dehydrated in graded ethanol, embedded in epoxy resin, sectioned and stained with uranyl acetate and lead citrate according to the conventional procedure and were observed by transmission electron microscopy, many mucigen granules could be seen at the apical cytoplasm of the cells. These granules were 
less electron dense and appeared to be fused together in a mass. The whole cell body and nucleus of a cell, both goblet and absorptive columnar epithelial cell, appeared with normal ultrastructure containing cell organelles such as endoplasmic reticulum, mitochondria or microvilli. The X-ray spectrum obtained from the mucigen granules in these specimens showed several peaks of $\mathrm{P}$ (phosphorus), $\mathrm{S}$ (sulfur), $\mathrm{Cl}$ (chlorine) and background with $\mathrm{Ni}$ (nickel) peaks which came from the grid meshes. However, when the same tissues were cryo-fixed by the immersion fixation in the mixture of isopentane and propane cooled with liquid nitrogen at $-196^{\circ} \mathrm{C}$, followed by freeze-substitution in absolute acetone, embedding, and dry-sectioning on ethylene glycol, the mucigen granules appeared less electron dense and separated each other. The apical cytoplasm containing cell organelles and the nucleus located superficially were well preserved. However, the cytoplasm and nucleus located deeper from the apical cytoplasm sometimes showed small ice crystal formation as freezing artifacts. Therefore, the X-ray microanalysis was carried out only in the apical cytoplasm located superficially from the cell surface not deeper than several micrometers. The spectrum (Fig. 9B) obtained from these specimens showed several peaks of $\mathrm{Na}$ (sodium), Si (silicon), $\mathrm{P}$ (phosphorus), $\mathrm{S}$ (sulfur), $\mathrm{Cl}$ (chlorine), $\mathrm{K}$ (potassium) and $\mathrm{Ca}$ (calcium). The peaks were higher than the chemically fixed tissues (Fig. 9A) and some of them such as $\mathrm{P}$ and $\mathrm{Si}$ were not so much detected in the chemically fixed tissues. When the same tissues were prefixed with acrolein gas before cryo-fixation with immersion method using isopentane-propane mixture cooled in liquid nitrogen followed by freeze-substitution in absolute acetone, embedding, and dry-sectioning on ethylene glycol, the mucigen granules were fused each other and the cell organelles and microvilli were not so well preserved as the former methods. The spectrum from the mucigen granules in these specimens shows several peaks of $\mathrm{Na}$ (sodium), $\mathrm{Si}$ (silicon), $\mathrm{P}$ (phosphorus), $\mathrm{S}$ (sulfur), $\mathrm{Cl}$ (chlorine), $\mathrm{K}$ (potassium) and $\mathrm{Ca}$ (calcium). The peaks of $\mathrm{Na}$, Si and $\mathrm{P}$ were higher than the chemically fixed tissues, but the peaks of $\mathrm{S}$ and $\mathrm{Cl}$ were lower. On the other hand, when the same tissues were cryo-fixed by metal contact method using a JFD-RFA (JEOL, Tokyo, Japan) freezing apparatus cooled with liquid nitrogen at $-196^{\circ} \mathrm{C}$ and freeze-substituted in absolute acetone containing osmium tetroxide with the freeze-substitution apparatus, the apical cytoplasm of these goblet cells containing mucigen granules appeared amorphous and dense surrounded with amorphous cytoplasm with cell organelles such as endoplasmic reticulum and mitochondria. The microvilli covering the apical surface of the columnar epithelial cells appeared looser than the chemically fixed specimens. The mucigen granules of the goblet cells were much electron denser than those fixed chemically or than those cryo-fixed by immersion because of osmium in acetone and appeared to be separated each other enveloped with limiting membranes. The spectrum obtained from the mucigen granules resulted in higher peaks of $\mathrm{Na}$ (sodium) Si (silicon), $\mathrm{P}$ (phosphorus), $\mathrm{S}$ (sulfur), $\mathrm{Cl}$ (chlorine), $\mathrm{K}$ (potassium) and $\mathrm{Ca}$ (calcium) and background with $\mathrm{Ni}$ (nickel) and Os (osmium) as compared with the conventional chemical fixation or immersion cryo-fixation. To the contrary, the spectrum obtained from the specimens cryo-fixed by metal contact method but freeze-substituted in simple acetone without osmium tetroxide shows higher peaks of $\mathrm{S}$ and $\mathrm{K}$, lower peaks of $\mathrm{Cl}$ and $\mathrm{Si}$, no peak of Os and lower background. Thus, the $\mathrm{P} / \mathrm{B}$ ratios of respective elements appeared a little higher in the spectra obtained from the specimens without osmium. When the tissues were prefixed with acrolein gas before the cryo-fixation with metal contact method followed by freeze-substitution, the mucous granules in the goblet cells appeared less electron dense and they were fused each other. However, the microvilli covering the epithelial cells and the cell organelles in cytoplasm of both goblet and columnar epithelial cells were well preserved. The spectrum obtained from the granules in these specimens showed several peaks of $\mathrm{Na}$ (sodium), $\mathrm{Si}$ (silicon), $\mathrm{P}$ (phosphor), S (sulfur), $\mathrm{Cl}$ (chlorine), $\mathrm{K}$ (potassium) and $\mathrm{Ca}$ (calcium) and background with Ni similarly to the previous procedure without acrolein gas pretreatment. These peaks were higher than the chemically fixed specimens and immersion cryo-fixation without acrolein. Figure $2 \mathrm{~F}$ shows an electron micrograph of the tissues cryo-fixed in isopentane cooled with liquid nitrogen, then freeze-substituted, embedded and dry-sectioned. The mucigen granules in the goblet cells appeared less electron dense and they were fused to 
each other. The cell organelles in the cytoplasm were not well preserved as compared with the previous procedures by freeze-substitution and embedding. However, the spectrum obtained from these specimens showed several higher peaks of $\mathrm{Na}$ (sodium), $\mathrm{P}$ (phosphorus), $\mathrm{S}$ (sulfur), $\mathrm{Cl}$ (chlorine), $\mathrm{K}$ (potassium) and $\mathrm{Ca}$ (calcium). As the results of these X-ray spectra obtained from respective procedures, the representative values of respective elements, $\mathrm{Na}, \mathrm{P}, \mathrm{S}, \mathrm{Cl}, \mathrm{K}$ and $\mathrm{Ca}$ were calculated as means of 20 granules in each procedure. The mean values of $\mathrm{P} / \mathrm{B}$ ratios calculated from the spectra are shown as histograms in Figure 26. From the results, it is clearly demonstrated that several elements such as $\mathrm{Na}, \mathrm{S}, \mathrm{Cl}, \mathrm{K}$ and $\mathrm{Ca}$ were more detected by cryo-fixation cryo-sectioning freezedrying procedure than the other 5 procedures. The only exception was higher peak of $\mathrm{P}$ observed by chemical fixation, which should be originated to the phosphate used as buffer in the fixative which induced phosphate deposits in the tissues that did not dissolve during dehydration, embedding and aqueous sectioning. The peaks of $\mathrm{Cl}$ also appeared higher in the freeze-substituted and embedded tissues than the cryo-sections, which should also be due to the epoxy resin (Epok 812, Oken, Tokyo, Japan) used for embedding that contained chlorides. On the other hand, two specimens obtained by the cryo-fixation with metal contact method followed by freeze-substitution with osmium, embedded in Epok, either dry-sectioning on ethylene glycol or absolute dry-sectioning without trough liquid were compared in Figure 27A. The results showed that the $\mathrm{P} / \mathrm{B}$ ratios of all the elements were a little higher in absolute dry-sectioning than dry-sectioning on ethylene glycol. The two spectra obtained from the mucigen granules and the supranuclear cytoplasm between the granules and the nuclei in the specimens prepared by metal contact method followed by freeze-substitution and dry-sectioning on ethylene glycol were also compared in Figure 27B. The results showed that the $\mathrm{P} / \mathrm{B}$ rations of $\mathrm{S}, \mathrm{Na}, \mathrm{K}$ and $\mathrm{Ca}$ in mucigen granules were higher but $\mathrm{P}$ was lower than the cytoplasm (Nagata et al., 2000c).

We also studied quantitative changes of several elements in the secretory granules of goblet cells in the jejunums and colons of ddY strain mice during postnatal development and aging (Ichikawa et al., 1994). Twenty ddY stain mice of both sexes and ages ranging from postnatal day 14, to month 1, 3, 6, 15 and 18 were used. Small tissue blocks were taken out from the jejunum and the descending colon close to the ileocecal junction, cut into thin coronal slices, quickly frozen by the metal contact method at $196^{\circ} \mathrm{C}$ using JFD-RFA freezing apparatus (JEOL, Tokyo, Japan) in order to keep soluble compounds according to the cryo-techniques (Nagata, 1992, 1994 $)$. Frozen tissue blocks were trimmed in liquid nitrogen and were cut on an LKB-NOVA ultramicrotome equipped with cryokit (LKB, Bromma, Sweden). Semithin cryo-sections at $0.2 \mu \mathrm{m}$ thickness were cut with a diamond knife (Dupont-Sorvall, Newtown, USA) with the knife temperature at $-96^{\circ} \mathrm{C}$ and the specimen temperature at $-90^{\circ} \mathrm{C}$. The cryo-sections were collected on formvar-coated 100 mesh nickel holding grids (VECO, Eeerbeek, The Netherlands) using eye lash probes. They were freeze-dried in an Eiko FD3 freeze-drying apparatus (Eiko, Tokyo, Japan) at $-95^{\circ} \mathrm{C}$ in a vacuum at $5 \times 10^{-7}$ Pascal for $3 \mathrm{hr}$, coated with carbon and analyzed with a JEM-4000EX TEM (JEOL, Tokyo, Japan) equipped with a TN-5400 energy-dispersive X-ray analyzer (Tracor-Northern, Middleton, USA) at an accelerating voltage of $400 \mathrm{kV}$. The accelerating voltage at $400 \mathrm{kV}$ was decided according to the data obtained from the previous experiment changing the accelerating voltages at 100, 200, 300 and $400 \mathrm{kV}$, resulting in the maximal $\mathrm{P} / \mathrm{B}$ ratio of $\mathrm{P}$ at $400 \mathrm{kV}$. Electron beams were focused onto goblet cell granules by TEM mode, with the fixed spot size at $0.2 \mu \mathrm{m}$ in diameter and the X-ray spectra were analyzed with a dead time of $25 \%$ for $100 \mathrm{~s}$. The peak counts $(\mathrm{P})$ of respective elements were counted within the peak energy of $0.2 \mathrm{keV}$, while the background counts (B) were counted with the range of 4.6-4.8 keV. The relative concentrations of respective elements in each cell were represented as the mean peak-tobackground ratio from 3 randomly selected granules in a cell. The representative values in the jejunum and the colon were calculated as the mean $\mathrm{P} / \mathrm{B}$ ratios of 20 cells from at least 3 animals of each aging group. As the results, the jejunal goblet cells showed similar ultrastructure to the colonic goblet cells. However, X-ray microanalysis revealed that the concentrations of various elements in the jejunum and the colon were different (Ichikawa 
Figure 27. Histograms showing the $\mathrm{P} / \mathrm{B}$ ratios of several elements in the two specimens obtained by the cryofixation with metal contact method followed by freeze-substitution with osmium, embedded in Epok, dry sectioned either using ethylene glycol or without ethylene glycol in the knife trough (A) or showing the $\mathrm{P} /$ $B$ ratios of several elements at the two points, mucigen granules and the cytoplasmic matrix (B), in the same specimens prepared by the cryofixation with metal contact method followed by freeze-substitution with osmium, embedded in Epok, dry sectioned using ethylene in the knife troughs. Note that the $\mathrm{P} / \mathrm{B}$ ratios of dry-sections (complete dry sectioning) are higher than the ethylene glycol sections and $\mathrm{Na}, \mathrm{S}, \mathrm{K}$ and $\mathrm{Ca}$ are significantly higher in mucigen granules than in cytoplasmic matrix. From Nagata et al. $\left(2000^{c}\right)$.

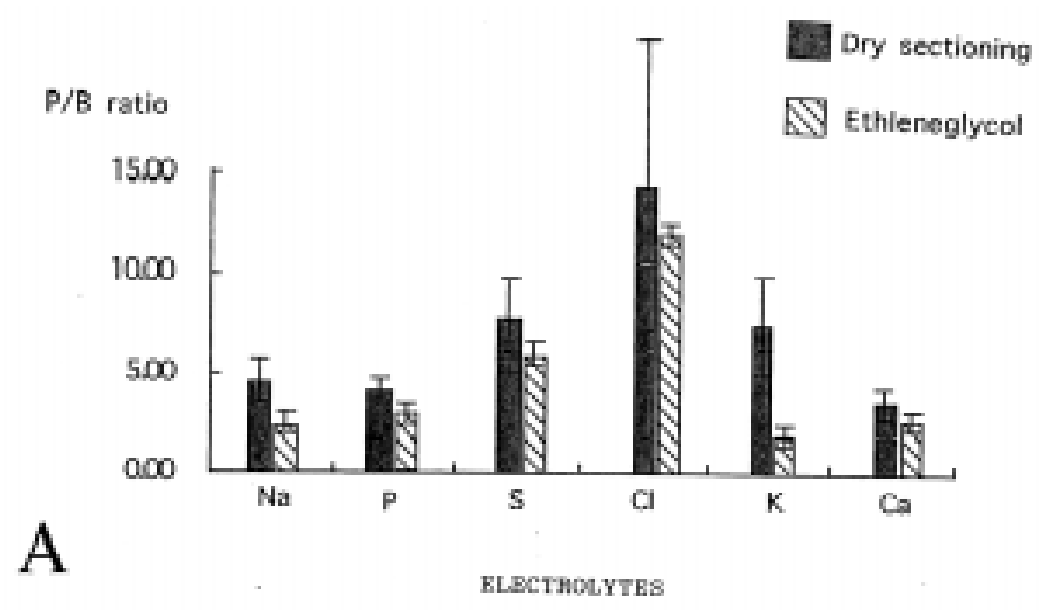

P/B ratio

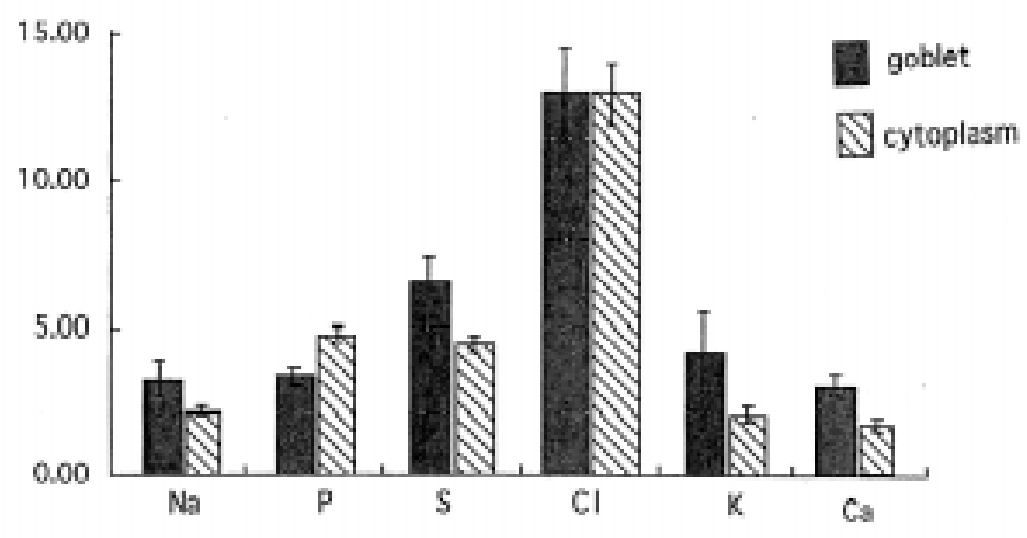

RLECTHOLFTES

et al., 1994). The results demonstrated that $\mathrm{P}$ reached the highest peaks in the colon and those of $\mathrm{S}, \mathrm{Cl}, \mathrm{Ca}, \mathrm{P}, \mathrm{Na}$, respectively, were lower. The $\mathrm{P} / \mathrm{B}$ ratio of $\mathrm{P}$ in the jejunum was 12.8 at postnatal day 14 and increased to 15.4 at postnatal month 1 , reached the highest peak 15.8 at postnatal month 3 , then gradually decreased with aging to month 18 . In the colon, on the other hand, the $\mathrm{P} / \mathrm{B}$ ratios at respective age groups were lower than those of the jejunum at the same ages. These results suggest the functional difference of the goblet cells in the jejunum and the colon as well as the difference with aging changes.

\section{Sulfur in the colonic goblet cells}

We have studied macromolecular synthesis of various organic and inorganic substances by light and electron microscopic radioautography since many years (Nagata, 1992, 1994, 1996, 1997). With regards to goblet cells, we were first interested in the incorporation of ${ }^{35} \mathrm{SO}_{4}$ in the mucigen granules in the goblet cells of mouse colon (Nagata et al., 1988', 1999; Nagata \& Kawahara 1999). When we observed light and electron microscopic radioautographs of proximal and distal colons of adult mice labeled with ${ }^{35} \mathrm{SO}_{4}$, showing mucosubstance synthesis at 30 to 180 minutes after ${ }^{35} \mathrm{SO}_{4}$ injections, we could demonstrate that many goblet cells in the crypts of Lieberkuehn were labeled with many silver grains (Nagata et al., 1988a, 1999). It was very interesting to see that many silver grains were localized over the mucigen granules of the goblet cells as compared with the other absorptive columnar epithelial cells covering the intestinal crypts. It was found that more silver grains were observed over the goblet cells in the upper region of 
the crypt than the goblet cells in the lower region in the same intestinal crypt of the mice (Nagata et al., 1988a). For the purpose of demonstrating the total sulfur (S) contents in the goblet cells in the colonic crypts, we examined the chemically fixed goblet cells in aging mice from fetal stages to postnatal adult and senescent stages up to 1 year and analyzed the $\mathrm{S}$ contents by means of X-ray microanalysis which resulted an increase of $\mathrm{S}$ content per cell with the aging of animals (Maruyama \& Nagata, 1987; Maruyama, 1991). The P/ $\mathrm{B}$ ratios of sulfur in mucigen granules in the goblet cells in the lower crypts of mice aged from fetal day 19 to postnatal day 3 were higher than in the upper crypts of the same ages (Fig. 28). The $\mathrm{S}$ peaks in the spectra at 30 days were the highest in both the upper and lower crypts. However, the $\mathrm{P} / \mathrm{B}$ ratios at 14 days were the highest in both the upper and lower crypts. The transitional curves obtained from $\mathrm{P} / \mathrm{B}$ ratios in both upper and lower crypt cells in relation to aging were shown in Figure 28. From these results, it was demonstrated that $\mathrm{P} / \mathrm{B}$ ratios of sulfur in the goblet cells of aging mice increased from perinatal stages to postnatal 2 weeks and decreased to senescence at 1 year and they were higher in the upper crypts than the lower (Maruyama \& Nagata, 1987). Thus, it was found that the total contents in the goblet cells in the upper regions in the crypts were more than the lower regions (Maruyama \& Nagata, 1987; Maruyama, 1991). The results accorded well with the results obtained from the radioautographic studies on the incorporation of radiosulfate (Nagata, $2002^{\mathrm{e}}$ ).

On the other hand, we have studied the difference of S contents between the goblet cells in the small intestine and the large intestine using cryo-sections to demonstrate both soluble and insoluble compounds. Twenty ddY strain mice of both sexes and ages ranging from postnatal day 14, to month 1, 3, 6, 15 and 18 were used. The animals were sacrificed by decapitation after starving for $10 \mathrm{hr}$. Small tissue blocks were taken out from the jejunums and the descending colons close to the ileocecal junctions, cut into thin coronal slices, put on the tops of silver pins and quickly frozen by the metal contact method at $-196^{\circ} \mathrm{C}$ using JFD-RFA freezing apparatus (JEOL, Tokyo, Japan). Frozen tissue blocks were trimmed in liquid nitrogen and were cut on an LKB-NOVA ultramicrotome equipped with cryokit (LKB, Bromma, Sweden). Semithin cryo-sections at $0.2 \mu \mathrm{m}$ thickness were cut with a diamond knife (Dupont Sorvall, Newtown, USA) at $-96^{\circ} \mathrm{C}$ knife temperature and $-90^{\circ} \mathrm{C}$ specimen temperature. The cryo-sections were collected on formvar-coated 100 mesh nickel holding grids (VECO, Eerbeek, The Netherlands) using eye lash probes. They were freeze-dried in an Eiko FD3 freeze-drying apparatus (Eiko, Tokyo, Japan) at $95^{\circ} \mathrm{C}$ in a vacuum at $5 \times 10^{-7}$ Pascal for $3 \mathrm{hr}$, coated with carbon and analyzed with a JEM4000EX TEM (JEOL, Tokyo, Japan) equipped with a TN-5400 energy-dispersive X-ray analyzer (Tracor-Northern, USA) at an accelerating voltage of $400 \mathrm{kV}$. Electron beams were focused onto goblet cell granules by TEM mode, with the fixed spot size at $0.2 \mu \mathrm{m}$ in diameter and the X-ray spectra were analyzed with a dead time of $25 \%$ for $100 \mathrm{~s}$. The peak counts $(\mathrm{P})$ of respective elements were counted within the peak energy of $0.2 \mathrm{keV}$, while the background counts (B) were counted with the range of 4.6-4.8 keV. The relative concentrations of respective elements in each cell were represented as the mean peak-tobackground ratio from 3 randomly selected granules in a cell. The representative values in the jejunum and the colon were calculated as the mean P/B ratios of 20 cells from at least 3 animals of each aging group. As the results, the jejunal goblet cells showed similar ultrastructure to the colonal goblet cells in morphology. However, XMA revealed that the concentrations of various elements in the jejunum and the colon were different (Ichikawa et al., 1994). The results showed the highest peak at postnatal month 1 in the jejunum, while the highest peak at postnatal month 3 in the colon. It is also interesting that those of $\mathrm{K}, \mathrm{Cl}, \mathrm{Ca}, \mathrm{P}, \mathrm{Na}$, respectively, were lower in the jejunal goblet cell granules than the colon. The $\mathrm{S}$ concentrations in the jejunum were much higher than those of the colon at respective ages. In the jejunum, the $\mathrm{P} / \mathrm{B}$ ratio of $\mathrm{S}$ was 13.37 at postnatal day 14 and increased to 18.18 at postnatal month 1 , then gradually decreased with aging to month 18 (1 year and half). On the other hand, the $\mathrm{P} / \mathrm{B}$ ratio of $\mathrm{S}$ in the colon was 7.02 at postnatal day 14 , increased to 7.59 at month 1 , reached peak to 9.03 at month 3 , then gradually decreased with aging. These results suggest the functional difference of the goblet cells in the jejunum 
Figure 28. Transitional changes of $\mathrm{S}$ in mucigen granules of the goblet cells in the colons of aging mice, as quantified by $\mathrm{P} /$ $\mathrm{B}$ ratios calculated from the spectra, showing the relation between the ages of animals and $\mathrm{P} / \mathrm{B}$ ratios of $\mathrm{S}$ in the goblet cells in upper and lower crypts of the colons. From Nagata $\left(2001^{\mathrm{c}}\right)$.

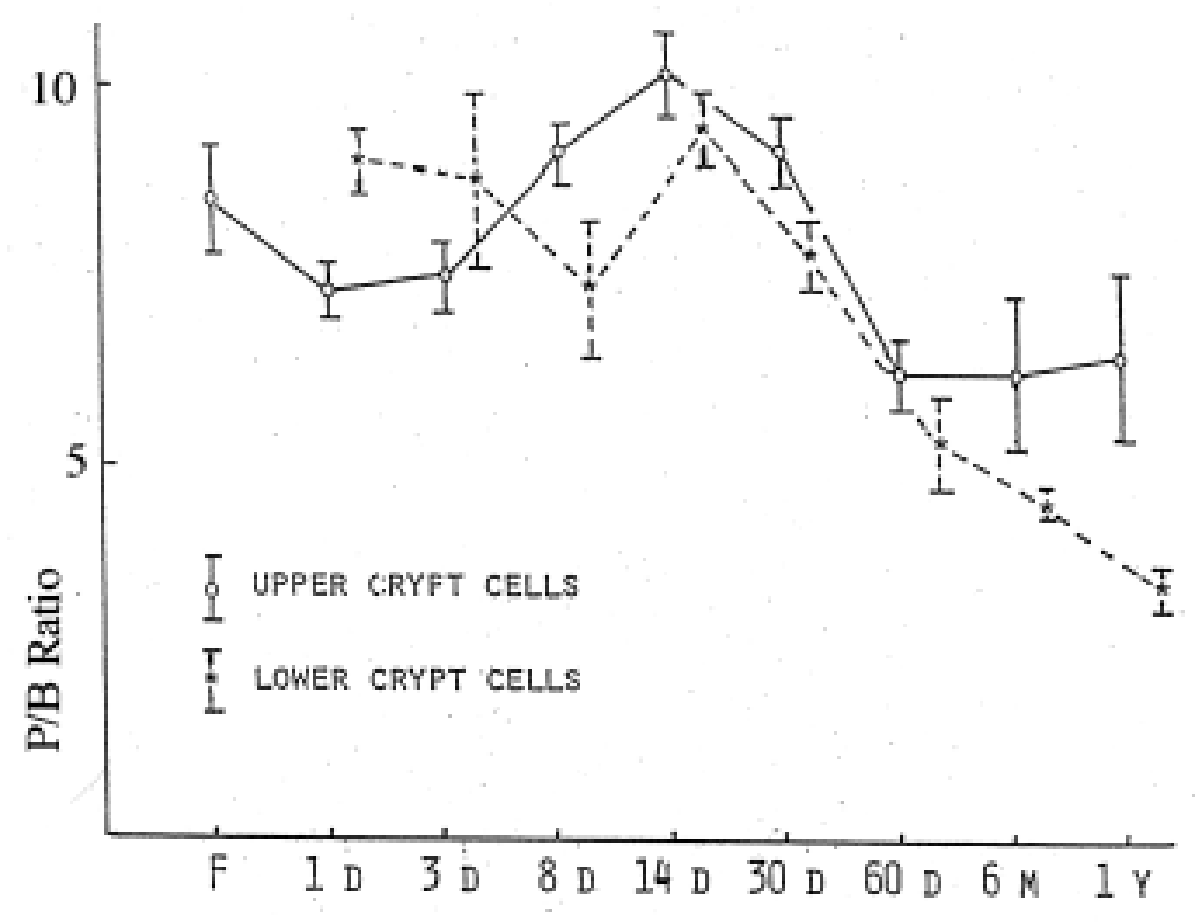

Age of Animals

and the colon as well as the difference with aging changes.

It is well known that the goblet cells in the digestive tract in the experimental animals such as mice, rats, or guinea-pigs distribute throughout the whole intestines from the small intestines to the large intestines. Especially they are more frequently found in the large intestines than the small intestines in any kinds of animals. The cells synthesized and secreted glycoconjugates which showed diversities of the chemical components in various animal species as demonstrated by histochemical staining techniques (Spicer \& Schulte, 1992). For the purpose of demonstrating incorporation and synthesis of any precursors for the glycoconjugates such as amino acids, sugars or sulfuric acids, radioautographic techniques using radiolabeled compounds to demonstrate the sites of incorporation in cells are useful (Nagata, 1992, 1994, 1996, 1997, 1998). We have studied the DNA and glycoprotein synthesis in the small and large intestines of mice and demonstrated that the goblet cells differentiated from the columnar epithelial cells and they were not capable of cell divisions synthesizing DNA (Jin \& Nagata, 1995 a,b, Morita et al., 1993). We have also demonstrated that incorporations of ${ }^{3} \mathrm{H}$-glucosamine and ${ }^{35} \mathrm{~S}$-labeled sulfuric acid in the goblet cells in the ileum, caecum, proximal and distal colons were more than the adjoining absorptive epithelial cells in the same regions (Nagata et al., 1988a, Maruyama, 1991, Morita, 1993). On electron microscopic radioautographs, silver grains were localized over the mucigen granules and the Golgi apparatus, showing that the sulfuric acid and glucosamine were incorporated into the Golgi apparatus and transferred to the mucigen granules and finally discharged into the intestinal lumen (Nagata et al., 1988a , Nagata, 1998). It was, therefore, supposed that sulfuric acid as the precursor of the glycoproteins synthesized in the mucigen granules of the goblet cells was incorporated intensely into these cells. It was obvious that the silver grains developed over the mucigen granules of these goblet cells could only demonstrate the sites of glycoprotein synthesis incorporating ${ }^{35} \mathrm{SO}_{4}$ (Nagata, 1998; Nagata \& Kawahara, 1999) but not demonstrate the total $\mathrm{S}$ contents in these cells. From the results obtained by XMA, it was clearly demonstrated that the mucigen granules contained higher concentration of $\mathrm{S}$ than the cytoplasmic matrix of the goblet cells. The data demonstrating higher concentration of $\mathrm{S}$ in the mucigen granules than the cytoplasmic matrix suggest that $S$ is one of the constituents of glycoproteins synthesized in the goblet cells and then discharged into the intestinal lumen. 


\section{The liver}

We studied localizations of silver grains in the radioautographs of hepatocytes of mice and aluminum accumulated in the pancreas after oral administration of $\mathrm{Al}$ to mouse.

\section{Silver in the radioautographs of hepatocytes}

We formerly used the radioautograph prepared from mouse hepatocytes labeled with ${ }^{3} \mathrm{H}$-thymidine as the models for the purpose of quantifying the silver content in silver grains in radioautographs. Figure 2A shows an example of electron microscopic radioautogram of mouse hepatocyte labeled with ${ }^{3} \mathrm{H}$-thymidine, demonstrating DNA synthesis. For quantifying the silver $(\mathrm{Ag})$ contents of these grains by XMA, we changed the accelerating voltages from 100, 200,300,350, and $400 \mathrm{kV}$. As the results, four spectra were obtained from a single silver grain observed at accelerating voltages of 100, 200, 300, 350 and $400 \mathrm{kV}$, respectively (Fig. 3). From the results, the mean $\mathrm{P} / \mathrm{B}$ ratios at different accelerating voltages were counted (Fig. 4), which showed the maximum at $350 \mathrm{kV}$. Thus, we used the accelerating voltage at $350 \mathrm{kV}$ for further quantification of silver grains in radioautographs prepared from various cells and organs (Nagata, 1991, 2002c , 2003, 2004; Nagata et al., 1991).

\section{Aluminum in the liver after Al administration}

Formerly, Spencer et al. (1995) monitored aluminum (Al) levels in the plasma, urine and liver tissues of rats after intravenous administration of $\mathrm{Al}$ citrate or chloride by atomic absorption spectroscopy as well as the Al content in the livers at the cellular and subcellular level by XMA. They found that Al concentrations were significantly higher in the plasma, urine and livers of rats administered with $\mathrm{Al}$ than controls without administration by atomic absorption spectroscopy. They also found that $\mathrm{Al}$ was distributed in all liver organelles analyzed such as cytoplasm, mitochondria, ER and nuclei of the liver cells.

We first studied several adult ddY mice at 4 weeks after birth which were intraperitoneally injected with aluminum chloride and the liver tissues were examined by both aluminon staining and XMA at an accelerating voltage of $300 \mathrm{kV}$ (Kametani, 2002). Then, we studied Al contents in the liver tissues of several adult ddY mice aged 4 weeks which were administered orally with $2 \% \mathrm{AlCl}_{3}$ for 2 weeks analyzed by means of XMA. As the results, it was demonstrated that Kupffer cells were positively stained with aluminon staining while many high electron dense bodies were observed in Kupffer cells and hepatocytes which showed Al peak in X-ray spectra (Fig. 25B). Thus, it was suggested that $\mathrm{Al}$ which was administered orally to mouse was absorbed from the intestines and accumulated in the liver (Kametani, 2002).

\section{Iron in the livers of human thalassemia patients}

Recently, patterns of iron $(\mathrm{Fe})$ distribution in liver cells in human betathalassemia patients were studied by XMA (Faa et al., 2002). X-ray microanalysis may be useful in clarifying the pathogenesis of such a very rare disease as thalassemia.

\section{Gadolinium in rat liver under experimental conditions}

The distribution of gadolinium $(\mathrm{Gd})$ was lately observed in several organs of rats under experimental condition administered with gadolinium chloride (Spencer et al., 1997). Groups of 10 male and 10 female Sprague-Dawley rats were given a single intravenous injection of gadolinium chloride solution at dosages of $0.07,0.14$, and $0.35 \mathrm{mmol} / \mathrm{kg}$. Histopathological examination was undertaken on all organs from high-dose and control animals necropsied $48 \mathrm{hr}$ postdose and on tissues that showed treatment-related changes from all other rats either $48 \mathrm{hr}$ or 14 days postdose. Electron microscopy and XMA of the spleens and the livers revealed electron-dense deposits 
in splenic macrophages, Kupffer cells, and hepatocytes composed of gadolinium, calcium, and phosphate.

\section{The pancreas}

\section{Electrolytes in the pancreatic acinar cells}

The advantages of cryo-fixation followed by freeze-substitution or freezedrying for examining electrolytes by XMA were formerly used and discussed by many authors in various kinds of organs and tissues. Several electrolytes such as $\mathrm{Na}, \mathrm{Cl}, \mathrm{K}$ were demonstrated in the exocrine pancreas by means of such cryo-techniques (Roos \& Barnard, 1986; von Euler et al., 1992).

\section{Silver in the radioautographs of pancreatic acinar cells}

We studied silver (Ag) grain contents in radioautographs of pancreatic acinar cells when EMRAG obtained from the pancreases of fetal day 19 embryos, newborn day 1 and newborn day 14 mice labeled with ${ }^{3} \mathrm{H}$-uridine, demonstrating RNA synthesis. As the results, numbers of silver grains in the nucleoli, nuclear chromatin and cytoplasm increased (Nagata, 1985' ; Nagata \& Usuda, 1985, 1986; Nagata et al., 1990). In order to quantify the silver contents of grains observed over the nucleoli, nuclei and cytoplasm, X-ray spectra were recorded by energy dispersive X-ray microanalysis (JEM-4000EX TN5400) as is shown in Figure 1A (day 1) and Figure 1B (day 14), demonstrating Ag-K $\alpha$ peaks at higher energy parts in the spectra. Thus, $\mathrm{P} / \mathrm{B}$ ratios expressing relative silver contents were counted and compared between the two age groups. The results obtained by visual grain counting in respective cell compartments in 1 day and 14 day old animals were also calculated. Both the numbers by grain counting and the $\mathrm{P} / \mathrm{B}$ ratios by XMA were calculated to express the silver grains per unit area and compared. These two results, the silver contents analyzed by XMA and the results obtaining from visual grain counting were in good accordance with each other. Thus, X-ray microanalysis for quantifying silver contents of radioautographs was further used instead of grain counting in radioautographs of various cells (Nagata, 2002a).

\section{Tin in bilopancreatic concrements}

Recently, electron microscopic detection of tin (Sn) accumulation by XMA was reported on biliopancreatic concrements after induction of chronic pancreatitis in rats by di-n-butyltin dichloride (Jonas et al., 2002). Thus, XMA was also useful in analyzing the mechanism of pathological concrements in various organs.

\section{The Respiratory System}

The respiratory system of mammals is divided into two portions, air conducting passages and the respiratory portion. The former consists of the nose, the pharynx, the trachea and the bronchus, while the latter consists of the lung. Several papers have been published dealing with the human occupational exposures to dusts or fumes by inhalation into the respiratory organs as studied by XMA.

\section{The Iron in the lung}

Pulmonary siderosis is a well-established disorder in welders. It is generally accepted that more than 150 cases of interstitial pulmonary siderofibrosis were associated with long-standing and heavy exposure to welding fumes at poorly ventilated working places. Buerke et al. (2003) reported that 3 cases of welders suffering from pulmonary siderofibrosis were found who had characteristic job histories, and lung function analyses, histological examinations as well as elemental microanalysis by energy dispersive X-ray analysis (EDX) were demonstrated. Histological examinations showed a patchy interstitial fibrosis with 
accumulations of particulate material typical for welding fumes. EDX disclosed an increase of iron $(\mathrm{Fe})$ load in activated macrophages as well as in lung tissue and a close topographical relationship of welding fume particles and interstitial fibrotic reactions. Lung function analysis showed predominantly loss of pulmonary performance during spiroergometry. Regarding the actual knowledge about the pathomechanisms of ultrafine particles on lung tissue, the evidence from animal experiments, the histological and electron microscopical results, the clinical examinations of welders and some epidemiological evidence, they concluded a causal relationship of interstitial pulmonary siderofibrosis in welders with long-standing exposure to high concentrations of welding fumes under poor working conditions.

\section{Aluminum in the lung}

Recent studies show that aluminum (Al) accumulations occur in the tissues of workers with long-term occupational exposure to $\mathrm{Al}$ dusts or fumes by inhalation into the respiratory organs which caused subtle neurological effects (Flatten et al., 1996). Several papers reported cognitive changes and possible impairment and other neurological effects associated with such occupational exposure to $\mathrm{Al}$ inhalation as miners (Rifat et al., 1990) or workers in aluminum smelting plants (White et al., 1992). However, there were no direct evidences available demonstrating that $\mathrm{Al}$ was localized in the tissues of the respiratory organs such as the lung. Further studies should be required for clarifying this point.

\section{The Urinary System}

The urinary system consists of the kidney and the urinary tracts. Several papers are available concerning the electrolytes detected in the kidney. We mainly studied the acid phosphatase reaction as demonstrated by Ce substrate method as well as the Al accumulation in the kidney.

\section{The Electrolytes in the kidney}

The advantages of cryo-fixation followed by freeze-substitution or freezedrying for examining electrolytes by either radioautography or X-ray microanalysis were formerly used and discussed by many authors in various kinds of organs and tissues (Nagata, $2002^{c}$ ). Several electrolytes were analyzed in the proximal uriniferous tubule cells of chicken kidney infected with avian virus by XMA using cryo-sections (Condron \& Marshall, 1991).

\section{Cerium in the acid phosphatase activity in the kidney}

As was previously described in the methodology section, the acid phosphatase activity of splenic macrophages was demonstrated by means of cerium (Ce) substrate method (Olea, 1991; Olea \& Nagata, 1991, 1992). Electron dense Ce deposits were observed in lysosomes of macrophages and reticular cells in the splenic tissues (Fig. 1B). By XMA in TEM mode at the accelerating voltages from 100, 200, 300,350 , and $400 \mathrm{kV}$ the localization of Ce deposits was confirmed with two peaks at 4.84 and $5.26 \mathrm{keV}$, respectively. When the cerium spectra were observed by changing the accelerating voltages at 100,200, 300 and $400 \mathrm{kV}$, the intensities of the peaks increased with increasing accelerating voltages from 100 to 400 (Fig. 5). Thus, the average peak to background ratios (P/B) counted at 100, 200, 300 and $400 \mathrm{kV}$ increased from 100 to $400 \mathrm{kV}$ (Fig. 6) similarly to Ag. Therefore, XMA in quantifying Ce contents showing acid phosphatase activity in lysosomes of the uriniferous tubules in the kidneys in several groups of aging mice from newborn day 1 to 10 months was carried out using the accelerating voltage at $400 \mathrm{kV}$ (Olea et al., 1991). The X-ray spectrum obtained from the lysosomes showing the Ce peak at $4.84 \mathrm{keV}$ was used for quantitative analysis. Other peaks are $\mathrm{Fe}, \mathrm{Ca}$, $\mathrm{Os}$ and $\mathrm{Cu}$, which should be due to the reabsorbed degradation products of hemoglobin, fixative and grid meshes, respectively (Fig. 29B). It was found that the intensity of AcPase activity as demonstrated by the number and size of lysosomes measured on photographs (Fig. 29A) and the intensity of Ce peak (Fig. 29C) parallelly decreased from day 1 to 10 months due to aging in the 
kidneys of aged mice. These results demonstrated that aging changes of AcPase activity as quantified by Ce X-ray microanalysis was related to the development and aging of animals (Olea et al., 1991).

\section{Aluminum in the kidney after Al administration}

Spencer et al. (1995) monitored aluninum (Al) levels in the plasma and urine of rats after intravenous administration of $\mathrm{Al}$ citrate or chloride by atomic absorption spectroscopy as well as the $\mathrm{Al}$ content at the cellular and subcellular level by XMA. They found that $\mathrm{Al}$ concentrations were significantly higher in the plasma and urine of rats administered with $\mathrm{Al}$ than controls without administration by atomic absorption spectroscopy. They also found that significant amounts of $\mathrm{Al}$ were found in cytoplasm and mitochondria of proximal convoluted tubule cells of rats given $\mathrm{Al}$ citrate, but not in nuclei or lysosomes of these cells, while $\mathrm{Al}$ levels were not detectable in control kidneys, in proximal tubule cells after $\mathrm{Al}$ chloride administration or distal tubule cells after either $\mathrm{Al}$ citrate or chloride treatment.

We first studied several adult ddY mice 4 weeks after birth which were intraperitoneally injected with aluminum chloride and the duodenum, the liver, the kidney and the cerebral cortex were examined by both aluminon staining and XMA at an accelerating voltage of $300 \mathrm{kV}$ (Kametani, 2002). By light microscopic aluminon staining, no positive reaction was observed in the kidney. However, by transmission electron microscopy, many pinocytotic vesicles with high electron density were observed in the apical cytoplasm of the proximal convoluted tubule cells of the kidney, which resulted in the spectra showing high $\mathrm{Al}$ peaks by XMA (Fig. 25C). The results revealed that administered $\mathrm{Al}$ was absorbed and accumulated in the proximal convoluted cells. Then, we studied 9 groups of ddY mice at various aging stages, each consisting of 3 littermates, from postnatal week 1, 3, 5, 7, 9, 11, 13, 15 and 17 . They were administered orally with deionized water containing $2 \%$ aluminum chloride $\left(\mathrm{AlCl}_{3}\right)$ at $\mathrm{pH}$ 2.5, ad libitum immediately after birth until 17 weeks. As normal control animals, some animals were administered with only deionized water without aluminum chloride. The animals were sacrificed at each administration period and the kidney tissues were fixed only in $2.5 \%$ glutaraldehyde in phosphate buffer, dehydrated in ethanol, substituted in propylene oxide and embedded in Technovit VL7200 resin (Meiwa Co., Tokyo, Japan). Thick sections at $1.0 \mu \mathrm{m}$ were cut, mounted on nylon grids, stained with only uranyl acetate, observed and analyzed in a JEOL JEM-4000EX TEM equipped with a TN-5400 EDX microanalyzer (TracorNorthern, Wisconsin, USA) at an accelerating voltage of $300 \mathrm{kV}$. The results showed that many high electron dense lysosomes were observed in the proximal convoluted tubule cells of the $\mathrm{Al}$ administered mice which increased from newborn to 17 weeks after birth. The EDX spectra obtained from the lysosomes and the nuclei of the tubule cells showed not only $\mathrm{Al}$ but also $\mathrm{Na}, \mathrm{Si}, \mathrm{P}, \mathrm{S}, \mathrm{Cl}, \mathrm{U}, \mathrm{K}, \mathrm{Ca}, \mathrm{Fe}$ and $\mathrm{Cu}$. The transitional changes of $\mathrm{P} / \mathrm{B}$ ratio of $\mathrm{Al}$ with administration periods in both lysosomes and nuclei of either administered with $\mathrm{Al}$ or not for 17 weeks are shown in Figure 30. The highest peak of $\mathrm{Al} \mathrm{P} / \mathrm{B}$ ratio was at the period after $\mathrm{Al}$ administration for 1 week. Comparing the $\mathrm{P} / \mathrm{B}$ ratios of $\mathrm{Al}$ in both the lysosomes (Fig. 30A) and the nuclei (Fig. 30B) of convoluted tubule cells between the two groups of the experimental animals administered with $\mathrm{Al}$ and without $\mathrm{Al}$, the former were higher than the latter at respective administration periods. The stochastical analysis on the significant differences between the quantities of $\mathrm{Al}$ in the lysosomes and the nuclei of the kidneys of mice in the two experimental groups with and without $\mathrm{Al}$, as well as the transition during the administration, was calculated using factorial design. The results showed that the significance of Al administration in the lysosomes and the nuclei as well as the significance of administration periods were highly significant (Kametani et al., 2003).

\section{The Reproductive System}

The reproductive system is divided into two parts, the male and the female genital organs. We have not studied these organs by X-ray microanalysis. Just a brief review on some papers available in the literature by CTEM should be here mentioned. 
Figure 29. Graphs showing the aging changes of proximal convoluted tubule cells of the kidneys of mice at various ages demonstrating acid phosphatase activities with Ce substrate method. A: Histogram showing the average size (diameter in $\mathrm{nm}$ ) and number of AcPase positive lysosomes (number of lysosomes per cell in cross sections) in the proximal convoluted tubule cells mice at various ages. Mean \pm standard deviation. B: X-ray spectrum obtained from a lysosome of a tubule cell of a mouse at postnatal day 1 observed at accelerating voltage of $300 \mathrm{kV}$. The main spectral line of cerium (shaded) was determined at $\mathrm{L}=4.84 \mathrm{keV}$. The arrow indicates the point at which the background spectrum was determined. C: Transitional curve demonstrating the relation between the $\mathrm{P} / \mathrm{B}$ ratios of AcPase activity (abscissa) and the aging of animals (ordinate). From Olea et al. (1991).
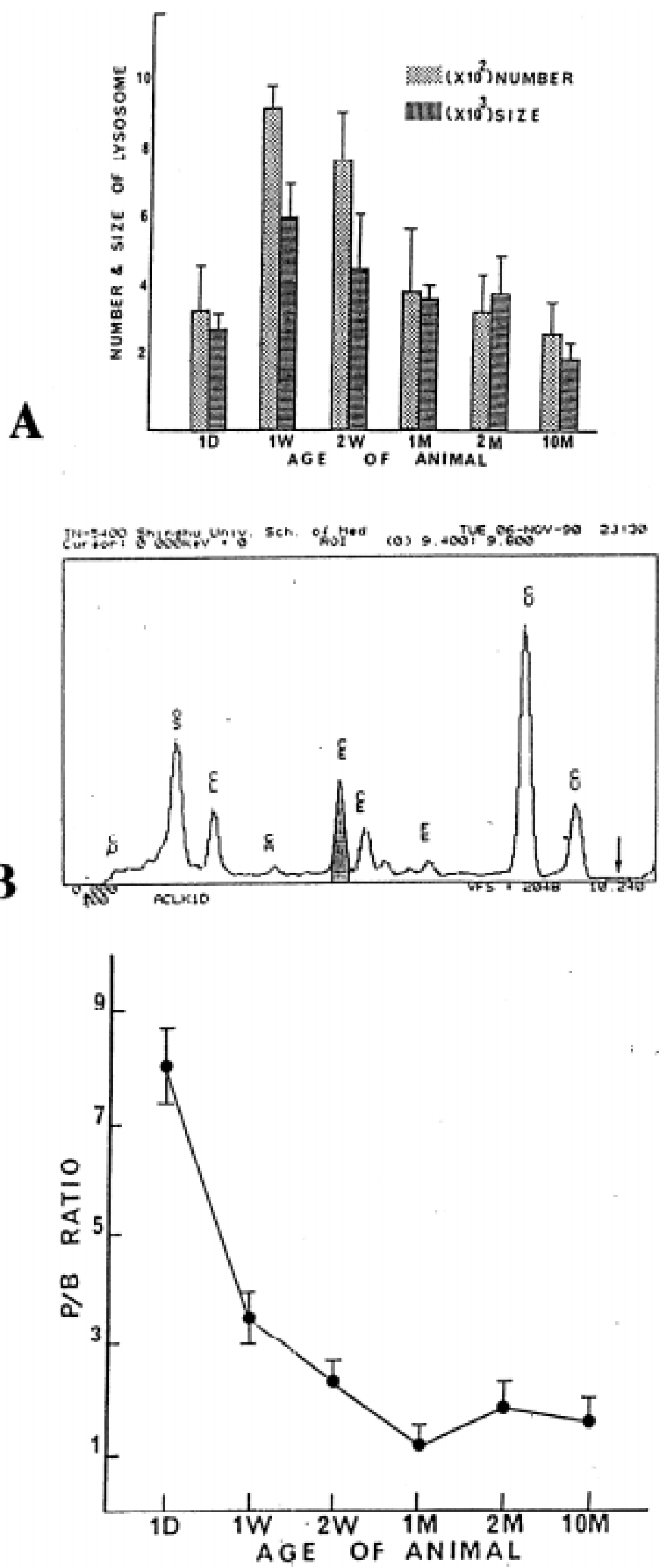


\section{Male genital organs}

The male genital organs consist of the testis and its excretory ducts, auxiliary glands and penis. Several papers are available treating the testis and the auxiliary glands.

\section{Lead in the testis}

Over the period of the last 40 years there was a marked decrease in the number of spermatozoa produced by the gonads of men. It was supposed that this observation was due to the influence of environmental pollution, wherein the lead $(\mathrm{Pb})$ plays quite an important role. In sperms of men, who are professionally exposed to lead compounds, oligo-, asteno-, and teratospermia were disclosed. In order to clarify this point, studies were performed on sexually mature male rats after 9-month-long exposure to lead acetate as well as a group of animals after 3-month-long interval in the exposure and the localization of $\mathrm{Pb}$ in the testis of rats experimentally exposed to lead acetate was reported (Marchlewicz, 1994). The changes provoked by the lead were evaluated by employing a number of study techniques, namely: morphological examination of testes with taking into account the stages of seminiferous epithelial cycle, and epididymis, giving due consideration to zones; electron microscopic examination of seminiferous cells and interstitial tissue, as well as the cells in the wall of epididymis and spermatozoa; XMA determining the presence and type of elements on ultrathin section; spectrophotometrical determination of $\mathrm{Pb}$ content in blood, testes and epididymides; determination of testosterone concentration in blood serum. It was revealed that the blood-testis barrier protects seminiferous epithelium against the toxic action of the lead. No deposits of $\mathrm{Pb}$ were observed either in germinal cells or Sertoli cells. The endocrine testicular cells outside the barrier had also unchanged ultrastructure, and contained no $\mathrm{Pb}$. That finding was expressed by normal testosterone level in blood serum. The only cell in the area of the testis, in whose cytoplasm there was $\mathrm{Pb}$ confirmed by XMA, was macrophage in the interstitial tissue of the testis. Apart from that, it was disclosed that the blood-epididymis barrier does not provide a barrier against this element. $\mathrm{Pb}$ deposits were seen in smooth myocytes, epithelial cells and in the lumen of epididymal duct. That correlated with a marked decrease in the number of epididymal spermatozoa and numerous damages involving their ultrastructure. It was shown that lead, when passing to the duct lumen of epididymis through cells and structures constructing the wall of that organ, was being excreted from the male genital system with the sperm.

\section{Zinc in normal and pathological prostate gland}

Zinc $(\mathrm{Zn})$ was detected in both normal and pathological prostate glands of men suffering from the prostatic diseases (Bataineh et al., 2002). Thus, $\mathrm{Zn}$ seemed to be the normal constituents of the male genital organs.

\section{Magnesium and sulfur in the bulbourethral gland}

The advantages of cryo-fixation followed by freeze-substitution or freezedrying for examining electrolytes by XMA were formerly studied and discussed by many authors in various kinds of organs and tissues. The method was applied to localize several electrolytes such as mangnesium $(\mathrm{Mg})$ and sulfur $(\mathrm{S})$ in the mucous granules of the bulbourethral glands of rats (Takaya \& Masuda, 1991).

\section{Female genital organs}

The female genital organs consist of the ovary, the oviduct, the uterus, the vagina and the external genitals. Several papers dealing with the XMA on these organs by CTEM are available.

\section{Calcium and cadmium in the ovarium}

In the vitellogenic follicles of the ovary of Galleria mellonella, the localizations of calcium (Ca) and cadmium (Cd) were observed by XMA (Przelecka \& Mrozinska, 
2002). The results revealed the relation between the calcium-cadmium competition in the ovarian vitellogenic follicles.

\section{Iron in the ovarian dermoid cyst}

Recently, peritoneal melanosis associated with a ruptured ovarian dermoid cyst of a human patient was studied by EDX analysis (Jaworski et al., 2001). A case of peritoneal melanosis due to a ruptured left ovarian dermoid cyst was described. Histology showed that the dermoid contained gastric mucosa associated with ulceration, necrosis, and hemorrhage. The areas of pigmentation within the dermoid, omentum, and peritoneal cavity were due to collections of heavily pigment-laden macrophages. The pigment lacked the histochemical features of either melanin or hemosiderin, but electron-probe energy dispersive XMA showed that the pigment contained a high concentration of iron (Fe). It was postulated that peptic ulceration with hemorrhage was the most likely source of the pigment and that the peritoneal pigmentation was secondary to spillage of the contents of the dermoid cyst.

\section{The Endocrine System}

The endocrine system consists of the hypophysis, the pineal body, the thyroid and parathyroid, the thymus, the adrenal gland, the pancreatic islet of Langerhans and the genital glands. Some literature is available on respective endocrine organs. However, we have not studied these organs yet. Thus, a brief review on several papers will be summarized below.

\section{The thyroid}

\section{Electrolytes in cultured thyroid follicular cells}

Wrobewski and Wrobewski (1994) studied the methods for preparation of cultured cells and organ cultures for analytical electron microscopy. These methods allowed qualitative and quantitative analysis of mobile ions in combination with biochemical or morphological studies. Cultured cells can be easily prepared for analytical electron microscopy. Two major, anhydrous preparation techniques, by which loss or redistribution of ions is minimized, were used. Cells were cryo-sectioned and analysis carried out on freeze-dried sections obtained from frozen cell monolayers, pelleted cells or organ cultures. Otherwise, cells cultured on supports compatible with elemental analysis were frozen after removal of experimental media by rinsing, freeze-dried and analyzed. The first technique was applied to the studies of the elemental content of isolated Langerhans islets and thyroid follicles cultured in collagen gel. The second was used in studies of the ionic changes in enterocytes. Data obtained from organotypic cell cultures and cultures of single cells were compared with analytical data obtained from sections of corresponding tissues, where isolation, culturing and steps in processing such as removal of culture or experimental medium were omitted. It was shown that often culture systems fully acceptable to physiologists have an elemental composition different from that of tissue in situ and can not be regarded as fully normal tissue.

\section{Chlorine in thyroid parafollicular cells}

The thyroid parafollicular cells are neural crest-derived endocrine cells that secrete serotonin and calcitonin. The secretory vesicles of parafollicular cells acidify when secretion is induced by increased extracellular $\mathrm{Ca}^{2+}$ or TSH. Tamir et al. (1994) tested the hypothesis that acidification is regulated by secretogogue-gated $\mathrm{Cl}^{-}$channels in vesicular membranes. Cl-channel (p64) immunoreactivity was enriched in purified parafollicular vesicles. XMA showed a change in chlorine $(\mathrm{Cl})$ level in parafollicular vesicles in response to secretogogue-stimulation of isolated cells. Secretogogue stimulation also altered the degree of p64 channel phosphorylation. Protein kinase and phosphatase inhibitors 
antagonized secretogogue-induced vesicle acidification and secretion; however, secretion could occur even when acidification was blocked. They concluded that acidification of parafollicular vesicles was regulated by a gatable $\mathrm{Cl}^{-}$channel in vesicle membranes and that protein phosphorylation and dephosphorylation were involved in channel activation. Acidification of vesicles was not required for exocytosis.

\section{The adrenal gland}

\section{Calcium in the adrenal medulla}

The relationship between the chromaffin granule number and the granule calcium $(\mathrm{Ca})$ content in the adrenal medulla of restrained rats was studied by XMA (Liu et al., 2000).

\section{The islets of Langerhans}

The pancreatic $\beta$-cells in primary culture isolated from mice or an established cell line RINm5F were cultured in vitro, as well as the pancreatic tissues taken out from non-inbred mice were cryo-fixed in liquid propane cooled by liquid nitrogen, freezesubstituted, embedded in Araldite, sectioned at $1 \mu \mathrm{m}$ thick, mounted on titanium grids and observed by either X-ray microanalysis (Palsgard et al., 1994a) or freeze-dried and observed by scanning transmission ion microscopy (Palsgard \& Grime, 1996; Palsgard et al., 1994 $)$. They observed the elemental maps of pancreatic $\beta$-cells showing elemental distributions of phosphorous $(\mathrm{P})$, potassium $(\mathrm{K})$, calcium $(\mathrm{Ca})$ and zinc $(\mathrm{Zn})$. Isolated cultured cells of islet cells were also studied after the cells were cryo-sectioned and freezedried (Wrobewski \& Wrobewski, 1994)

\section{The circulatory system}

The circulatory system or cardiovascular system consists of the heart, the blood vessels, the blood cells, the lymphatic organs and the spleen. We mainly studied the spleen and some of the blood cells. Other organs should be briefly reviewed from the literature.

\section{The heart}

Kramer et al. (2000) determined whether prior treatment of rats with subthreshold doses of iron, or in vitro ischemic pre-conditioning (IP) of hearts from untreated rats, can modulate redox-active cardiac tissue iron levels or distribution, leading to alterations in post-ischemic lipid peroxidation-derived free radical production and severity of reperfusion injury. In their first study, rats received biweekly i.p. injections of 0 (saline=S), 3, 6, or $12 \mathrm{mg} \mathrm{FeCl} 3 / \mathrm{ml}$ for 3 weeks prior to imposing $30 \mathrm{~min}$ in vitro. The highest dose caused no elevations in plasma or heart tissue Fe levels, but did further reduce post-ischemic recoveries of left ventricular developed pressure (17\% lower), cardiac work $(57 \%)$ and output (54\%), and increased effluent lipid hydroperoxides (2.1-fold) compared to the S-group. Post-ischemic free radical production was assessed in tolueneextracted effluent by ESR spectroscopy and alpha-phenyl-N-tert butylnitrone ( $\mathrm{PBN}=2.5$ $\mathrm{mM}$ perfusate) spin trapping. PBN/alkoxyl (alphaH=1.90 G, alphaN=13.63 G) was the dominant signal detected in all groups; however, Fe-treated groups displayed significant dose-dependent increases in total alkoxyl content $(3,6,12 \mathrm{mg} / \mathrm{ml}: 1.8-, 2.3-, 2.7$-fold higher) compared to the S-group. These data suggest that even mild, non-overloading doses of iron can be functionally and oxidatively detrimental to hearts when an I/R stress is imposed. In study 2, isolated hearts from untreated rats were exposed to two-IP cycles: during IP, total effluent iron content by atomic absorption increased 11.4-fold compared to control and analysis of cardiovascular tissue iron distribution by XMA suggested that iron loss from capillary endothelium was far greater than from tissue myocytes. Moreover, iron-catalyzed production of alkoxyl radicals following severe I/R stress (40 min I/15 
min R) was substantially lower (73\%) in IP hearts compared to the non-IP counterparts. These preliminary findings suggest that cardioprotection resulting from IP may, in part, be related to IP-induced release of cardiovascular endothelial iron (redox-active) prior to imposing severe I/R stress.

On the other hand, it was known that the patients with beta-thalassaemia major frequently suffer from hypersiderosis which lead to hemochromatosis of major organs such as the heart and the liver (Kyriacou et al., 2000). Little information existed about the ultrastructural pathology of the human heart in beta-thalassaemia patients. Five Cypriot patients with elevated blood ferritin and intractable heart failure were investigated. Cardiac biopsies from these patients were studied by light and electron microscopy, as well as by XMA. Ultrastructural examination revealed the presence of disrupted myocytes showing loss of myofibers, dense nuclei, and a variable number of pleomorphic electron dense granules. These cytoplasmic granules or siderosomes consisted of iron-containing particles as confirmed by XMA. It is likely that the ultrastructural changes observed in myocytes of patients with beta-thalassaemia were largely due to iron deposition (Kyriacou et al., 2000).

\section{The blood vessels}

The blood vessels consist of the arteries, the veins and the capillaries. An immense literature is available dealing with calcium (Ca) in the arteries. Among them, Ca content in the smooth muscle cells of the aortae of rabbits was studied by XMA (Maloney $\&$ Wheeler-Clark, 1996). They found that the reduction in sarcoplasmic reticulum $\mathrm{Ca}^{2+}$ ATPase activity contributed to age-related changes in the calcium content and relaxation rate of rabbit aortic smooth muscle. On the other hand, the pathogenesis of calcification in Monckeberg's disease was studied by XMA (Mohr \& Gorz, 2002). In contrast to granular mediacalcinosis of the aorta, Monckeberg's disease was characterized by the occurrence of sheet-like calcification. It was usually said that the pathogenesis of this calcification was unknown. To obtain some insight into the mechanism leading to this calcification, they performed light microscopic, SEM and XMA investigations on femoral arteries from human autopsies. By light microscopy preferentially sheet-like calcifications of different size appeared. In the alizarin red S stain in the neighborhood of these compact structures calcified globules were observed. By SEM in the neighborhood of the compact areas calcified granules were found; the compact structures themselves consisted of granules sticking one onto the other. XMA exhibited high contents of calcium and phosphorus in the compact calcifications; they also showed a minor content of magnesium. Isolated granules inside the compact calcifications showed a nearly identical composition, while granules outside in the surrounding media consisted preferentially from calcium and phosphorus, but they exhibited a slight higher magnesium content. It was concluded that Monckeberg's media calcification was due to dystrophic calcification. Calcified matrix vesicles from necrotic cells, as it was assumed for the pathogenesis of the calcification of arteriosclerotic plaques were interpreted as precursors of the solid calcifications which may develop by confluence and sticking one onto the other of calcified globules.

They also studied the calcifications in the temporal arteries of the human autopsies by XMA (Mohr \& Gorz, 2003). Vascular calcification, traditionally regarded as a dystrophic process, has recently been interpreted as a bone-like biologically regulated phenomenon. Because temporal arteries which also contain calcifications were easily available from biopsies of older individuals with suspected giant cell arteritis, they studied the morphogenesis of this calcification in comparison with the development of fetal bone. Formaldehyde fixed arteries were processed in paraffin sections and investigated by light, transmission-, and scanning electron microscopy. The atomic composition of the calcifications was estimated by XMA. Fetal bone, also fixed with formaldehyde, was investigated using identical methods. Early calcifications were often present as focal or diffuse granular mediacalcinosis. With increasing age, calcified granules appear in association with the internal elastic membranes and progress to sheet-like calcifications. Ultrastructurally calcospherites, not rarely exhibiting the Liesegang phenomenon, were 
the hallmark of early calcifications. In advanced sheet-like calcification calcospherites could be detected as components of the calcified lumps. Calcospherites also appear in endochondral calcification, but were absent in calcified osteoid. The ultrastructure of calcospherites in provisional endochondral ossification differs from that in vascular calcification. Instead of corpuscles as with the Liesegang phenomenon, radial clusters of needle-like crystals resembling apatite are present. While calcospherites of the tunica media often contain a high amount of magnesium, calcified sheets as well as bone exhibited in contrast a low magnesium content. It is concluded that, comparable to granular mediacalcinosis of the aorta, development of calcified arteriosclerotic plaques, and Monckeberg's disease, calcification of small muscular temporal arteries was also initially a calcospherite-dependent process. It is generally accepted that these calcified corpuscles represent remnants of calcified necrotic or apoptotic cells. In the phase of confluence with the appearance of sheet-like calcification, a low bone-like magnesium content that differs from the high amount in the isolated medial calcospherites was measured. This finding, together with the observation that calcified sheets contain calcospherites, supports the hypothesis that vascular calcification in general is different from bone formation and has to be regarded as a biphasic process initiated by the appearance of calcospherites and followed by a secondary calcifying phase with the formation of bone-like apatite that leads to rock hard lumps of calcified vessels.

\section{The blood cells}

The mature blood cells circulating in the blood vessels of adult mammals can be classified into 3 types, the erythrocytes, the leukocytes and the platelets. These mature blood cells immigrate into the connective tissues outside the blood vessels and become the constituents of the free cells together with other cell elements such as macrophages, plasma cells and mast cells. The mature blood cells are formed in either the lymphatic tissues of the lymphatic organs or the myeloid tissues of the bone. We studied some elements in leukocytes as well as peritoneal mast cells.

\section{Sulfur in the leukocytes}

It was formerly demonstrated that the granules in leukocytes contained sulfated complex carbohydrate as stained with HID procedure (Spicer et al., 1978). In order to demonstrate the existence of sulfur $(\mathrm{S})$ in these granules, we studied the rabbit bone marrow cells by both radioautography and XMA (Murata et al., 1979). Carrier free sulfuric acid $\left({ }^{35} \mathrm{SO}_{4}\right)$ was incorporated into the Golgi regions and of the 3 kinds of immature and mature granulocytes, heterophilic, eosinophilic and basophilic promyelocytes, myelocytes and mature granulocytes. The intensity of incorporations as expressed by grain counting was the strongest in the heterophil, next strong in the eosinophil and the weakest in the basophil, while the more the immature the granulocyte was the stronger the incorporation. On the other hand, XMA revealed that the spectra obtained from the 3 kinds of granules, heterophil, eosinophil and basophil, 3 peaks, osmium, sulfur $(\mathrm{S})$ and chloride $(\mathrm{Cl})$ were found. The osmium (Os) peaks should be originated from the fixative and the chlorine $(\mathrm{Cl})$ peaks from the epoxy resin, while the sulfur $(\mathrm{S})$ peaks should be due to the specific granules of the heterophil, the eosinophil and the basophil. Thus, it was concluded that the $\mathrm{S}$ detected in the specific granules of these granulocytes was derived from the acid glycosaminoglycan in the granules (Murata et al., 1979).

\section{Magnesium and sulfur in megakaryocytes}

The advantages of cryo-fixation followed by freeze-substitution or freezedrying for examining electrolytes by XMA were formerly used and discussed by many authors in various kinds of organs and tissues (Nagata, 1991). Among them, several electrolytes such as magnesium $(\mathrm{Mg})$ and sulfur $(\mathrm{S})$ in the blood platelets and megakaryocytes were analyzed by this method (Takaya, 1984; Takaya et al., 1994). The results demonstrated that cryo-sections contained much more electrolytes than conventional chemically fixed sections. 


\section{Electrolytes in the dense bodies of blood platelets}

The dense bodies of the blood platelets of men and animals contain several electrolytes such as $\mathrm{Na}, \mathrm{Mg}, \mathrm{P}, \mathrm{S}, \mathrm{Cl}, \mathrm{K}$, Ca when fixed either by chemical fixation or cryofixation followed by cryo-sectioning, freeze-drying and quantified by XMA (Takaya, 1975). It was found that the platelet dense bodies of normal human and monkeys contained high concentrations of $\mathrm{P}$ and $\mathrm{Ca}$ with small amount of $\mathrm{Mg}$ (Takaya, 1984). To the contrary, the dense bodies of several normal experimental animals such as rat, mouse, guinea pig, rabbit, hamster, dog and cat contained high concentrations of $\mathrm{Mg}$ as well as $\mathrm{P}$ and $\mathrm{Ca}$ (Takaya, 1984). However, it is worthy of notice that the dense bodies of human patients suffering from chronic myelogenous leukemia and atopic dermatitis revealed that higher concentrations of $\mathrm{Mg}$ as well as $\mathrm{P}$ and Ca similarly to rat and mouse (Takaya et al., 1994).

\section{Calcium in peritoneal mast cells}

Mast cells are widely found in the loose connective tissues in various organs as well as in the serous exudate in the peritoneal cavity of most mammals. We had previously demonstrated intracellular localization of a synthetic anti-allergic drug, tranilast, in the peritoneal mast cells of Wistar rats by means of radioautography (Nagata et al., 1986). As was demonstrated by light and electron microscopic radioautography, accumulation of silver grains over mast cell granules suggested the inhibition of degranulation of mast cells for anti-allergic reaction (Nagata et al., 1986a'; Nishigaki et al., 1987, 1990). From these results, it was presumed that this agent might interfere with the calcium (Ca) influx resulting in the histamine release in allergic reaction.

In order to clarify the relationship between the mast cell granules and intracellular Ca localization, we detected the intracellular distribution of $\mathrm{Ca}$ ions in mast cells in relation to granules (Nagata, 2000a). As the intracellular Ca sites, we set up 5 areas around a granule in mast cell cytoplasm which were cryo-fixed and freeze-dried (Fig. $2 \mathrm{~F}$ ). The 5 points were designated as area No. 1, 2, 3, 4 and 5 as is shown in Figure 31A. The area No. 1 is the center of a granule, while No. 2 is the midpoint between the center of the granule and the limiting membrane of the granule, No. 3 is the limiting membrane of the granule, No. 4 is the midpoint between the limiting membrane of the granule and the cytoplasmic ground substance surrounding the granule, and No. 5 is the midpoint in the ground substance between the two granules. We calculated the mean peak counts of $\mathrm{Ca}-\mathrm{K} \alpha$ and background counts at the 5 points in 10 mast cells sectioned at $0.4 \mu \mathrm{m}$ at accelerating voltage of $300 \mathrm{kV}$ (Fig. 15). The results are shown in Figure 31B, which depicts the transitional curves of $\mathrm{P} / \mathrm{B}$ ratios obtained from 5 points of mast cell granules. The maximum was found at the point No. 1 , that is the center of the granule. From these results, it was demonstrated that highest concentration of calcium ions around the granules was found at the center of the granule and it was speculated that the higher concentration of calcium ions inside the granules inhibited the discharge of the granule contents (Nagata, 2001º).

\section{The spleen}

Spleen is one of the blood cell forming organs and contains various mature and immature blood cells. We first studied the acid phosphatase activity in the spleen by means of cerium substrate method, then we studied the cerium (Ce) localization by XMA.

\section{Cerium in macrophages in the spleen}

The acid phosphatase activity of splenic macrophages and reticular cells were demonstrated by means of cerium substrate method (Olea, 1991; Olea \& Nagata, 1991, 1992). Electron dense deposits were observed in lysosomes of macrophages and reticular cells in the splenic tissues (Fig. 2B). By X-ray microanalysis in TEM mode, with beam currents from 2 to 8 nano ampere and the accelerating voltages from 100, 200, 300, 350, and $400 \mathrm{kV}$ using a microprobe from 1 to $2 \mu \mathrm{m}$ in diameter, the localization of cerium 
Figure 30. Transitional changes of $\mathrm{P} / \mathrm{B}$ ratios of $\mathrm{Al}$ spectra obtained from the lysosomes (A) and nuclei (B) of convoluted tubule cells of adult mice administered orally with $\mathrm{Al}$ for 1-17 weeks. From Kametani et al. (2003).
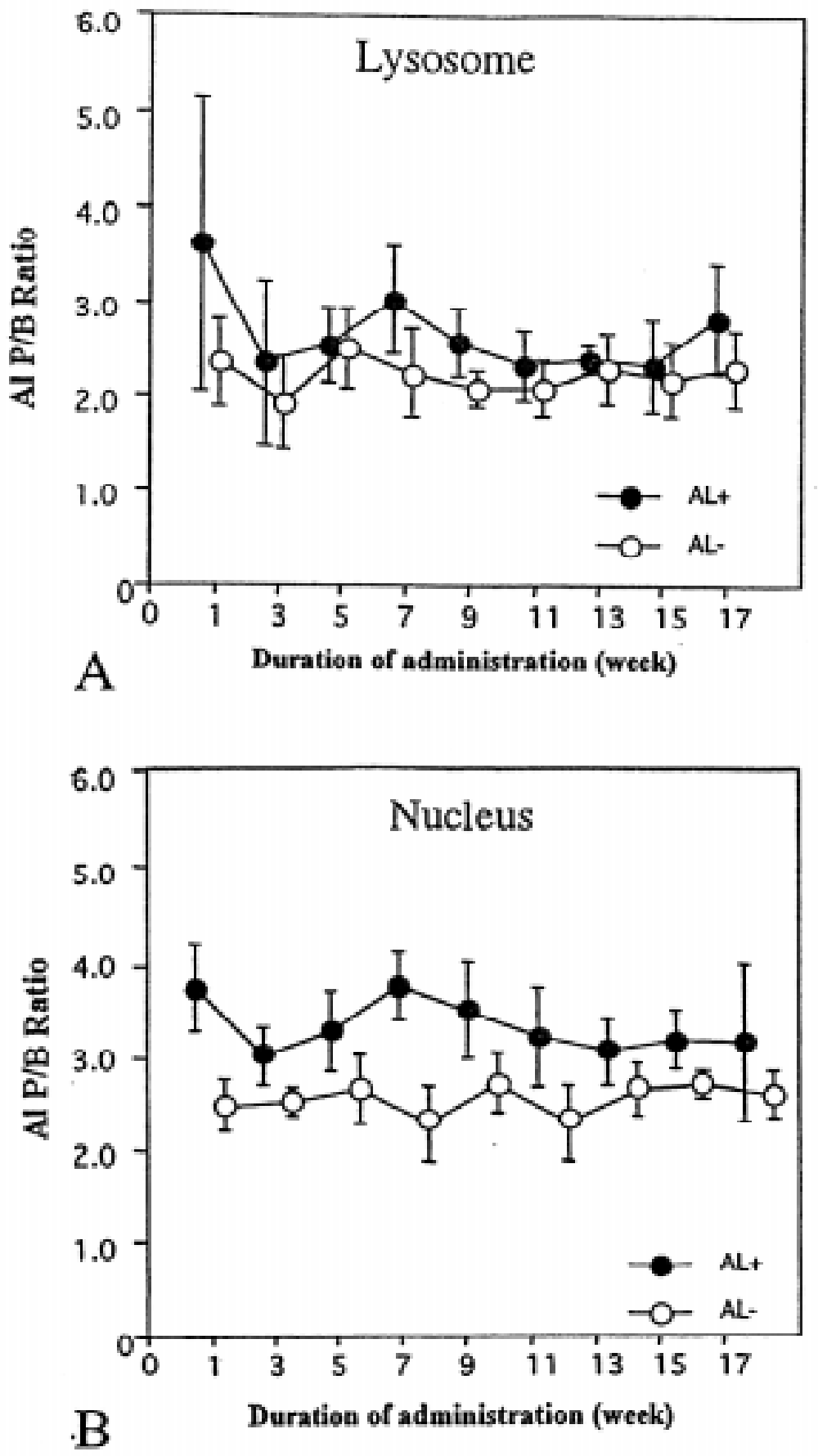

deposits was confirmed with two peaks at 4.84 and $5.26 \mathrm{keV}$, respectively (Fig. 5). These spectra did not interfere with the osmium line at $1.914 \mathrm{keV}$. When the cerium spectra were observed by changing the accelerating voltages at $100,200,300$ and $400 \mathrm{kV}$, the intensities of the peaks decreased with increasing accelerating voltages from 100 to 400 . On the other hand, the background also decreased with the changes of accelerating voltages (Olea, 1991). However, the average peak to background ratios (P/B) counted at 100 , 200, 300 and $400 \mathrm{kV}$ increased from 100 to $400 \mathrm{kV}$ (Fig. 6) similarly to Ag. Therefore, XMA for quantifying cerium deposits showing acid phosphatase activity in lysosomes of both the macrophages in the spleens in several groups of aging mice from newborn day 1 to 10 months were carried out using the accelerating voltage at $400 \mathrm{kV}$ (Olea \& Nagata, 1992). The X-ray spectrum obtained from the lysosome showing the Ce peak at 4.84keV (Fig. 32A) was used for quantitative analysis. Other peaks are $\mathrm{Fe}, \mathrm{Ca}, \mathrm{Os}$ and $\mathrm{Cu}$, which should be due to the reabsorbed degradation products of hemoglobin, fixative and grid meshes, respectively (Olea et al., 1991). It was found that the intensity of AcPase activity as demonstrated by the 
Figure 31. Diagrams showing the concentrations of $\mathrm{Ca}$ in rat mast cell granules. The mast ells from rat peritoneal exudate which were quickly frozen, freezesubstituted, embedded in Epon, drysectioned, observed by JEOL-JEM 4000EX TEM with TN-5400 EDX for Xray microanalysis as shown in Figs. 2F, 13, 14,15 and $\mathrm{P} / \mathrm{B}$ ratios were calculated. A: Diagram showing 5 areas between the granule and surrounding cytoplasm of a mast cell. 1. Center of the granule; 2 . The midpoint between the center and the membrane of the granule; 3 . The point on the limiting membrane of the granule; 4 . The midpoint between the limiting membrane of the granule and the cytoplasmic ground substance; 5 . The midpoint in the cytoplasm between the two granules. $\mathrm{B}$ : Transitional curve of $\mathrm{P} / \mathrm{B}$ ratios in relation to the intracellular localization between the granules and surrounding cytoplasm. From Nagata $\left(2001^{\mathrm{c}}\right)$.
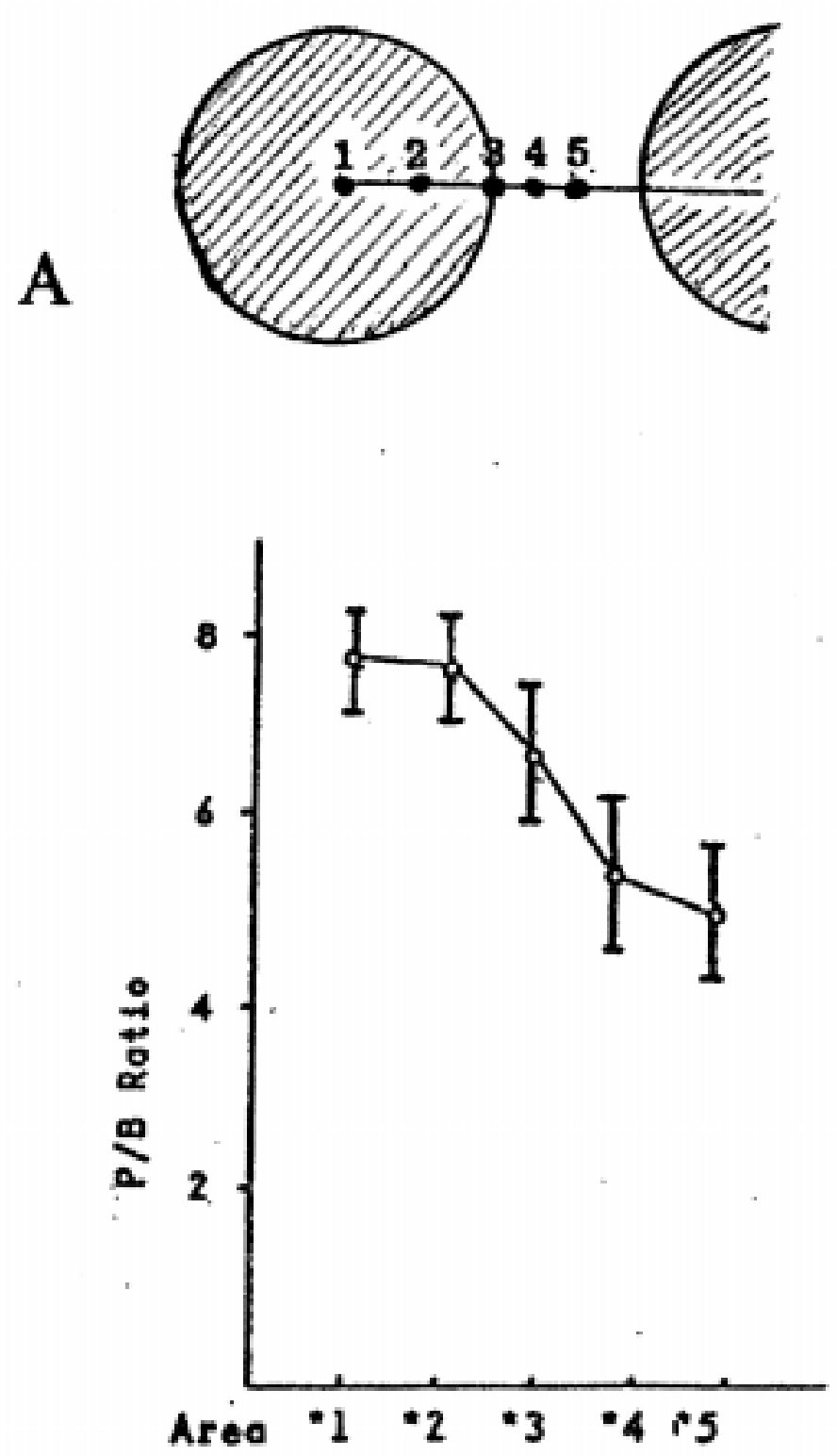

number and size of lysosomes measured on photographs (Fig. 2A) and the intensity of Ce peak (Fig. 32B,C) parallelly increased from postnatal day 1 and decreased from week 1 to month 10 due to aging in the spleen (Olea \& Nagata, 1992) similarly to the kidney (Olea et al., 1991). These results demonstrated that aging changes of AcPase activity as quantified by XMA was related to the development and aging of animals.

\section{Gadolinium in the spleen}

Gadolinium $(\mathrm{Gd})$ accumulation in the spleens of rats were studied by XMA under experimental conditions (Spencer et al., 1997). Groups of 10 male and 10 female Sprague-Dawley rats were given a single intravenous injection of gadolinium chloride solution at dosages of 0 (saline vehicle), $0.07,0.14$, and $0.35 \mathrm{mmol} / \mathrm{kg}$ and the spleens were studied at $48 \mathrm{hr}$ or 14 days postdose by XMA. Major lesions related to gadolinium chloride administration consisted of mineral deposition in capillary beds (particularly lung and kidney), phagocytosis of mineral by the mononuclear phagocytic system, hepatocellular and splenic necrosis followed by dystrophic mineralization. Electron microscopy and XMA of the spleen revealed electron-dense deposits in splenic macrophages composed of gadolinium, calcium, and phosphate. 

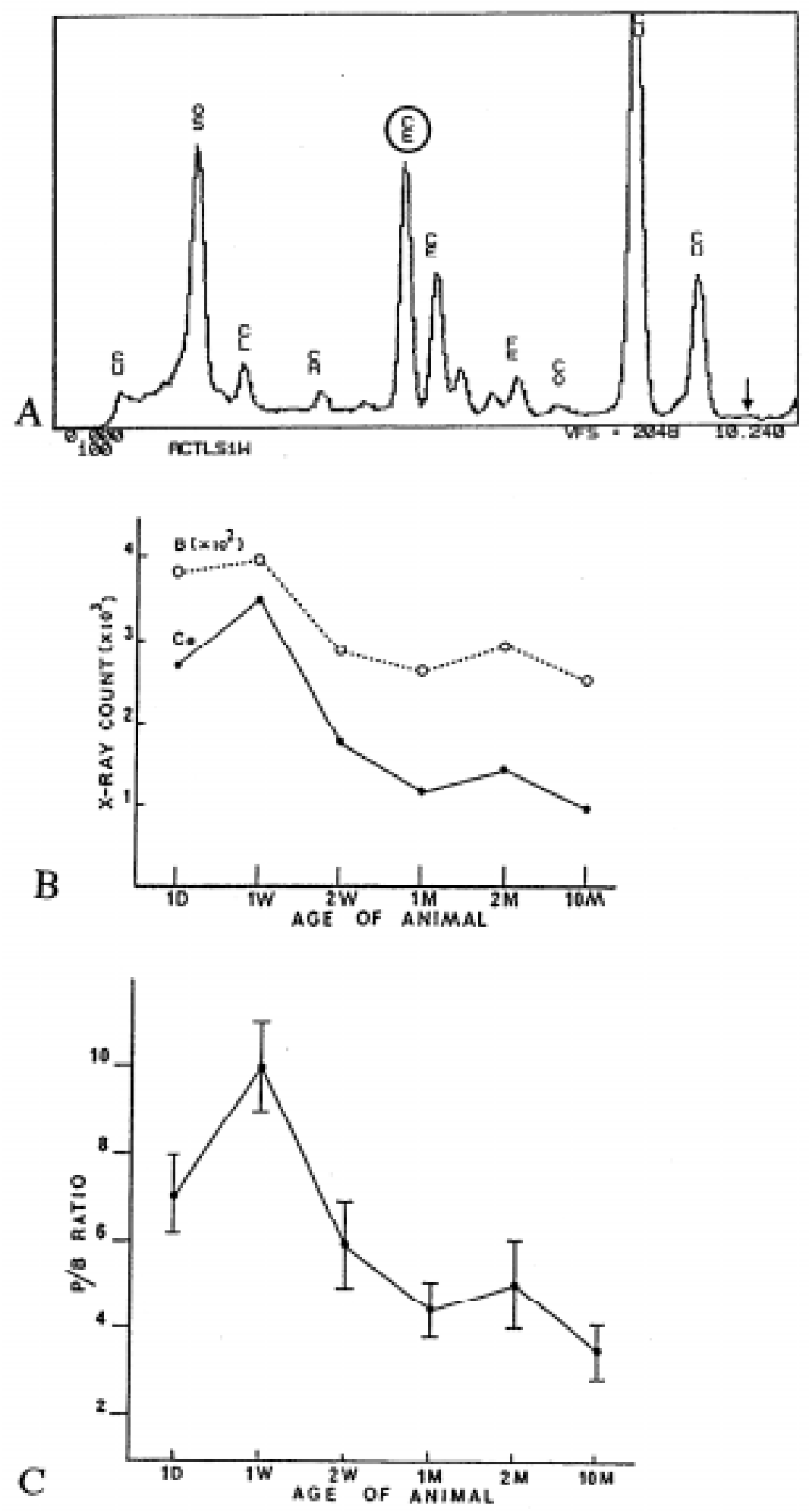

Figure 32. Graphs showing the aging changes of spleen cells of mice at various ages, demonstrating acid phosphatase activities with Ce substrate method as shown in Figure 2B. A: X-ray spectrum obtained from a lysosome of a mouse at postnatal week 1 observed at accelerating voltage of $300 \mathrm{kV}$. The main spectral line of cerium was determined at $\mathrm{La}=4.84 \mathrm{keV}$. The arrow indicates the point at which the background spectrum was determined. B: The transitional curves of average X-ray count of cerium peaks (Ce) and background count (B) plotted against the age of animals. The peak counts were plotted with the magnification of 103, while the background counts were plotted with the magnification of 102. If we plot the both counts with the same magnification, we can not compare the 2 transitional curves. C: Transitional curve demonstrating the relation between the $\mathrm{P} / \mathrm{B}$ ratios of AcPase activity (abscissa) and the aging of animals (ordinate). From Olea et al. (1991). 


\section{The Nervous System}

The nervous system consists of the central nervous system and the peripheral nervous system. We are interested in $\mathrm{Al}$ accumulation in the brains related to $\mathrm{Al}$ accumulations in other organs. However, we have not completed the study yet. Thus, a brief review on some literature will be made.

\section{Electrolytes in the cerebral cortex}

Takaya (1982) and Takaya and Masuda (1991) reported on the application of $\mathrm{X}$-ray microanalysis to the mouse cerebral cortex in unstained, fresh air-dried spreads and fresh frozen dried ultrathin cryo-sections which were dried with nitrogen gas flow where several electrolytes were detected by XMA at $200 \mathrm{kV}$.

\section{Calcium in the brain}

In the brains of rats, calcification associated with excitotoxicity was proposed to play a protective role, whereas in human brains, nonartherosclerotic calcification was present in several pathological conditions without any clear significance. To determine if calcification can be viewed as a protective step of calcium $(\mathrm{Ca})$ homeostasis during chronic and acute neuronal suffering, cerebral cortex and hippocampus of patients with Alzheimer's disease, vascular dementia and neonatal hypoxia-ischemia were investigated (Ramonet et al., 2002). To investigate the human specificity, these two areas were also studied in dogs with established cognitive deficits. In all groups, calcium precipitates were observed in the cerebral parenchyma associated with neuronal damage. The cerebral cortex presented a higher degree of calcification than the hippocampus. The neonatal hypoxia-ischemia group was characterized by a higher degree of calcification, whereas the groups with lowest calcification were the Alzheimer's patients and dogs. In the precipitates, as shown by Xray microanalysis, $\mathrm{Ca}$ was mainly associated with phosphorus in a form that resembled hydroxyapatites. Thus, intracellular Ca concentration associated with neuronal suffering may reduce the energy extrusion.

\section{Aluminum in the brain}

As already mentioned previously, aluminum (Al) has received attention as a neurotoxic factor in dialysis encephalopacy and neurological disorders such as Alzheimer's disease (Yokel, 2000). Although several papers were published denying the links between the $\mathrm{Al}$ and the encephalopacy, $\mathrm{Al}$ is still suspected to cause dialysis encephalopathy or dialysis osteosis due to dialysis treatment of patients suffering from renal insufficiency. Although $\mathrm{Al}$ is unquestionably neurotoxic in both experimental animals and certain human diseases, the question as to whether $\mathrm{Al}$ presents a health hazard to humans as a contributing factor to Alzheimer's disease is still the subject of debate. Considerable epidemiological evidence was reported that $\mathrm{Al}$ may play a role in the etiology or pathogenesis of Alzheimer's diseases (Flatten, 2001). One of the reasons for this controversy may be the methods chosen for quantitation and standardization of $\mathrm{Al}$ measurements. Recent report suggested that X-ray microanalysis is a useful tool to demonstrate $\mathrm{Al}$ localization in nerve cells of cerebral cortex in encephalopathy patients who had chronic renal failure and $\mathrm{Al}$ gel treatment for a long period (Shirabe et al., 2002). Yokel and McNamara (2001) reviewed the Al toxicokinetics in men using $\mathrm{RI}{ }_{26} \mathrm{Al}$ analyzed by accelerator mass spectrometry. Oral $\mathrm{Al}$ availability from water appears to be about $0.3 \%$, from food, industrial and medicinal exposure and perhaps antiperspirant use can increase absorbed Al. Al distributes unequally to all tissues.

We first studied several adult ddY mice 4 weeks after birth which were intraperitoneally injected with aluminum chloride and the duodenum, the liver, the kidney and the cerebral cortex tissues were examined by both aluminon staining and $\mathrm{X}$-ray microanalysis at an accelerating voltage of 300kV (Kametani, 2002). By light 
microscopic aluminon staining, no positive reaction was observed in these tissues. However, by transmission electron microscopy, many lysosomes with high electron density were observed in the lysosomes of the absorptive epithelial cells, the wandering cells in the duodenal mucosa, the hepatocytes and the proximal convoluted tubule cells of the kidney, which resulted in the spectra showing high $\mathrm{Al}$ peaks by X-ray microanalysis (Fig. 25). However, no Al peak was detected in neuronal cells nor in glial cells in the cerebral cortex. Then, we studied 9 groups of ddY mice at various aging stages, each consisting of 3 littermates, from postnatal week 1, 3, 5, 7, 9, 11, 13, 15 and 17. They were administered orally with deionized water containing $2 \%$ aluminum chloride $\left(\mathrm{AlCl}_{3}\right)$, ad libitum immediately after birth until 17 weeks. As normal control animals, some animals were administered with only deionized water without aluminum chloride. The animals were sacrificed at each administration period and the duodenum, the liver, the kidney and the cerebral tissues were fixed only in $2.5 \%$ glutaraldehyde in phosphate buffer, dehydrated in ethanol, substituted in propylene oxide and embedded in Technovit VL7200 resin (Meiwa Co., Tokyo, Japan). Thick sections at $1.0 \mu \mathrm{m}$ were cut, mounted on nylon grids, stained with only uranyl acetate, observed and analyzed in a JEOL JEM-4000EX TEM equipped with a TN-5400 EDX microanalyzer (Tracor-Northern, Wisconsin, USA) at an accelerating voltage of $300 \mathrm{kV}$. The results showed that many high electron dense lysosomes were observed in the duodenum, the liver and the proximal convoluted cells of the $\mathrm{Al}$ administered mice which revealed $\mathrm{Al}$ peaks by XMA. However, no $\mathrm{Al}$ peak was detected in the cerebral cells (Kametani et al., 2003). Thus, further study on the neuronal and glial cells in the cerebral tissues by XMA under other experimental conditions should be required to clarify this point.

\section{The Sensory System}

The sensory system of mammals consists of the eye, the ear, the tongue, the nose and the skin. We have not studied these organs by XMA. Several papers are available on the eye and the skin by means of CTEM, which will be reviewed briefly.

\section{The eye}

Yoshizuka et al. (1990) reported Cd toxicity to the cornea of pregnant rats using XMA. In in-vivo experiments, severe corneal edema occurred in pregnant dams that received intraperitoneal injections of cadmium sulphate for 4 days during gestation, but not in nonpregnant rats. Prominent swelling of mitochondria and the occurrence of intraand inter-cellular vacuoles in the corneal endothelium were observed only in pregnant dams. In in-vitro experiments, electron dense deposits consisting of cadmium-oxine complexes were preferentially found in swollen mitochondria of the endothelial cells. Cadmium peaks were obtained from these deposits with XMA. These data suggest that the corneal edema observed after administration of cadmium may imply the disturbance of pump function and barrier function of the corneal endothelium due to the primary toxic effects of this metal on mitochondria (Yoshizaki et al., 1990).

\section{The skin}

The skin covers the surface of the animal body, consisting of 3 layers, i.e., the epidermis, the dermis and the hypodermis. The skin possesses accessories such as the hairs, the nails and the glands. Several papers are available dealing with XMA of the epidermis and the sweat glands.

\section{The epidermis}

The epidermal cells of vertebrates consist of 5 layers of keratin-producing cells (keratinocytes), i.e., the stratum germinativum, spinosum, granulosum, lucidum and corneum. These cells have been the subjects of cytochemical analysis by many scientists 
using various techniques. Alibardi (2002) recently demonstrated that there are 2 modalities of keratinization present in lizard epidermis: alpha (soft-pliable corneous layers) and beta (hard and inflexible corneous layers) by XMA. While beta-keratinization is probably due to the synthesis of a new (beta)-keratin gene product, alpha keratinization resembles in part that of mammalian epidermis. The goal of this study was to test whether a sulfur-rich molecule similar to the mammalian corneous cell envelope protein loricrin can also be present in lizard epidermis. This was done using $\mathrm{X}$-ray microanalysis and immunocytochemical methods. In the epidermis of the lizard Podarcis muralis small (0.10.3 micron) to large (1-5 micron) keratohyalin-like granules (KHLGs) were produced in alpha-keratinizing cells, especially in the clear layer. Small granules contained sulfur and showed weak filaggrin-like and stronger loricrin-like immunoreactivities. The latter was also present in keratinizing alpha-layers but was absent in the beta layers. Large granules in the clear layer derived from the aggregation of the small granules with other components, including lipid material. These large granules showed some loricrin-like immunoreactivity and contained sulfur and phosphorous, histidine, but not filaggrin-like immunoreactivity. It was suggested that phosphorous was derived from their phospholipid component. The study showed that the modality of alpha-keratinization of lizard epidermis resembled that of mammals and suggested that the basic molecular mechanisms of keratin aggregation and formation of the corneous cell envelope were already present in the therapsid line of reptiles from which mammals evolved.

\section{The sweat glands}

A few papers are available dealing with the sweat glands. Saga (2002) reviewed the basic structure and the physiological function of human sweat glands. Histochemical and cytochemical techniques greatly contributed the elucidation of the ionic mechanism of sweat secretion. XMA using freeze-dried cryo-sections clarified the level of $\mathrm{Na}, \mathrm{K}$, and $\mathrm{Cl}$ in each secretory cell of the human sweat gland. Enzyme cytochemistry, immunohistochemistry and radioautography elucidated the localization of $\mathrm{Na}$, K-ATPase. These data support the idea that human eccrine sweat is produced by the model of N-K$2 \mathrm{Cl}$ cotransport. Cationic colloidal gold localized anionic sites on histological sections. Human eccrine and apocrine sweat glands showed completely different localization and enzyme sensitivity of anionic sites studied with cationic gold. Human sweat glands have many immunohistochemical markers. Some of them are specific to apocrine sweat glands, although many of them stain both eccrine and apocrine sweat glands.

\section{Concluding Remarks}

For the purpose of analyzing various kinds of components in biological specimens, electron microscopic radioautography is the best method to demonstrate the intracellular localization of incorporation sites and the quantity of incorporation of various kinds of organic and inorganic compounds which can be labeled with radioactive substances. On the other hand, X-ray microanalysis is the best method to qualify and quantify the total basic elements contained in biological specimens.

We have developed principles and techniques to quantify various elements in biological specimens by means of intermediate high voltage electron microscopy using semi-thin sections which contain much more elements than ultrathin sections. The basic elements detected in the experimental animals and human tissues can be classified into 3 categories, (1) endproducts of histochemical reactions such as silver grains (Ag) in radioautographs, $\mathrm{Ce}$ in the deposits demonstrating phosphatase activity or gold particles $(\mathrm{Au})$ in immunostaining, (2) endogenous trace elements such as $\mathrm{S}, \mathrm{Cl}, \mathrm{Ca}$ and $\mathrm{Zn}$ which originally exist in karyoplasm, cytoplasm or cell organelles of various cells and intracellular matrix after conventional chemical fixation or cryo-fixation, and (3) absorbed elements from gastrointestinal or respiratory tracts such as Al.

From our results, it was shown that the $\mathrm{X}$-ray microanalysis using intermediate high voltage transmission electron microscopy at accelerating voltages of around 300 or 
$400 \mathrm{kV}$ was very useful resulting in high $\mathrm{P} / \mathrm{B}$ ratios for quantifying these trace elements in biological specimens. These methodologies should be used in microanalysis of various compounds and elements in various cells and tissues of men and animals.

\section{Acknowledgments}

Most part of the studies cited in this review article which were carried out in our laboratory were supported by the Grants-in-Aids for Scientific Research from the Ministry of Education, Science, Sports and Culture of Japan given to the author during the period when the author worked at the Department of Anatomy and Cell Biology, Shinshu University School of Medicine, Matsumoto, from 1956 to 1996, as well as the Grants for Promotion of Characteristic Research and Education from the Japan Foundation for Promotion of Private Schools during the period when the author worked at the Department of Anatomy and Physiology, Nagano Women's Jr. College, Nagano, from 1997 to 2002.

The author is also grateful to many collaborators during the period from 1974 to 2003, while the author worked together with them as Professor of Anatomy and Chair (1974-1996) at Department of Anatomy and Cell Biology, and Director (1975-1990) of Central Research Laboratory, Shinshu University School of Medicine, as well as Professor of Anatomy and Physiology at Nagano Women's Jr. College (1997-2002), whose names are listed as the co-authored references at the end of this article, especially to the late Dr. Ryouji Ichikawa, Electron Microscopy Unit at the Central Research Laboratory, Shinshu University School of Medicine and Dr. Kiyokazu Kametani, Research Center for Instrumental Analysis, Shinshu University.

\section{References}

Alfrey AC, LeGendre GR, Kachny WD. The dialysis encephalopathy syndrome. Possible aluminum intoxication. New Engl J Med 1976;294:184-8.

Alibardi L. Loricrin-like immunoreactivity during keratinization in lizard epidermis. J Morphol 2002;254:132-8.

Bando Y. Microstructure analysis of advanced ceramics by high-resolution analytical transmission electron microscopy. J Electron Microsc 1995;44:115-23.

Bando Y, Matsui Y, Uemura Y. The usefulness of a $400 \mathrm{kV}$ high-resolution analytical electron microscope. Ultramicroscopy 1985;18:117-24.

Bataineh ZM, Bani-Hani IH, Al-Alami JR. Zinc in normal and pathological human prostate gland. Saudi Med J 2002;23:218- 20.

Bennet G, Leblond CP, Haddad A. Migration of glycoproteins from the Golgi apparatus to the surface of various cell types as shown by radioautography after labelled fucose injection into rats. J Cell Biol 1974;60:258- 70 .

Berry J-P. The role of lysosomes in the selective concentration of mineral elements. A microanalytical study. Cell Mol Biol 1996;42:395-422.

Buckley IK, Porter KR. Electron microscopy of critical point dried whole cultured cells. J Microscopy 1975;104:107-20.

Buerke U, Schneider J, Muller KM, Woitowitz HJ. Interstitial pulmonary siderofibrosis: requirements for acceptance as new occupational disease. Pneumologie 2003;57:914.

Castaing R. La microanalyse par sonde électronique. Adv Electr Phys 1960;13: 317-86.

Chandler JA. X-ray microanalysis in the electron microscope. In: Glauert A M (ed). Practical Methods in Electron Microscopy. Amsterdan: North-Holland Publishing Co.; 1976.

Condron RJ, Marshall AT. X-ray microanalytical investigation of the response of chicken proximal tubule cells to infection with avian infectious bronchitis virus. J Submicrosc Cytol Pathol 1991;23:159- 65.

Cooper RR, Misol S : Tendon and ligament insertion. J Bone Joint Surg 1970;52A:1-20.

Cui H, Gao F, Nagata T. Light microscopic radioautographic study on protein synthesis in perinatal mouse cornea. Acta Histochem Cytochem 2000;33:31-7. 
Edelmann L. Subcellular distribution of potassium in striated muscles. Scanning Electron Microsc 1984;2:875-88.

Faa G, Terlizzo M, Gerosa C, Congiu T, Angelucci E. Patterns of iron distribution in liver cells in beta-thalassemia studied by X-ray microanalysis. Haematologica 2002;87:47984.

Flatten TP. Aluminium as a risk factor in Alzheimer's disease, with emphasis on drinking water. Brain Res Bull 2001;55:187-96.

Flatten TP, Alfrey AC, Birchall JD, Savory J, Yokel RA. Status and future concerns of clinical and environmental aluminum toxicology. J Toxicol Environ Health 1996;48:527-41.

Gao F, Jin C, Ma H, Sun L, Nagata T. Ultrastructural and radioautographic studies on DNA synthesis in Leydig cells of aging mouse testis. Cell Mol Biol 1995;41:151-60.

Gao F, Ma H, Sun L, Jin C, Nagata T. Electron microscopic radioautographic study on the nucleic acid and protein synthesis in the aging mouse testis. Med Electron Microsc 1994;27:360-2.

Gorustovich A, Rosenbusch M, Guglielmotti MB. Characterization of bone around titanium implants and bioactive glass particles: an experimental study in rats. Internat J Oral Maxillofac Implants 2002;17:644-50.

Gunarso W, Gao F, Cui H, Ma H, Nagata T. A light and electron microscopic radioautographic study on RNA synthesis in the retina of chick embryo. Acta Histochem 1996;98:300-22.

Gupta B L. The relationship of mucoid substances and ion and water transport, with new data on intestinal goblet cells and a model for gastric secretion. Symp Soc Exp Biol 1989;43:81-110.

Hodges GM, Muir MD. Quantitative evaluation of autoradiographs in X-ray spectroscopy. J Microsc 1975;104:173-8.

Ichikawa R, Hayashi K, Nagata T. X-ray microanalysis of the secretory granules in the intestinal goblet cells of aging mice. Med Electron Microsc 1994;27:337-9.

Ichikawa R, Maruyama M, Nagata T. Quantification of zinc in mouse digestive epithelial cells by X-ray microanalysis. J Electron Microsc 1988;37:196-7.

Ito M, Nagata T. Electron microscopic radioautographic studies on DNA synthesis and the ultrastructure of aging mouse adrenal glands. Med Electron Microsc 1996;29:14552.

Izutsu KT , Cantino ME, Johnson DE. A review of electron probe X-ray microanalysis studied of salivary gland cells. Microsc Res Tech 1994;27:71-9.

Jaworski R C, Boadle R, Greg J, Cocks P. Peritoneal "melanosis" associated with a ruptured ovarian dermoid cyst: report of a case with electron-probe energy dispersive X-ray analysis. Internat J Gynecol Pathol 2001;20:386-9.

Jin C, Nagata T. Light microscopic radioautographic study on DNA synthesis in cecal epithelial cells of aging mice. J Histochem Cytochem 1995a;43:1223-8.

Jin C, Nagata T. Electron microscopic radioautographic study on DNA synthesis in cecal epithelial cells of aging mice. Med Electron Microsc 1995b;28:71-5.

Jonas L, Fulda G, Kroning G, Merkord J, Nizze H. Electron microscopic detection of tin accumulation in biliopancreatic concrements after induction of chronic pancreatitis in rats by di-n-butyltin dichloride. Ultrastruct Pathol 2002;26:89-98.

Joukura K, Usuda N, Nagata T. Quantitative studies on the aging changes of glycoconjugates synthesis in mouse kidney. Acta Histochem Cytochem 1996;29:5078.

Kametani K. Detection of aluminum by energy dispersive X-ray microanalysis at high accelerating voltages with semi-thin sections of biological sample. J Electron Microsc 2002;51;265-74.

Kametani K, Ichikawa R, Nagata T. X-ray microanalysis of the secretory granules in goblet cells of mouse intestinal tracts with aging change. Med Electron Microsc 1998;31:107-14.

Kametani K, Suzuki K, Nagata T. X-ray microanalysis at high accelerating voltage detecting 
$\mathrm{Al}$ accumulation in mouse kidney after short-term administration. Acta Histochem Cytochem 2003;36:221-30.

Kodaka T, Debari K. Scanning electron microscopy and energy- dispersive X-ray microanalysis studies of afibrillar cementum and cementicle-like structures in human teeth. J Electron Microsc (Tokyo) 2002;51:327-35

Kramer J H, Lightfoot F G, Weglicki W B. Cardiac tissue iron: effects on post-ischemic function and free radical production, and its possible role during preconditioning. Mol Biol 2000;46:1313-27.

Kyriacou K, Michaelides Y, Senkus R, Simamonian K, Pavlides N, Antoniades L, Zambartas C. Ultrastructural pathology of the heart in patients with beta-thalassaemia major. Ultrastruct Pathol 2000;24:75-81.

Lacy ER. Functional morphology of large intestine. In: Field M, Frizzell RD (ed). Handbook of Physiology, Section 6. The Gastrointestinal System. IV. Intestinal Absorption and Secretion. Bethesda: Amer Physiol Soc; 1991.

Langford RJ, Frame JW: Surface analysis of titanium maxillofacial plates and screws retrieved from patients. Internat J Oral Maxillofac Surg 2002;31:511-18.

Lian Y, Ito M, Nagata T. Light and electron microscopic radioautographic study on the RNA synthesis in aging mouse adrenal gland. Acta Anat Nippon 1999;74:291-300.

Liu Y, Ling YP, Yu Z, Wu ZQ, Zhong CS. The relationship between the chromaffin granule number and the granule calcium content in the adrenal medulla of restrained rats. Sheng Li Xue Bao 2000;52:5-9.

$\mathrm{Ma} \mathrm{H}$, Nagata T. Electron microscopic radioautographic study on DNA synthesis of the livers in aging mouse. Med Electron Microsc 1988;21:335-43

Ma H, Nagata T. Electron microscopic radioautographic Study on RNA synthesis in the livers of aging mice by means of electron microscopic radioautography. Cell Mol Biol 1990;36:589-600.

Maloney JA, Wheeler-Clark ES. Reduction in sarcoplasmic reticulum $\mathrm{Ca}^{2+}$-ATPase activity contributes to age-related changes in the calcium content and relaxation rate of rabbit aortic smooth muscle. J Hypertens 1996;14:65-74 .

Marchlewicz M. Effectiveness of blood-testis and blood-epididymis barriers for lead. Ann Acad Med Stetin 1994;40:37-51.

Martin R B. The chemistry of aluminum as related to biology and medicine. Clin Chem 1986;32:1797-806.

Martins R C, Bahia M G, Buono V T. Surface analysis of profile instruments by scanning electron microscopy and X-ray energy-dispersive spectroscopy: a preliminary study. Int Endod J 2002;35:848-53.

Maruyama M. Histochemical studies on glycoprotein synthesis in the colonic goblet cells of mice. Shinshu Med J 1991;39:467-78.

Maruyama M, Nagata T. X-ray microanalysis with a high voltage electron microscope quantifying sulfur in colonic goblet cells of aging mice. Med Electron Microsc 1987;20:678- 9.

Mohr W, Gorz EZ. Morphogenesis of media calcinosis in Monckeberg disease. Light microscopy, scanning electron microscopy and roentgen microanalysis findings. $\mathrm{Z}$ Kardiol 2002;91:557-67.

Mohr W, Gorz EZ. Calcifications in temporal arteries - their morphogenesis in comparison to physiological osteogenesis. Z Kardiol 2003;92:60-72.

Momose Y, Naito J, Suzawa H, Kanzawa M, Nagata T. Radioautographic study on the intracellular localization of bezafibrate in cultured rat hepatocytes. Acta Histochem Cytochem 1995;28:61-6.

Mörk A C , Zhang A, Martinez J R, Roomans G M. Chloride secretion in the submandibular gland of adult and early postnatal rats studied by X-ray microanalysis. Histochem Cell Biol 1996;105:297-303.

Morita T. Radioautographic study on the aging change of ${ }_{3} \mathrm{H}$-glucosamine uptake in mouse ileum. Cell Mol Biol 1993;35:347-55.

Morita T, Usuda N, Hanai T, Nagata T. Changes of colon epithelium proliferation due to 
individual aging with PCNA/cyclin immunostaining comparing with ${ }_{3} \mathrm{H}$-thymidine radioautography. Histochemistry 1993;101:13-20.

Murata F, Yoshida K, Ohno S, Nagata T. Mucosubstances of rabbit granulocytes studied by means of electron-microscopic radioautography and X-ray microanalysis. Histochemistry 1979;61:139-50.

Nagata T. Chapter 3. Application of microspectrophotometry to various substances. Introduction to Microspectrophotometry. In: Isaka S, Nagata T, Inui N (ed.). Introduction to Microspectrophotometry. Tokyo: Olympus Co.; 1972.

Nagata T. Image analysis on electron microscopic radioautograms I. Sorts of available image analyzers and measurements with fully automated apparatuses. The Cell (Tokyo) $1985^{\mathrm{a}} ; 17: 255-9$.

Nagata T. Image analysis on electron microscopic radioautograms II. Measurements with semi-automated apparatuses and X-ray microanalyzers. The Cell (Tokyo) 1985'b; $17: 303$ 6.

Nagata T. Application of high voltage electron microscopy to bio-medical research. The Cell (Tokyo) 1985c;17:521-4.

Nagata T. X-ray microanalysis of biological specimens with $400 \mathrm{kV}$ electron microscopes. J Electron Microsc 1988;37:95-6.

Nagata T. Electron microscopic radioautography and analytical electron microscopy. Med Electron Microsc 1991;24:441-2.

Nagata T. Radiolabeling of soluble and insoluble compounds as demonstrated by light and electron microscopy. In: Wegmann R J, Wegmann M (ed). Recent advances in cellular and molecular biology . Vol. 6. Molecular biology of nucleus, organelles and cell movement. Leuven: Peeters Press; 1992;9-21.

Nagata T. Quantitative analysis of histochemical reactions: Image analysis of light and electron microscopic radioautograms. Acta Histochem Cytochem 1993;26:281-91.

Nagata T. Introductory remarks to advances in cytochemistry with physical methods. Acta Histochem Cytochem 1994; $27: 469-70$.

Nagata T. Electron microscopic radioautography with cryo-fixation and dry mounting procedure. Acta Histochem Cytochem 1994할:471-89.

Nagata T. Three-dimensional observation of whole mount cultured cells stained with histochemical reactions by ultrahigh voltage electron microscopy. Cell Mol Biol 1995;41:783-92.

Nagata, T. Morphometry in anatomy: image analysis on fine structure and histochemical reactions with special reference to radioautography. In: Motta P M (ed). New Trends in Microanatomy, Ital J Anat, Editrice IL Sedicesimo, Firenze, 1996a;100(suppl 1):591605.

Nagata T. Introductory remarks to the techniques of radioautography and its application to histochemistry and cytochemistry. Acta Histochem Cytochem 1996 ;29:335- 6.

Nagata T. Three-dimensional observation on whole mount cultured cells and thick sections stained with histochemical reactions by high voltage electron microscopy. In: Motta PM (ed). Recent Advances in Microscopy of Cells, Tissues and Organs, Roma: Antonio Delfino Editore; 1997.

Nagata T. Technique of radioautography for medical and biological research. Braz J Med Biol Res 1998;31:185-95.

Nagata T. Aging changes of macromolecular synthesis in various organ systems as observed by microscopic radioautography after incorporation of radiolabeled precursors. Methods Find Exp Clin Pharmacol 1999;21:683-706.

Nagata T. Biological microanalysis of radiolabeled and unlabeled compounds by radioautography and X-ray microanalysis. Scanning Microsc Internat 2000a;14:on line.

Nagata T. Light microscopic radioautographic study on radiosulfate incorporation into the tracheal cartilage of aging mice. Acta Histochem Cytochem 2000

Nagata T. Techniques and applications of electron microscopic radioautography. In: MahLee MNG (ed). Proc. $7^{\text {th }}$ Asia-Pacific Electron Microsc Conf, Life Sci, Singapore: Times Printers Pte., 2000 $; 68-70$. 
Nagata T. Introductory remarks to workshop 1 "Imaging" 41st Annual Meeting of the Japan Society of Histochemistry and Cytochemistry. Acta Histochem. Cytochem 2001; $34: 151-2$.

Nagata T. Three-dimensional and four-dimensional observation of histochemical and cytochemical specimens by high voltage electron microscopy. Acta Histochem Cytochem 2001' ;34:153-69.

Nagata T. Special cytochemistry in cell biology. In: Jeon KW (ed). International Review of Cytology, Vol 211, Chapter 2, New York: Academic Press, 2001'.

Nagata T. Three-dimensional high voltage electron microscopy of thick biological specimens. Micron 2001d;32:387-404.

Nagata T. Aging changes of macromolecular synthesis in the respiratory organs as revealed by microscopic radioautography. ARBS Ann Rev Biomed Sci 2001 ;3:127-155.

Nagata, T. Radioautographology, general and special. In: W Graumann (ed.). Progress in Histochemistry and Cytochemistry 2002a ;37(2):57-228.

Nagata T. Three-dimensional and four-dimensional studies on cell organelles stained with hitochemical reactions observed by HVEM. In: Engelbrecht J, Sewell T, Witcobm M, Cross R, Richards P (eds). Proc $15^{\text {th }}$ Internat Cong Electron Microsc, Microscopy Society of Southern Africa. Durban: Life Sciences 2002 $; 2: 153-4$.

Nagata T. X-ray microanalysis of biological specimens by high voltage electron microscopy. In: Engelbrecht J, Sewell T, Witcobm M, Cross R, Richards P (ed). Proc 15th Internat. Cong Electron Microsc. Microscopy Society of Southern Africa, Durban, Life Sciences 2002 ${ }^{c}$;2:165-6.

Nagata T. High voltage electron microscopy is useful for X-ray microanalysis. Acta Histochem Cytochem 2002d;35:228-9.

Nagata T. Aging changes of macromolecular synthesis in the digestive organs of mice as revealed by microscopic radioautography and X-ray microanalysis. ARBS Ann Rev Biomed Sci 2002 ; 4:79-132.

Nagata T. The utility value of high voltage electron microscopy for X-ray microanalysis. Acta Histochem Cytochem 2003;36:299-315.

Nagata T, Kametani K. X-ray microanalysis of gold particles in immuno-gold staining by high voltage electron microscopy. Ann Microsc 2004;4: in press.

Nagata,T, Kametani K, Maruyama M. X-ray microanalysis of sulfur in cryo-fixed colonic goblet cells in mice by high voltage electron microscopy. Scanning Microsc Internat 2000c; 14: on line.

Nagata T, Kawahara I. Radioautographic study of the synthesis of sulfomucin in digestive organs of mice. J Trace Microprobe Analysis 1999;17:339-55.

Nagata T, Kawahara I, Usuda N, Maruyama M, Ma H. Radioautographic studies on the glycoconjugate synthesis in the gastrointestinal mucosa of the mouse. In: Ohyama M, Muramatsu T (ed). Glycoconjugate in Medicine. Tokyo: Professional Postgrad Service; $1988^{\text {a }}$.

Nagata T, Maruyama M, Ichikawa R, Usuda N. X-ray microanalysis of biological specimens by high voltage transmission electron microscopy. J Histochem Cytochem 1988b;36:858-9.

Nagata T, Morita T, Kawahara I. Radioautographic studies on radiosulfate incorporation in the digestive organs of mice. Histol Histopathol 1999;14:1-8.

Nagata T, Nishigaki T, Momose Y. Localization of anti-allergic agent in rat mast cells demonstrated by light and electron microscopic radioautography. Acta Histochem Cytochem 1986a;19:669-83.

Nagata T, Usuda N. Image processing of electron microscopic radioautograms in clinical electron microscopy. Med Electron Microsc 1985;18:451-2.

Nagata T, Usuda N. Studies on the nucleic acid synthesis in pancreatic acinar cells of aging mice by means of electron microscopic radioautography. Med Electron Microsc 1986;19:486-7.

Nagata T, Usuda N, Ma H. Electron microscopic radioautograpahy of nucleic acid synthesis in pancreatic acinar cells of prenatal and postnatal aging mice. In: Jap Soc Electron 
Microsc (ed). Proc XI ${ }^{\text {th }}$ Internat Cong Electron Microsc, Kyoto, 1986;3:2281-2.

Nagata T, Usuda N, Ma H. Electron microscopic radioautography of lipid synthesis in pancreatic cells of aging mice. Med Electron Microsc 1990;23:841-2.

Nagata T, Usuda N, Ma H. Image analysis of histochemical quantitation for macromolecular synthesis. J Histochem. Cytochem 1991;38:1080-81.

Nagata T, Usuda N, Maruyama M, Ma H. Quantitative studies on RNA synthesis in pancreatic acinar cells of aging mice as revealed by electron microscopic radioautography. J. Histochem Cytochem 1988c;36:877-78.

Nakamura H, Rose PG, Blumer JL, Reed MD. Acute encephalopahty due to aluminum toxicity successfully treated by combined intravenous deferoxamine and hemodialysis. J Clin Pharmacol 2000;40:296-300.

Navarro C, Ramis A, Sendros S, Bulbena O, Ferrer L, Escolar G. Relationship between gastric levels and antiulcerogenic activity of zinc. Arch Int Pharmacodyn Ther 1990;307:119-29.

Nishigaki T, Momose Y, Nagata T. Light microscopic radioautographic study of the localization of anti-allergic agent, Tranilast, in rat mast cells. Histochem J 1987;19:5336.

Nishigaki T, Momose Y, Nagata T. Electron microscopic radioautographic study of the localization of an anti-allergic agent, tranilast, in rat mast cells. Cell Mol Biol 1990;36:65-71.

Olea MT. An ultrastructural localization of lysosomal acid phosphatase activity in aging mouse spleen: a quantitative X-ray microanalytical study. Acta Histochem Cytochem 1991;24:201-8.

Olea MT, Nagata T. X-ray microanalysis of cerium in mouse spleen cells demonstrating acid phosphatase activity using high voltage electron microscopy. Cell Mol Biol 1991;37:155-63.

Olea MT, Nagata T. Simultaneous localization of ${ }_{3} \mathrm{H}$-thymidine incorporation and acid phosphatase activity in mouse spleen: EM radioautography and cytochemistry. Cell Mol Biol 1992;38:115-22.

Olea MT, Nagata T. Application of high voltage electron microscopy to electron microscopic radioautography: a study on the protein synthesis in aging mouse spleen labeled with ${ }_{3} \mathrm{H}$-leucine. In: Engelbrecht J, Sewell T, Witcobm M, Cross R, Richards P (eds.) Proc $15^{\text {th }}$ Internat Cong Electron Microsc. Durban: Microscopy Society of Southern Africa, Life Sciences 2002;2:159-60.

Olea MT, Ma H, Nagata T. Quantitative assessment of lysosomal size, number and enzyme activity in mouse kidney during maturational development. Cell Mol Biol 1991;37:67985.

Ono S. Electron microscopy and electron probe X-ray microanalysis of human lumber yellow ligaments by frozen-dried cryosections. Med Electron Microsc 1991;24:37788.

Ono S, Nagata T. Electron microscopic observation on the ossification of human lumbar yellow ligaments. Med Electron Microsc 1989;22:723-4.

Ono S, Nagata T. Electron microscopic study on human lumber yellow ligaments with aging. Med Electron Microsc 1992;25:493-4.

Ono S, Maruyama M, Nagata T. X-ray microanalysis of Ca and S in human lumbar yellow ligaments. Med Electron Microsc 1988;21:644-5.

Ono S, Otsuka K, Terayama K, Nagata T. Quantitative electron probe X-ray microanalysis of calcium and phosphorus in human lumbar yellow ligaments. Med Electron Microsc 1994;27:323-5.

Palsgard E, Grime G W. Direct measurement of elemental distributions in insulin-producing cells using nuclear microscopy. Cell Mol Biol 1996;42:49-57.

Palsgard E, Lindh U, Roomans G M. Comparative study of freeze-substitution techniques for X-ray microanalysis of biological tissue. Microsc Res Tech 1994a;28:254-8

Palsgard E, Lindh U, Juntti-Berggren L, Berggren, P.-O, Roomans G M, Grime G W. Proton-induced and electron-induced X-ray microanalysis of insulin-secreting cells. 
Scan Microsc 1994b;8(suppl):325-33.

Porter KR, Claude A, Fullam ER. A study of tissue culture cells by electron microscopy. Methods and preliminary observations. J Exp Med 1945;81:233-46.

Przelecka A, Mrozinska, K. Calcium-cadmium competition in ovarian vitellogenic follicles of Galleria mellonella as revealed by X-ray microanalysis. Folia Histochem Cytobiol 2002;40:229-30.

Ramonet D, Pugliese M, Rodri;guez MJ, de Yebra L, Andrade C, Adroer R, Ribalta T, Mascort J, Mahy N. Calcium precipitation in acute and chronic brain diseases. J Physiol Paris 2002;96:307-12.

Recker RR, Blotcky AJ, Leffler A, Rack EP. Evidence of aluminum absorption from the gastrointestinal tract and bone disposition by aluminum carbonate ingestion with normal renal function. J Lab Clin Med 1977;90:810-5.

Rifat SL, Eastwood MR, MacLachlan DRC, Corey PN. Effect of exposure of miners to aluminum powder. Lancet 1990;336:1162-5.

Rodrigues LE, Mathias CM, Siry P, Galle P. Absence of zinc cytotoxicity. Effect of short-term zinc oral administration on rat gastric mucosa. Braz J Med Biol Res 1990;23:519-23.

Roos N, Barnard T. Preparation methods for quantitative electron probe X-ray microanalysis of rat exocrine pancreas: a review. Scanning Electron Microsc 1986;2:703-11.

Saga K. Structure and function of human sweat glands studied with histochemistry and cytochemistry. Prog Histochem Cytochem 2002;37:323-86.

Schmid K W, Morgan J M, Öffner D, Hittmair A, Haywood S, Jasani B. Quantitative immunohistochemical evaluation by image analysis of metallothionein in copper-loaded rat kidney. J Histochem Cytochem 1993;41:727-31.

Shirabe T, Irie K, Uchida M. Autopsy case of aluminum encephalopathy. Neuropathology 2002;22:206-10.

Spencer AJ, Wilson SA, Batchelor J, Reid A, Rees J, Harpur E. Gadolinium chloride toxicity in the rat. Toxicol Pathol 1997;25:245-55.

Spencer AJ ,Wood JA, Saunders HC, Freeman MS , Lote CJ. Aluminum deposition in liver and kidney following acute intravenous administration of aluminum chloride or citrate in conscious rats. Hum Exp Toxicol 1995;14:787-94.

Spicer SS, Hardin JH, Setser ME. Ultrastructural visualization of sulfated complex carbohydrates in blood and epithelial cells with the high iron diamine procedure. Histochem J 1978;10:435-52.

Spicer SS, Schulte BA. Diversity of cell glycoconjugates shown histochemically: A perspective. J Histochem Cytochem 1992;40:1-38.

Spicer SS, Staley MW, Wetzel MG, Wetzel BK. Acid mucosubstance and basic protein in mouse Paneth cells. J Histochem Cytochem 1967;15:225-40.

Sun L, Gao F, Jin C, Nagata T. DNA synthesis in the trachea of aging mice by light and electron microscopic radioautography. Acta Histochem Cytochem 1997a;30:211-20.

Sun L, Gao F, Nagata T. A light microscopic radioautographic study on protein synthesis in pulmonary cells of aging mice. Acta Histochem Cytochem 1997b;30:463-70.

Takaya K.Electron probe microanalysis of the dense bodies of human blood platelet. Arch Histol Jap 1975;37:335-41.

Takaya K. Electron microscopy of the mouse cerebral cortex in unstained, fresh air-dried spreads and fresh frozen dried ultrathin sections. Okajima Folia Anat Jap 1982;58:799808.

Takaya K. Energy dispersive X-ray microanalysis of platelet and megakaryocytes of several mammals using air dried smears and fresh frozen dried sections. J Physique 1984;45:4859.

Takaya K, Masuda T. Quantitative X-ray microanalysis of biological materials on freezedried stamps and fresh frozen dried ultrathin sections. Med Electron Microsc 1991;24:445-6.

Takaya K, Niya K, Toyoda M, Masuda T. High magnesium concentration in the dense bodies of human blood platelets from patients with atopic dermatitis and chronic 
myelogenous leukemia. Med. Electron Microsc 1994;27:330-2.

Tamir H, Piscopo I, Liu KP, Hsiung SC, Adlersberg M, Nicolaides M, Al-Awqati Q, Nunez EA, Gershon MD. Secretogogue-induced gating of chloride channels in the secretory vesicles of parafollicular cells. Endocrinology 1994;135:2045-57.

Tsunoda Y, Takeda H, Asaka M, Nakagaki I, Sasaki S. Initial and sustained calcium mobilizations in the parietal cell during stimulations with gastrin, inositol trisphosphate, phorbol ester and exogenous diacylglycerol. FEBS Lett 1988;232:83-90.

Usuda N, Nagata T. Post-embedding immunoelectron microscopy of tissues processed by rapid freezing and freeze-substitution without chemical fixatives. J Histochem Cytochem 1991;39:546-7.

Usuda N, Nagata T. The immunohistochemical and in situ hybridization studies on hepatic peroxisomes. Acta Histochem Cytochem 1995;28:169-72.

Usuda N, Hagiwara M, Kong Y, Shimizu T, Hidaka H, Nagata T. Immunohistochemical localization of protein kinase C isozymes. Acta Histochem Cytochem 1992;25:70715.

Usuda N, Hanai T, Nagata T. Immunogold studies on peroxisomes: Review of the localization of specific proteins in vertebrate peroxisomes. Microsc Res Tech 1995;31:79-92.

Usuda N, Hayashi S, Fujiwara S, Noguchi T, Nagata T, Rao MS, Alvares K, Reddy JK, Yeldandi AB. Uric acid degrading enzymes, urate oxidase and allantoinase, are associated with different subcellular organelles in frog liver and kidney. J Cell Sci 1994;107:1073-91.

Usuda N, Kuwabara T, Ichikawa R, Hashimoto T, Nagata T. Immunoelectron microscopic evidence for organ difference in the composition of peroxisome-specific membrane polypeptides among three rat organs: Liver, kidney and intestine. J Histochem Cytochem 1991 ; $39: 1357-66$.

Usuda N, Ma H, Hanai T, Yokota S, Hashimoto T, Nagata T. Immunoelectron microscopy of tissues processed by rapid freezing and freeze-substitution without chemical fixatives. Application to catalase in rat liver hepatocytes. J Histochem Cytochem 1990;38:61723.

Usuda N, Nakazawa A, Terasawa M, Reddy J K, Nagata T. Immunocytochemical study of the ultrastructure of peroxisomes and the effects of peroxisome proliferators. In: Reddy JK, Suga T, Mannaerts GP, Lazarow PB, Subramani S (eds). Peroxisomes, Biology and Role in Toxicology and Disease 1996;804:297-309.

Usuda N, Yokota S, Ichikawa R, Hashimoto T, Nagata T. Immunoelectron microscopic study of a new D-amino acid oxidase-immunoreactive subcompartment in rat liver peroxisomes. J Histochem Cytochem 1991; ;39:95-102.

von Euler A, Mörk AC, Roomans GM. Effects of chronic and in utero treatment with diuretics on mouse exocrine cells studied by X-ray microanalysis. J Submicrosc Cytol Pathol 1992;24:225-30.

White DM, Longstreth WT Jr, Rosenstock L, Claypoole KHJ, Brodkin CA, Townes BD. Neurologic syndrome in 25 workers from an aluminum smelting plant. Arch Intern Med 1992;152:1443-8.

Wilhelm M, Jäger DE, Ohnesorge FK. Aluminium toxicokinetics. Pharmacol Toxicol 1990;66:4-9.

Wolosewick JJ, Porter KR. High-voltage electron microscopy of WI-38 cells. Anat Rec 1975;181:511-12.

Wolosewick JJ, Porter KR. Stereo high-voltage electron microscopy of whole cells of the human diploid line, WI-38. Amer. J. Anat 1976;147:303-24.

Wolosewick JJ, Porter KR. Observations on the morphological heterogeneity of WI-38 cells. Amer J Anat 1977;149:197-226.

Wolosewick JJ, Porter KR. Microtrabecular lattice of the cytoplasmic ground substance. Artifact or reality. J Cell Biol 1979;82:114-39.

Wroblewski R, Wroblewski J. X-ray microanalysis of endocrine, exocrine and intestinal cells and organs in culture: technical and physiological aspects. Scanning Microsc 
1994;8(suppl):149-61.

Yokel RA. The toxicity of aluminum in the brain: a review. Neurotoxicology 2000;21:81328.

Yokel RA, McNamara, PJ. Aluminium toxicokinetics: an update minireview. Pharmacol Toxicol 2001;88:159-67.

Yokota S, Nagata T. Study on mouse liver urate oxidase. III. Fine localization of urate oxidase in liver cells revealed by means of ultracryotomy-immunoferritin method. Histochemistry 1973;39:243-50.

Yokota S, Nagata T. Ultrastructural localization of catalase on ultracryotomic sections of mouse liver by ferritin-conjugated antibody technique. Histochemistry 1974;40:16574.

Yokota S, Nagata T. Chapter 5. Urate oxidase. Vol 5. In: Hayat MA (ed). Electron microscopy of enzymes, Principles and methods. New York: Van Nostrand Reinhald Co.;1977.

Yoshizaki M, McCarthy KJ, Kaye GI, Fujimoto S. Cadmium toxicity to the cornea of pregnant rats: electron microscopy and X-ray microanalysis. Anat Rec 1990;227:13843. 